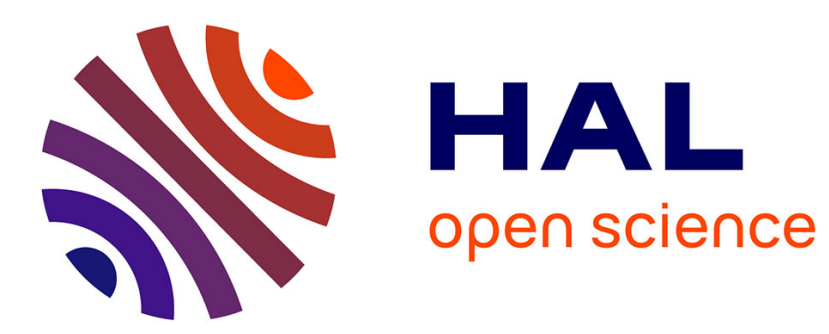

\title{
Le site naturel de Strasbourg et ses aménagements hydrographiques de l'Antiquité à l'époque moderne
}

Nathalie Schneider, Jean-Jacques Schwien

\section{To cite this version:}

Nathalie Schneider, Jean-Jacques Schwien. Le site naturel de Strasbourg et ses aménagements hydrographiques de l'Antiquité à l'époque moderne. Archéologie médiévale, 1998, 28, pp.33-69. halshs00006267

\section{HAL Id: halshs-00006267 https://shs.hal.science/halshs-00006267}

Submitted on 15 Feb 2006

HAL is a multi-disciplinary open access archive for the deposit and dissemination of scientific research documents, whether they are published or not. The documents may come from teaching and research institutions in France or abroad, or from public or private research centers.
L'archive ouverte pluridisciplinaire HAL, est destinée au dépôt et à la diffusion de documents scientifiques de niveau recherche, publiés ou non, émanant des établissements d'enseignement et de recherche français ou étrangers, des laboratoires publics ou privés. 
Article paru dans la revue « Archéologie Médiévale », tome XXVIII, 1998.

\section{CNRS EDITIONS}




\title{
LE SITE NATUREL DE STRASBOURG \\ ET SES AMÉNAGEMENTS HYDROGRAPHIQUES DE L’ANTIQUITÉ À L'ÉPOQUE MODERNE
}

\author{
Jean-Jacques SCHwIEN", Nathalie SCHNEIDER* \\ avec la collaboration de Marie-Dominique WATON ${ }^{\text {*at }}$
}

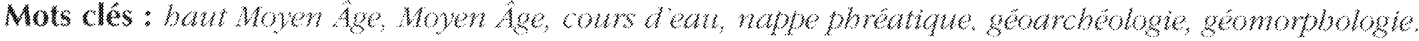
Key words: Lanly Midle Ages, waterways, water lable, geoanbacology, geomorpbology.

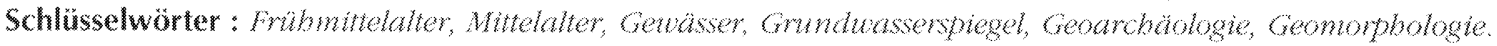

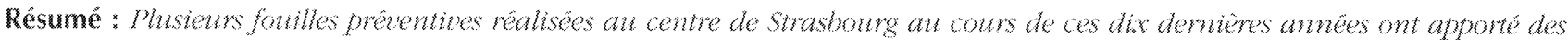

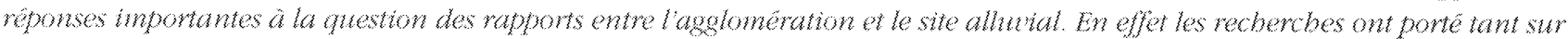

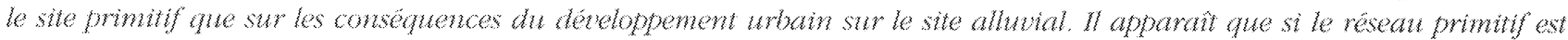
imposible a cemer a parir de ces foulles encore trop ponchelles la bierarchie des cous dean immédiatenent avant lins tallation de thomme est. on revanche, desomak bien bable. Il ne semble pas que la ville antique ait tente de dominer ce réseau bydrographique. La canalsation et le comblement systèmatique des cons d'eau débute senlement a lépoque carolin. gienne et s'amplifie avec la mise en place du systeme defensif entre le xit et le xut siecle: Thu des axes principanx du déte

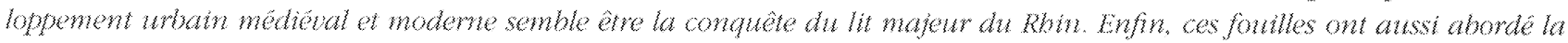
queston de la nappe phratique (qui sauere globalement stable entre l Antiquté et nos jours) ainsi que celle du seull dhabi-

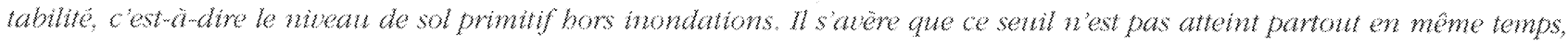
lextension de la ville baute médienle êtan justement conditonnè par la stabilisation de centanes terwasses allwiales.

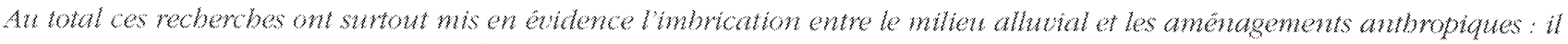

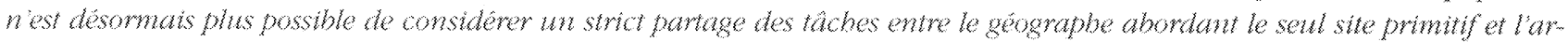
chéologue netudiant que la whe. Les deux disciphnes dowent an contraire collaborer pour comprendre les modalite de lessor whain jusquan seull de la përode contemporaine.

\begin{abstract}
The natural ste of Strasbourg and its bydrograpbic works, from the Roman to the Post Medieval peri-

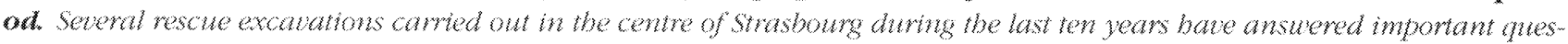
thons concening the relationslip between the agglomeration and the allwit site. Reseawh bas in fact concerwed both the

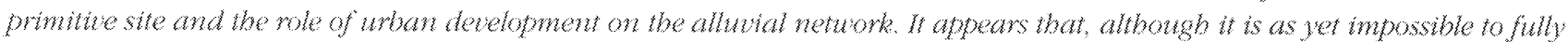
andestand the primitive netwonk, the bierarchy of the watenwas immedately following buman implantation is now well established. It does not seen that the Roman town attempted to dominate this bydrognaphic network. Canalisation and sys. tewatic infling of waterways began during we carohngian pertod, works being accentuated between the 13 th and the 17 b

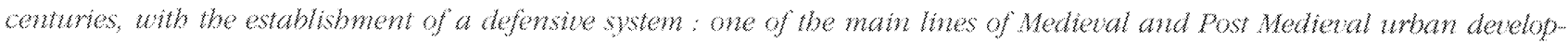

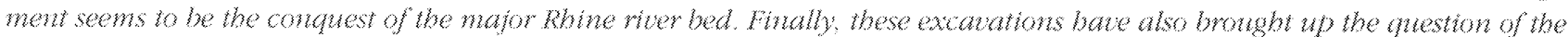
water whe (which, ower all, was achally qute stable between the Roman penod and now) abng with the babitability sill.
\end{abstract}

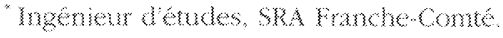

Doctorane, $\mathrm{NAN}$.

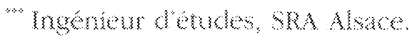




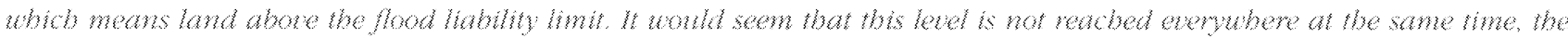

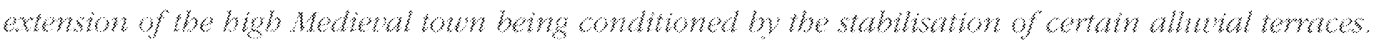

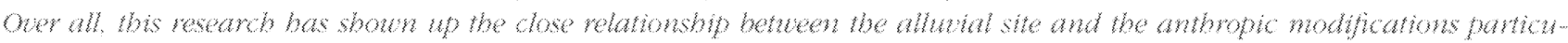

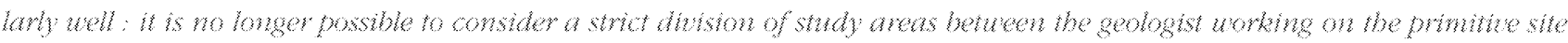

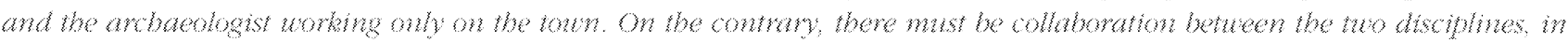

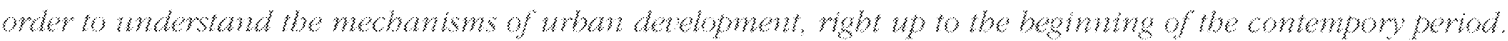

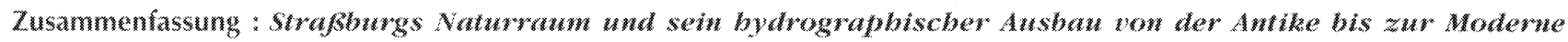

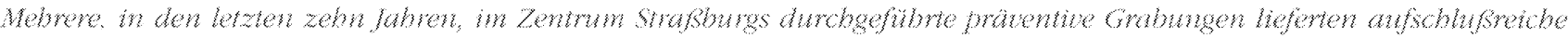

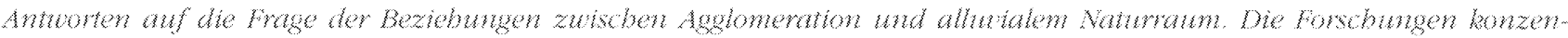

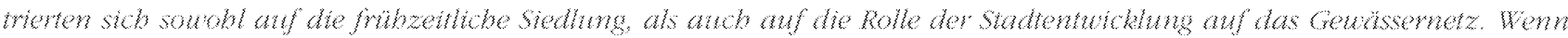

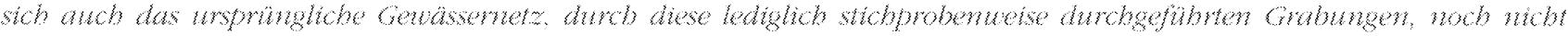

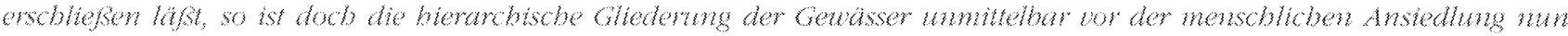

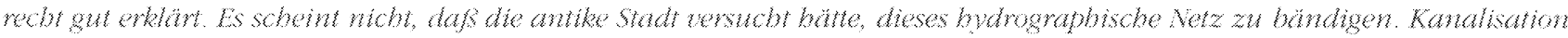

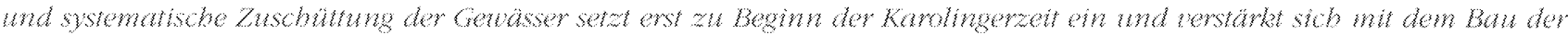

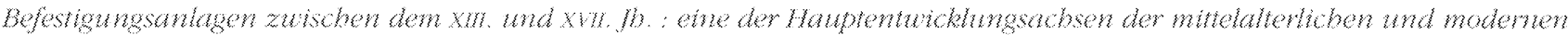

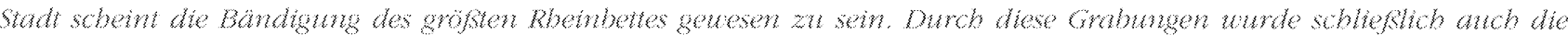

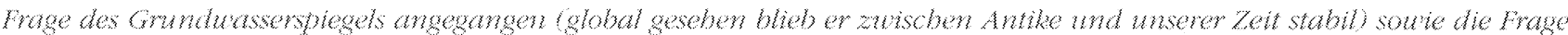

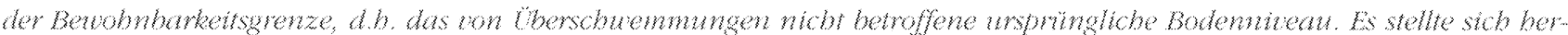

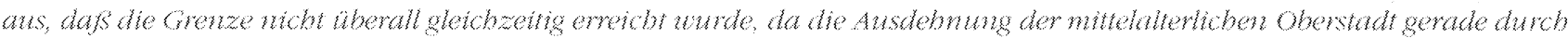

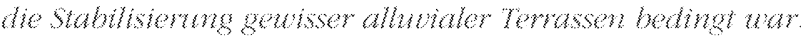

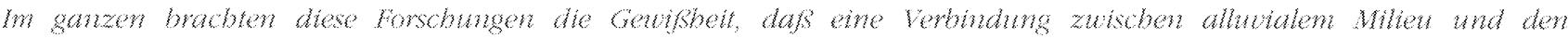

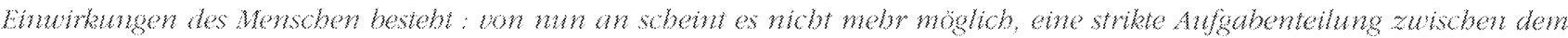

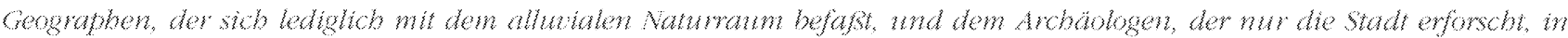

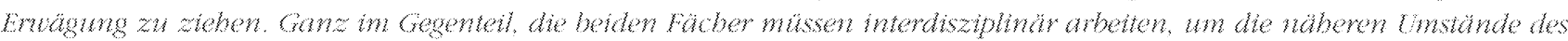

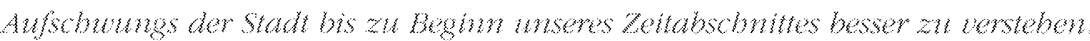

Beaucoup de villes ont pris naissance en bordure dun cours deau en raison de conains avantages majeurs comme laccessibilté (par la valee aluviale), la mise en defense (par des Cosses en eau), la consommation (domestique, artisanale) et ce, en deptr de contranes tout aussi imponantes comme les inondations, les broullards. les moustiques. Stasbourg ne deroge pas a cote regle pusquelle est sivee au point de rencontre de quatre cours deau importants, le Rhin, III, la Bruche et la Kinzig, Le role de leau dans le chox du heu at dans le développenent de la vile a été reconnu depuis longtemps par les historiens, les geologues et geographes seunt everubs de leur cốc a dênir les caractéristques du site Mais, depuis la demiere synthese datee de $1935^{\prime}$ mes son ceux qui ont dépasse les ammations de prin-

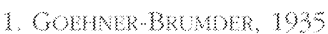

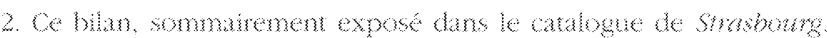

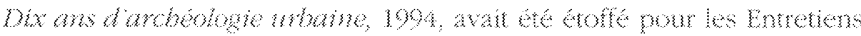

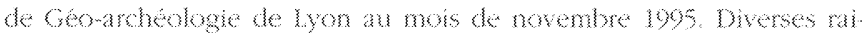

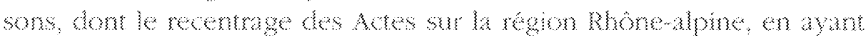

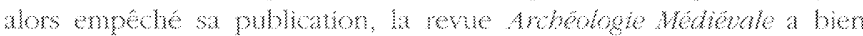

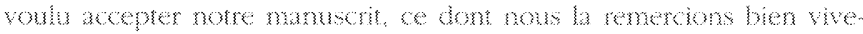

cipe pour aborder les notions de reseau, dévolution et damenagement de ces cours deau.

Lancheologie preventive, gui a pris son essor à Strasbourg au mileu des annees 1980, ayan demblee ete confronté a ces questions, il est possble aujoundhui de tenter un nouvau bilan combinant découvertes recentes etacous anterieurs ${ }^{2}$.

\section{LES DONNEES DE LA GEOGRAPMIE ET DE LHISTOIRE}

\section{SITUATION $3($ fg. 1$)$}

Lagglomeration strabourgeoise est situee au cour du Cossé defondrement héman qui, de Bale a Mayence et

ment. Un expos devalle des soures histongues hextes et iconogra-

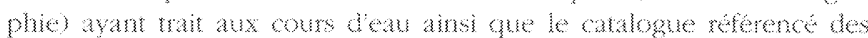
shes archologiques pour le cours utwain de lnl est presente, par

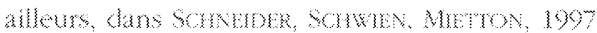

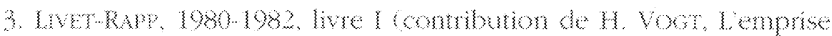
de la geographo: 


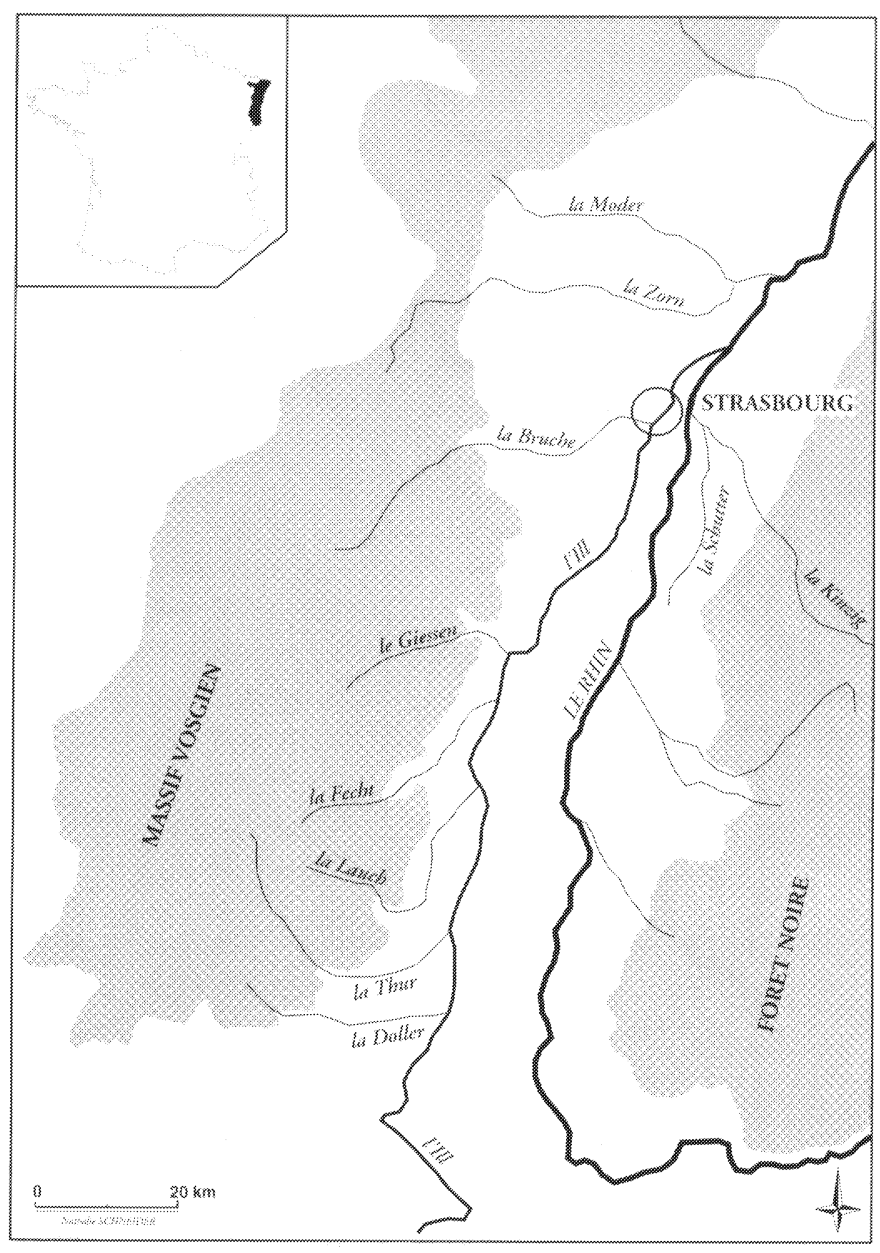

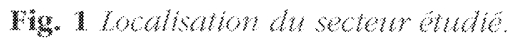

entre Vosges et Foret Noire, fome un couloir de 300 kilometres de long pour 50 kilometres de large.

Le Rhin ne s'y est fraye un chemin qu'au debut du quaternaire, il y a 1 million dannees, Son acton sest traduite par un apport massif dalluwions alpines (sables et graviers), formant un dépôt large de plusieurs kilometres et tres epais (100 a $150 \mathrm{~m}$ à Strasbourg). Ses sédiments contiennent une nappe phréatique piégee par les séries tertaires impermeables sous facentes (manes en particulier). Le jeu des altemances cimatiques quatemaires (periodes glaciaires et interglaciaires) et de la tectonique du fossé (affaissement, subsidence) a permis lédfication dune serie de terasses étagees. Apres le demier rechauffement climatique il y a 10000 ans ot le passage dune dynamique fluviale torrenticle à des conditions plus calmes, le Rhin s'est replie en partie droite du fossé : des lors, son lit majeur ne mesurat plus que un a deux kilom metres de large, contribuant cependant a modeler, par apports dalluions et érosion, le centre de la plaine aluviale telle quelle apparait encore tres globalement de nos jours.

Aux fomations alluyiales sticto sensu, il faut encore ajouter les placages de loess, ces sediments arraches par le vent aux épandages alluviaux et deposés sur les reliefs environnants au cours des épisodes secs du quaternaire. Ces formations ont aujourdhui une epaisseur variant entre 2 et $30 \mathrm{~m}$. Le depôt de loess à la hauteur de Strasbourg est particulerement important puisquil constitue un ensemble continu - le Kochersberg - entre la basse terasse du Rhin et les collines souswosgiennes.

\section{Srre (fig. 2)}

La vile chevauche plus précisement deux unites naturelles distinctes. A louest, elle mord le rebord oriental de la terasse dite de Schtighein (couverte de loess) qui surplombe la plaine alluvale de 5 a $10 \mathrm{~m}$ cote moyenne : 145-150 m NGP). Cost ha que se sont developpes les faubourgs de Koenigshoffen (des lepoque romaine) et de Cronenbourg (au vixe siede). Une langue de loess sétend mème vers le coeur de la vieille ville sous la rue du Fauboung National et la place de la gare actuelle.

Lessentel de lagglomération s'mscrit toutefós dans la plaine elloménane, à la confluence de quatre cours deau. Le premier à citer est lil puisque cest directement sur ses berges qu'elle est située. L'II prend sa source dans le Jura, sert de collecteur aux rivieres vosgiennes et se jette dans le Rhin - dont dle est le principal affuent alsacien - a la Wantzenau, we dizane de kilometres en ayal de Strasbourg. A lentré de la vielle ville, elle se divise en plusieurs bras (quarier de la petite France, pres des Ponts Couverts) dont le plus ocidental fosse du FauxRempart) rejoint le cours principal un kilometre et demi en aval: l'te ainsi fomee (dénommee localement ellipse insulaire) marque le cour de lagglomération. Dautres bras existaient encore recemment en aval dont l Aar, canalise au $\mathrm{xIx}^{\mathrm{e}}$ siecle, constue le dernier temoin. Entièrement régulée depuis le creusement dun canal de derivation vers le whin, a hateur derstein, en 1894, 111 ne présente plus que de fables crues d'automne et dhi. ver.

La Bruche est we niviere dorigine vosgienne (yallee de Schimeck) qui charrie essentiellement des sédiments issus de son bassin versant gréseux. Cle a edifé un imporant cône de déjection des le debut du quatemaire, en partie recouvert par des dépots de loess wümiens. Ce 


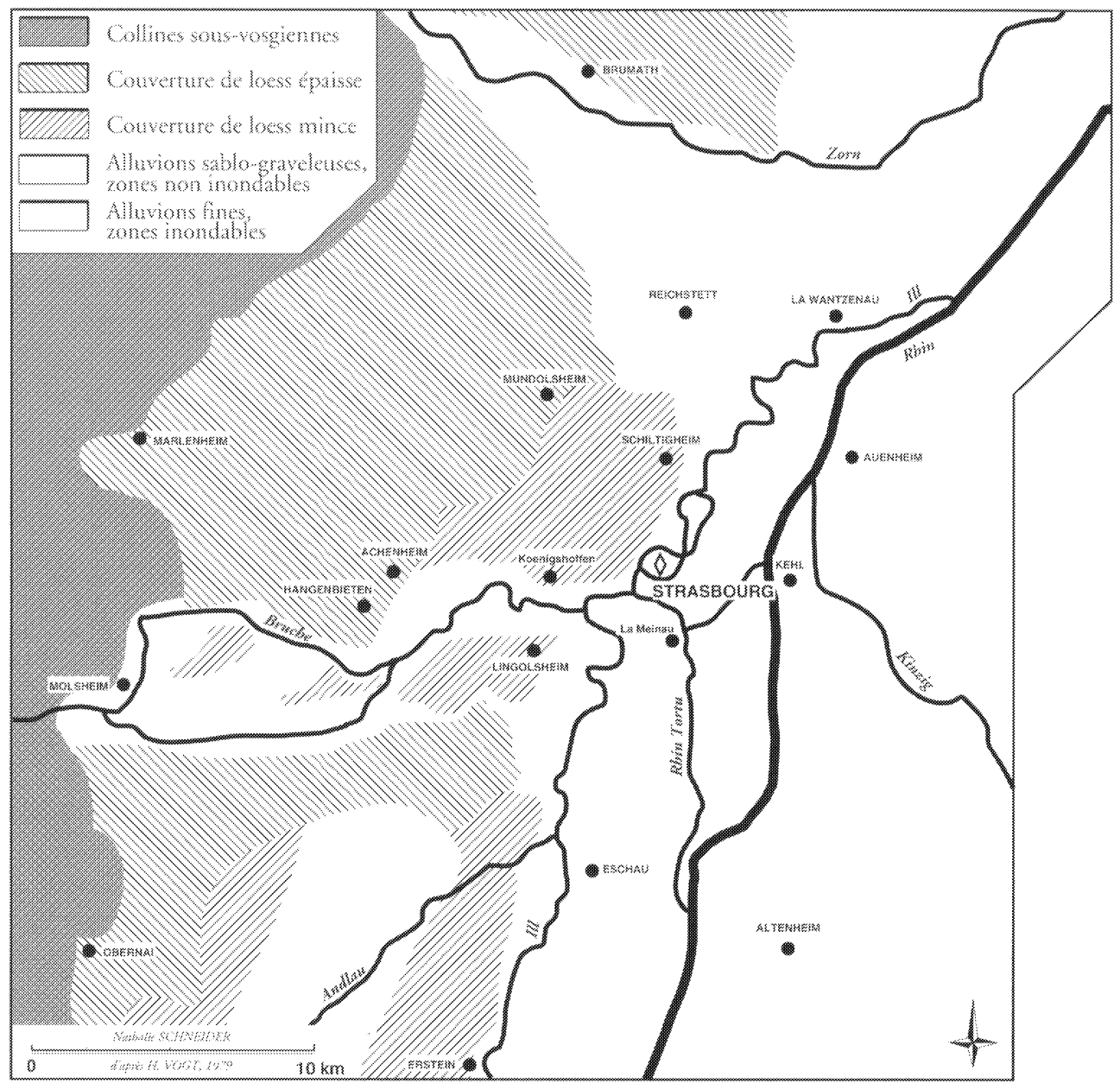

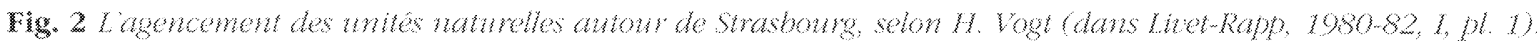

cône, qui attent Erstein an sud, semble se teminer sur ha bordure nord du centre ville actud de Strasbourg (place de Haguenau). Dans sa basse vallee, elle fome de nombreux meandres dont lun au nord, a ete canalisé par Vauban des 1681. Son regime reste du type torrentel avec des crues dautomne et dhiver. Sa contuence avec llll se situe au lieu-dit la Montagne Verte, a trois kilomètres en amont du centre de la ville.

Le lit du Rhin, avec ses chenaux principaux et secondaires, mesurat environ un kilometre et demi de large avant sa canalisation et regularisation entre 1838 et 1876 (250 mactuellement). Une série de bras rejoignant IIII, tel le Rhin Tortu, subsistent encore comme témoin dun reseau dense danciens chenaux lateraux. On peut y ajouter le Rhengiessen ou cand du Rhin, comblé apres 1870 : au Moyen Age au moins, il servait de jonction entre les deux cours deau pour les bateaux de commerce. A la différence des rivières vosgiennes, les cues du hewve se situent au debut de lete.

La Kinzig, enfin, est laffuent principal du hhin en rive droite, issu de la Forêt Noire. Son importance comme voie de communication est reconnue depuis lAntiquite. Sa confuence se situe actudlement a trois kilometres au nord de keh mais il est probable quavant les recents aménagements portudres, elle se soit fate a Kchl méme.

Cote ommipresence de leau pour le site de Strasbourg est encore accusé par la proximité de la nappe phréatique centre $2 \mathrm{~m}$ et $8 \mathrm{~m}$ sous le niveru du sol actuel. Le toil des alluvions grossières (Rhin et Bruche) est dattude variable mais, dans les proches environs de Strasbourg, in forme un plan régulier oscillant entre les cotes $135 \mathrm{~m}$ et $136 \mathrm{~m}$ NGF. Cette nappe est une masse en mowement constant. Elle 


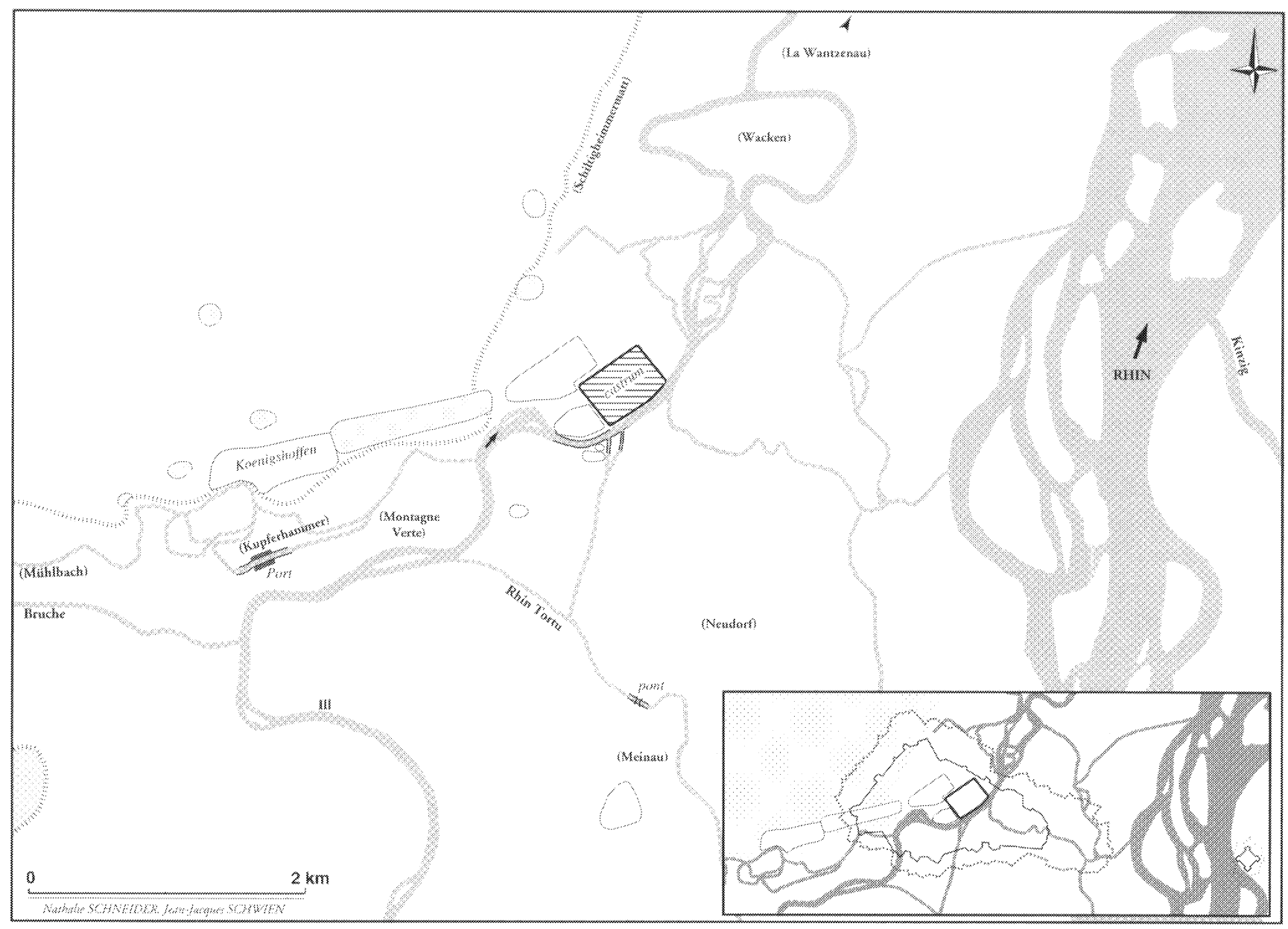

\begin{tabular}{|c|c|c|c|c|}
\hline \multicolumn{5}{|c|}{ MGENDE } \\
\hline ESPCES NAYUEES & AGOUOMYRMTON & & TOBSONYMES & 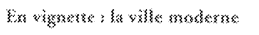 \\
\hline cilnes de toes: & (N came lemionnatre & Rhing Torst: & nom de coins d'eats & anceine $(1830-1700)$ \\
\hline piane incndable & zones drabitat & cameran: & toponyma concemant F antigute & Imotes a crericures losses \\
\hline partio da cours dian ascurb & zone de nécrople & (Mcinaz): & autre toponyme & colines ce loess \\
\hline 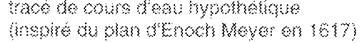 & is gntassine & & & ascomeraton anticue \\
\hline
\end{tabular}

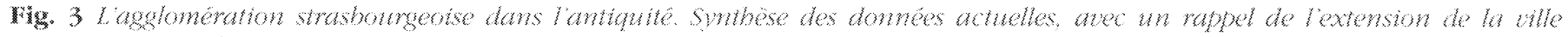
depoque modeme (of.J.). Schulen, 1902, 220).

s'coule globalement du sud vers le nord, suivant la pente du fossé thénan, mais connait aussi des battements ou variation du toit dont lamplitude est fonction de la distance par rappon aux rivieres et de leur regime (crues, etiage). Au centre ville, le toit moyen de la nappe se sine a une altude de $135,50 \mathrm{~m}$ pres des Ponts Converts (au sud et de $134,50 \mathrm{~m}$ sous la place de la Républque fau nord. Le battement maximal est de un metre.
HSTOIRE' (hg. 3$)$

Sans exclure la possibilite dine implantation gauloise dans les proches enyirons, cest sans aucun doute a lar. mée romaine quest revenu lo choix de fxer un établisse-

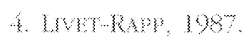


ment permanent à Argentorate? peu ayant notre ere . La premiere gamison est modeste (un corps de cavalene auxillaire de 500 à 1000 hommes) mais bientot remplace par une legion (soit 6000 hommes). Si le camp primitif n'est pas encore situé precisément, les traces doccupation d'époque augusteenne sont néammoins concentrees dans Gactuelle ellipse insulaire. Le camp légionnaire est, lui, parfaitement localisé en bordure de 1TIl : pardela plusieurs reamenagements, il constituera le noyau dur de lagglomération, son enceinte servant encore a la défense urbaine au xire siecle

Comme il est de règle dans le monde romain, à ce camp sest en effet mpidement ajouté une agglomeration civile "spontanee ", cestàmdire sans plan durbanisme volontaire, établie le long de la vole dacces ouest. Deux zones doccupation privilegiees ont été reconmues. La prem miere, en bordure immediate du camp et dans la plaine alluviale, comprend deux secteurs dhabitat bien distincts de part et dautre de la voie principale; un port y est supposé mais sans preuves. La seconde, au lieu-dit actuel de Koenigshoffen, sur la terrasse de loess, est spécialisee dans les activités artisanales (poterie, métallurgie); un port sur la Bruche y a été fouillé au début de ce siécle. Larchitecture monumentale, outre les murs du camp, y est des plus reduite avec seulement un bâtiment avec mosaique, des thermes légionnaires et quelques édifices à la fonction indéterminée; le seul lieu de culte attesté, dédie a Mithra, est une construction en tere et bois comme lessentiel des autres batiments. Par alleurs, plusieurs zones de nécropoles ont été localisees, lensemble le plus important étant situé entre les deux quartiers d'ham bitation (coté camp et koenigshoffen), mais dejà sur la terrasse de loess. La population au rie siede, moment de la plus grande extension, est estimee a 15-20000 per. sonnes.

A partir du Bas Empire, avec le transfert du chef lieu de cité (fonction exercée jusque la par Brumath, à 20 kilom mètres plus au nord) puis la creation de lévêché, la ville devient la véritable capitale régionale. De fait, comme l'at. testent les monnaies dor frappees sur place et le nom donne à lancien grand faubourg civil, Koenigshoffen de palais royal, Strasbourg, à lépoque merovingienne et

5. Ce nom higue une premere fos sur une bome miliane en 74 ap.

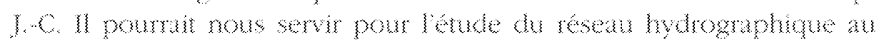
moment de la conquête si sa signffication n'eut pas aussi controversee. W. Forrer, qui sinsurge contre les erymologes fantaisistes de fomeresse

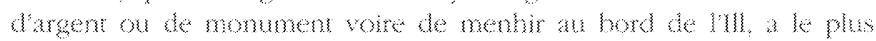
savament analyse les pites posibles. I penche fondement pou un

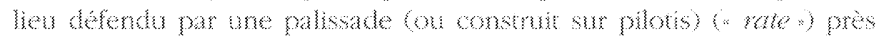

carolingienne est au moins provisoirement une ville royale. Ce role historique et une richesse bien attestes par les textes n'ont malheureusement laissé aucune trace monu. mentale dans le paysage ubain mème si lon peut penser que la première cathédrale occupait deja l'emplacement de lactuelle. Lespace urbanise semble restreint au camp, à ses proches environs et a la zone des nécropoles.

Entre lepoque carolingienne et le xur" siede, le pouvoir est exerce directement par lévêue. Comme dans beau. coup dautres villes, In bourgeoisie y acquiert son indépendance par les armes en 1262. En obtenant, en 1358, le statut de ville libre, elle se défait en outre de la tutelle imperiale. Comme pour lagglomération antique, les activités de la ville médiévale étaient centrees sur lapprovin sionnement de la population; le supplus de richesses etait toutefois apporte par sa place dans le commerce menan (dont lexportation des vins). La hierarchie des corporations fixée au wre siecle pour la gestion des affaires publiques est edifinte à cet egard avec, par ordre décroissant dimportance, les marchands, bateliers, merciers, aubergistes et bouchers.

Dans ses grandes lignes, lespace urbanise evolue au rythme de ces changements politiques. La ville episcopale jusque vers 1200 perpétue lorganisation antique (enceinte du castrum, églises paroissiales le long des axes principaux), Le xme siecle marque une ruphure fondam mentale. De mème que la spécialisation des quartiers de la ville antique (defense, habitat, production, funeraire) est abandonnée au profit dune imbrication de toutes les fonctions dans un même espace, la zone ouest sur la terrasse de loess est definitivement delaissee en faveur d'une extension dans la plaine alluviale: l'emprise et le rythme de construction des enceintes montrent clairement que cest la mainmise sur les voies deau (III aux xm" Xve siecles, le Rhin à partir du xye s) qui fome lun des soucis majeurs du pouvoir urbain 7. La population, a la fin du xve siede est chifree a 18000 personnes, pour une surface urbanisée quasi de même importance que dans lAntiquite, soit 200 hectares environ.

Le xy siede t la premiere moitie du xume siede sont dominés par la Réforme religicuse et son cortege de conflits sociaux. Hormis la disparition dune partic des

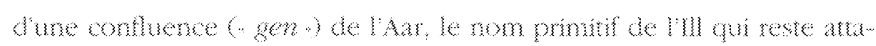

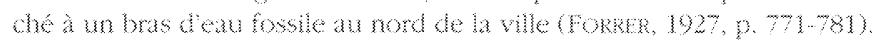
ka guestion, kapus, na pas the rexaminee.

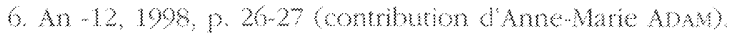

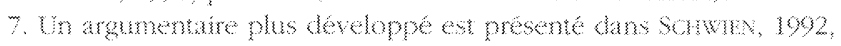

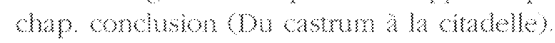


comvents et la consmuction progressye dune enceine bastomee, la topographe ubane heriee du Moyen Age reste sans changement.

Si, avec la conquete hancise en 1681, Stashourg perd son independance, ele retrouve toutehis sa prosperite economique apres pres dun siecle de recesion ainsi que son role de capitale réglonale. Ceci sest traduit par une réorgansaton de sa rame ubane pour laccuel de 6000 hommes de ganison, d'unstances administrutyes regio nales nowveles, dune unverste et detablissements reli gieux catholques, les chanters de construction se pour suivan jusquaux annees 1750 . La place de la vile dans la defense de la crontiere du royame a, de meme, necessite lamenagement dun remou sur le Rhin citadele en rive gawhe for de Keh on rive drote). Avec cete nouvelle extension, la vile bare desomais toute la plane aluvide ente la terasse de loess at le hin, apponant ansi la demiere touche an developpement engage au mileu du Moyen Age.

Par dela les vicissitudes des revolutions - poltuques et industrelles -... des debus de lepoque contemporane, la vile conserva cete organisation termorale jusquaux vupures des annés 1880 et surtout $1950-1960$ : Funbanm sation est regie aujounthu par des logiques tres dife rentes de celles mises en ceuve par le passe.

\section{HISTORIOGRAPHIE DES RECHERCHES}

La configuration precise du sie au cours de la prehism wire et surtout au moment de la creation de laggloméam won antque anme la recherche archeologique, historique et geographique locale depuis ses origines.

Des lepoque modeme, plusieurs erudis, a la fois his. whens et complateurs, ont propose une cartognaphie sommaire du réseau hydrographique onginel (hg, 4). Les premers dessins de l'architecte et chroniqueur Daniel Specklin, vers 1580 , son restes inedits" mais is ont form tement inspiré les cartes de topogmapie historique de Mathias Merian en 1663 de Jean-Andre Sibemann en 1775. Johann Enoch Meyex, drecteur des travax publics de la ville, a réalisé de son côté le premer leve topogra-

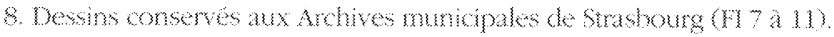

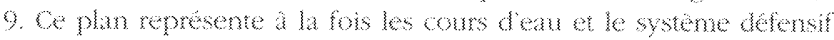
sur un herwive couran a pet pres les bmites communales actuelles

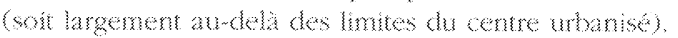

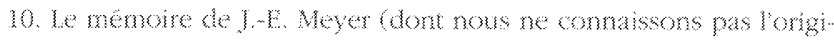

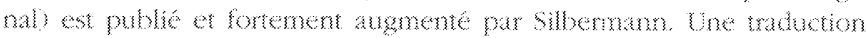

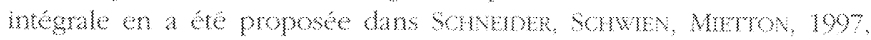
p. 4352 phique du reseau en 1617 (fy. 5) . Les canes de Meyer et de Shbemann llustrent en fait un catalogue wasone des "riveres, canaux et losses qui coulent dans athors de Strasbourg $*$,

De cet ensemble se degagent un cerain nombre de lignes de hore (hig. 6). Les cours deau fommen un reseau heranchise avec deux viveres importanes - In et la Bruche - et une serie damuents on deluents, we hin, simplement cite, est generalement absent des descrip tons et representations carographiques du territoire ubain ". Ces riveres ont une histoire nominale pusque certanes ont change de nom : le Kalglessen est wansfor mé en Ziegelwasser au xw siede ayec Implantaton dune tulere municipale; le canal du Rhin (Rhengiessen) est appele canal Saint-lean-aux-Ondes (du nom din couvent proche) Uusqua la modification de son cours au moment de la constucton de la citadele par Vauban. Les auteurs insistent aussi, mas sans avancer dexplication, sur la confusion des temes dll et de Bruche : selon une wadtion attestee par les textes depuis 845, la premere prend le nom de la seconde dans son parcours urbain, alors meme quin autre bras de la Bruche amente le Cosse uban nord-ouest de la vile. Mas deniere cette drersite des temes, le resenu luim même est stable. Les creusements ex nibilo sont rares, comme ceux du Riepergergraben qui sen de deversoir a une nouvelle digue dinondation a parir de 1542 . Il y a enfin un non-dit font, cest a dre absent des descriptions et prégnant sur les cates, c'est ladequation entre cours d'eau naturels et fossés defensils, les seconds sinscrivant obligatoirement dans un lit preatabl.

La sconde moite du XIX siecle marque une rupture: hee a lessor général des sciences de la terre, elle se caractexise par lintroduction dune conception dynamique dans lanalyse du réseau hydrographoue grace aux traw vaux conjoints des historiens toponyme, publication de sources ecries), des geographes (dynamque huvale, for mations sedinentaires supenficles) et des archéologues. Pami ces trandx, if faut citer la premiere care geolom gique au $1 / 25000$ de stashourg et ses environs publée en 1883 par schmacher. Celuma analyse pour la prem

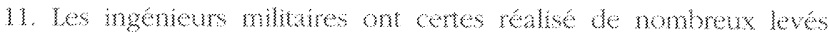

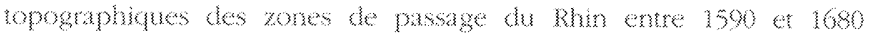

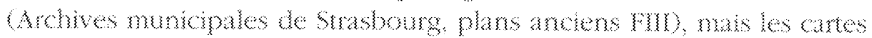

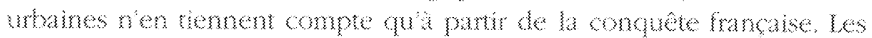

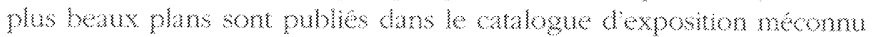

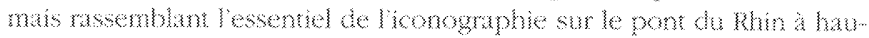

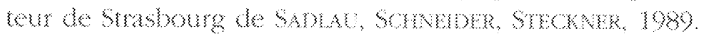




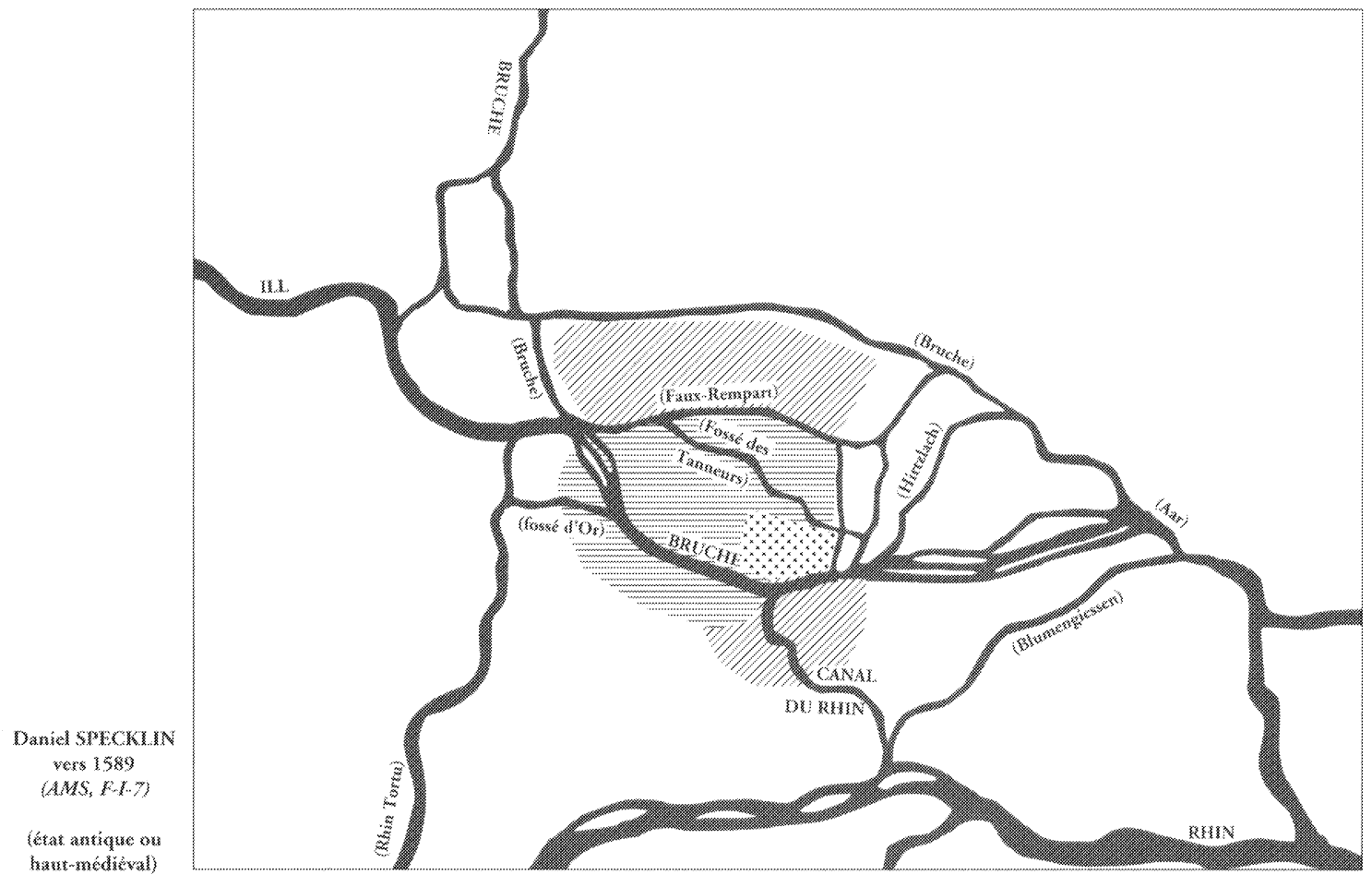

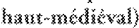

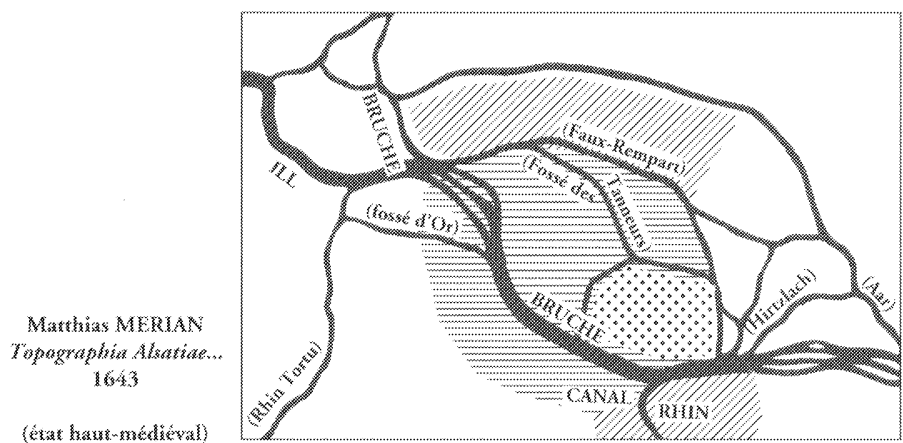

Fig. Le nsean bytrographique orighel dapres 3 canes anchenes avec une localsation schematious de lemprise ales encemtes (1).

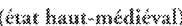
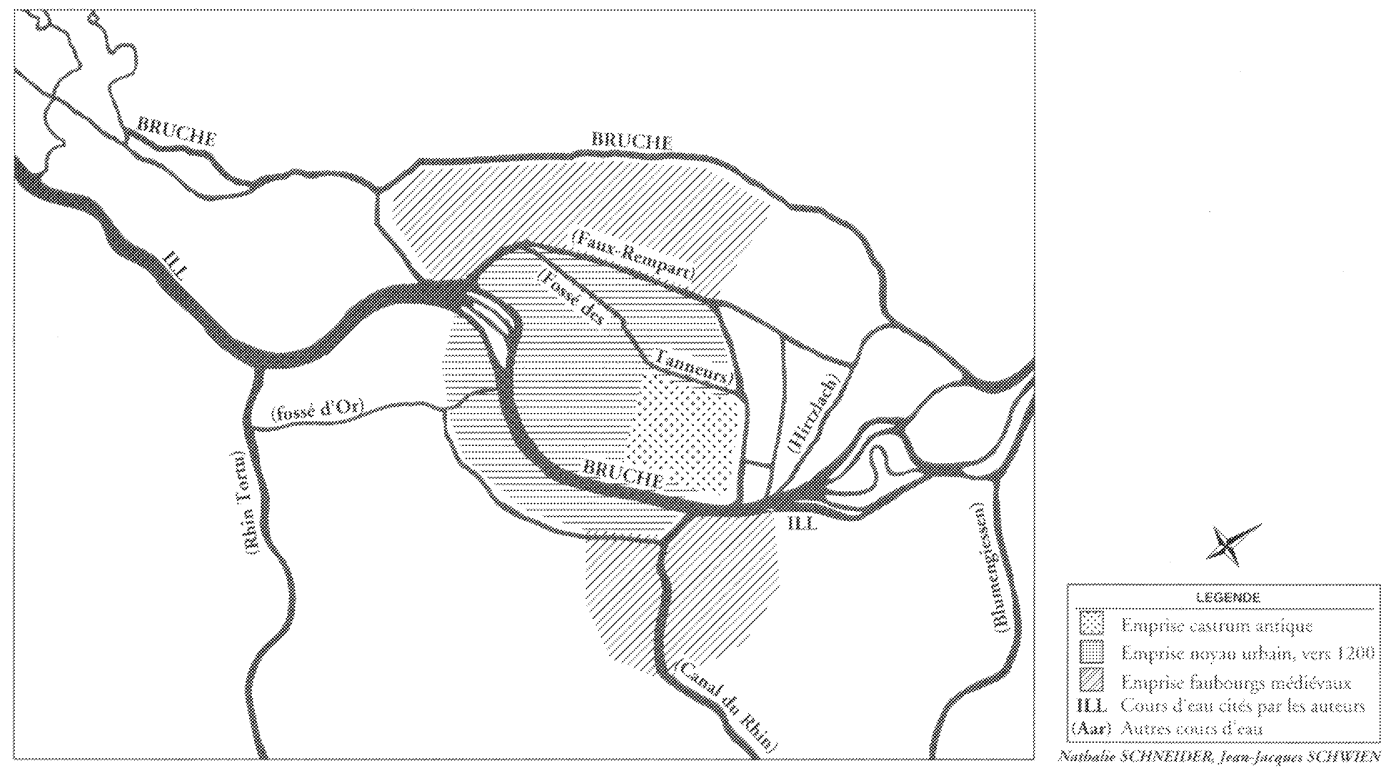


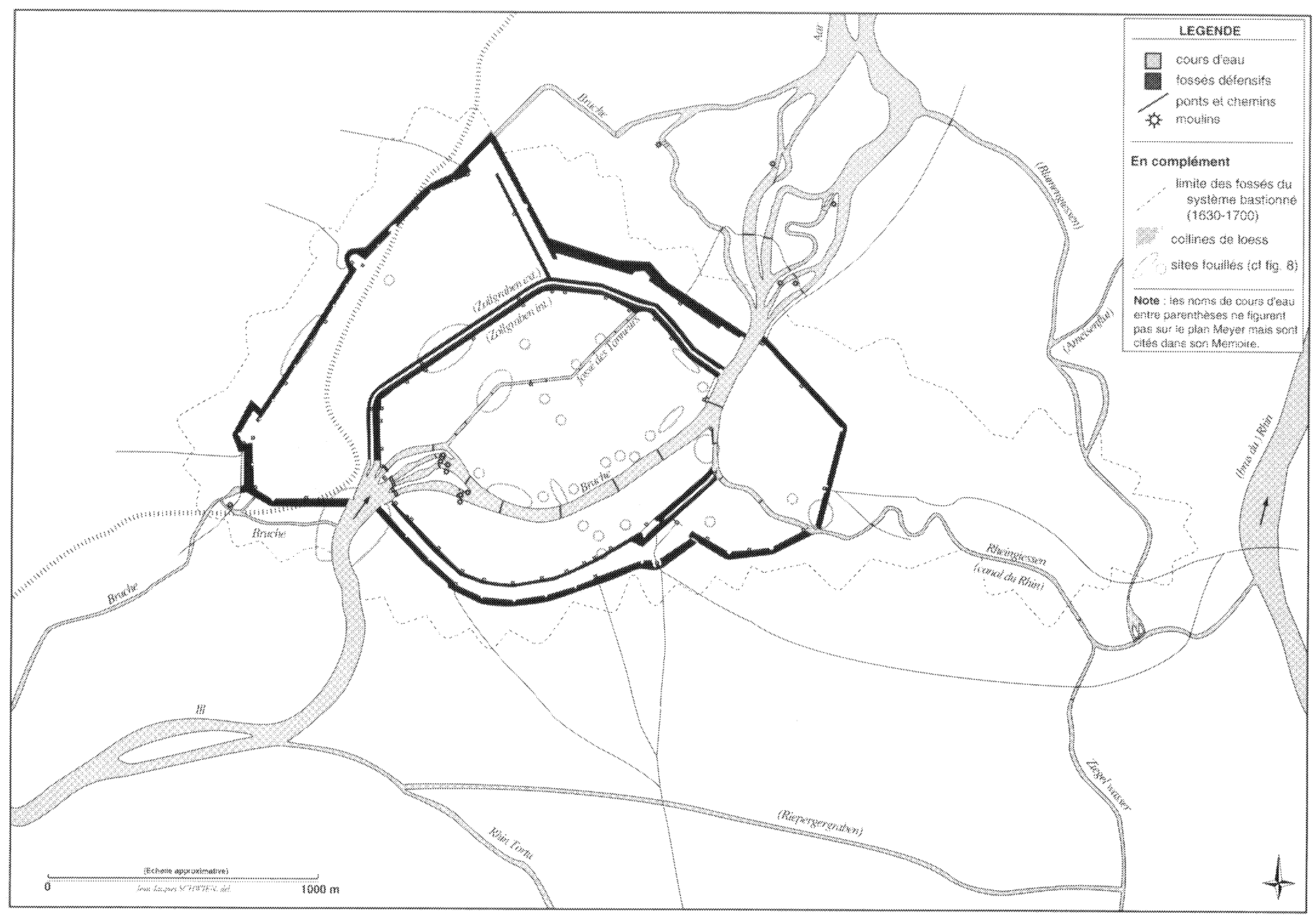

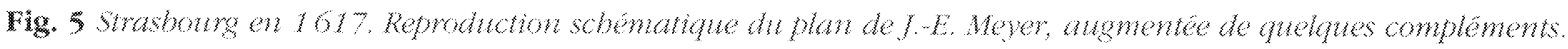

miere fois les sêries sédimentaires en fonction de leur origine (Vosges ou Rhin) et de leur mode de mise en place (mode torrentiel pour les périodes bien nommées " ante diluviennes ", puis depóts fins holocenes des plaines dinondation). II definit aussi plus précisement le site de la ville: encadrée par la terrasse haute couverte de loess, a louest, la ville ancienne sétend dans le domaine des alluvions récentes, où se mêlent des influences vosgiennes (va la Bruche) ou ello-rhénanes. Un complément important est apporte par le Dr Hammerle qui, à partir de 71 sondages carottés, propose une coupe en travers du sous-sol de lagglomération et en particulier un schéma dextension de ces alluyions respectives $\left(\mathrm{hg}, 7^{12}\right.$.

12. Ces travax, avec la coupe geologicue, son resumes dan Krmom, 1889, p. 81.83 .
Les archéologues ne sont pas en reste. Dès ses origines au milieu du xx siecle, larcheologie strasbourgeoise severtue en effet à recueillir les traces des cours d'eau disparus ou modifés. Deux exemples, pris parmi dautres, peuvent être cités : en 1859, De Morlet publie une belle coupe de la berge antique de l'll avec ses aménagements de pieux, a proximite de l'eglise Saint-Étienne ${ }^{33}$; Chanles Goehner, en 1935, hre un transect complet et inégalé à ce jour du fossé dor, sous la rue du même nom ${ }^{14}$. Certaines de ces foulles ont tete menees sur des surfaces consequentes et donc susceptibles, comme dans les cas préctés, de mettre au jour des structures sinon completes du moins comprehensibles. Robert Forrer, de son coté,

13. Dr Nower, $1860-1861$

14. Göknس $193 \%$ 


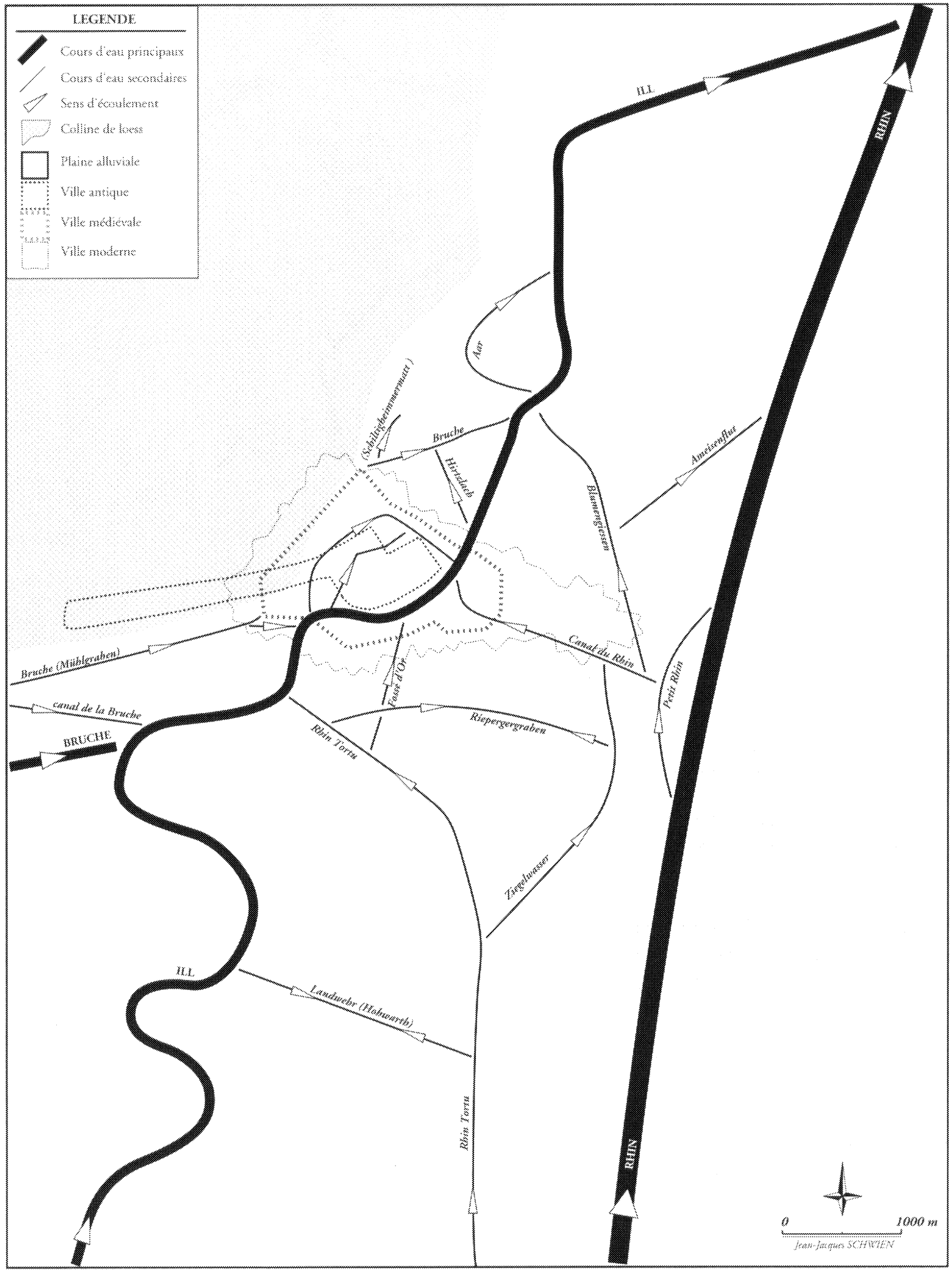

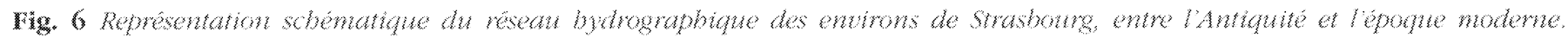
sumbize des données achelles. 


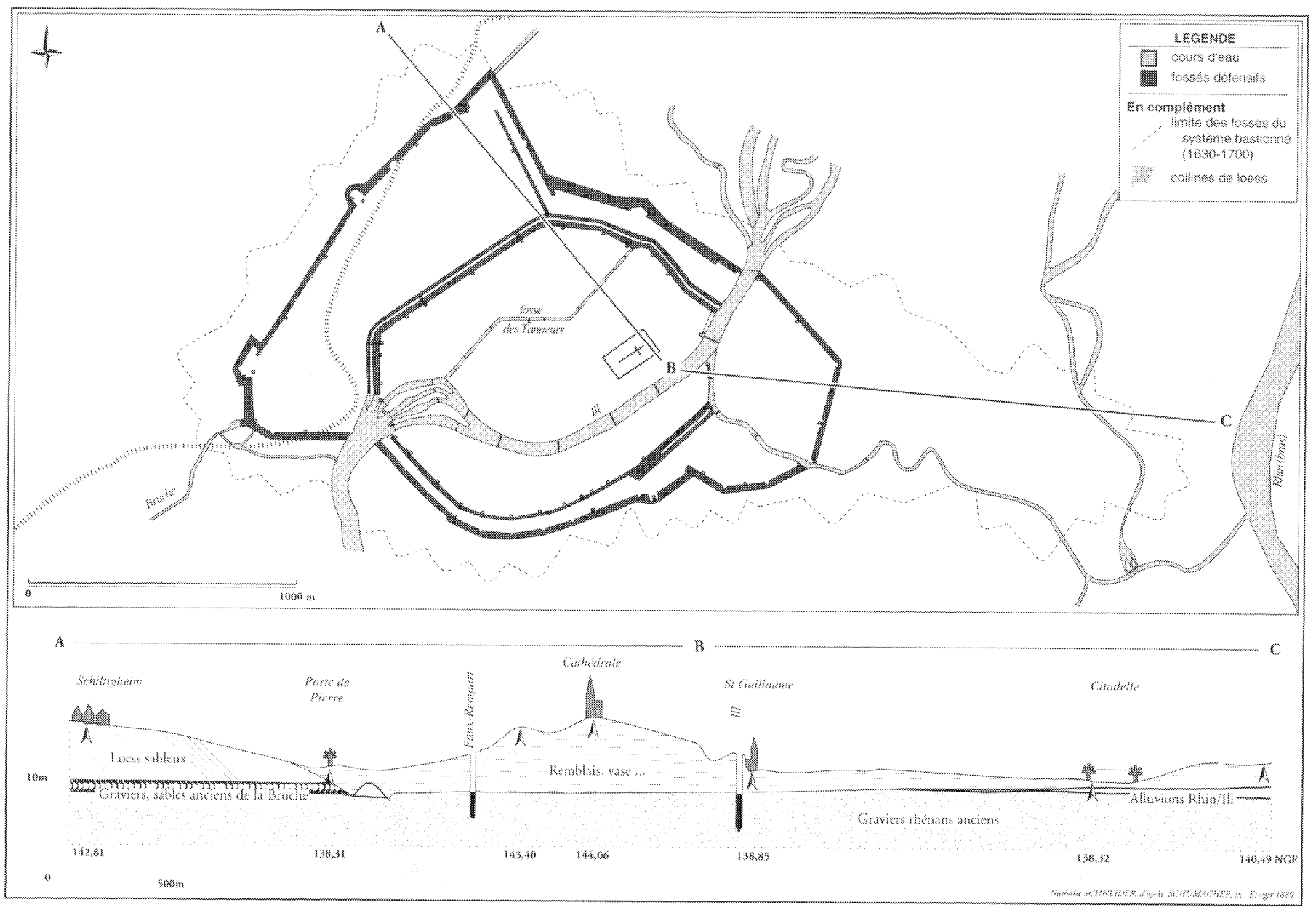

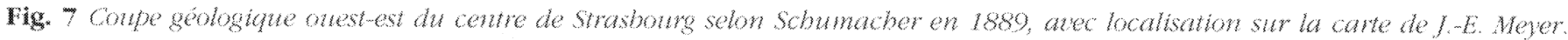

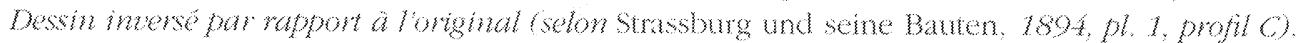

formule des hypotheses quant la configuration precise du site au moment de la création de lagglomération. Pour lui, le centre de Strasbourg reposait sur un lambeau de loess quaternaire réduit en hauteur par le Rhin; les noyaux dhabitat primitifs devaient aussi se situer sur des iles a une cote variant entre $136 \mathrm{et} 137 \mathrm{~m}$ NGF soit un mètre cinquante à deux metres au-dessus de la nappe phréatique. Ces lles - celles de la cathédrale ou de léglise Saint-Thomas - depassaient de peu le niveau des cours dean et étaient submergés à chaque grande crue. Elles auraient été exhaussées par un apport dalluvions et de remblais anthciels tandis que les cours deau qui les separaient se serajent rétrécis parfois jusqu'à leur disparition.

15. Fomkr, $192 \%, p \cdot 19^{*} \cdot 22^{*}$

16. Donom Gomtson, 1946 totale ${ }^{15}$. Les geologues Dubois at Goettsch ont conteste cette idee de lambeaux de loess formant le substrat du centre ville: pour eux, il ne pouvait s'agir que dalluvions fuviatles niches en dements empruntés aux loess du Kochersberg ${ }^{16}$.

Lensemble de ces travaux est résume, avec de belles cartes à lappui, par Charles Goehner en $1935^{17}$. II considèe alors que la plaine allwiale "naturelle aurait été parcoume dun lacis de bras dont seul le Rhin se serat d'abond démarque. Une individualisation des cours deau principaux aurait été manifeste des le debut de lepoque romaine. Le Rhin est alors constitué de plusieurs lits avec des chenaux en tresses et un reseau inextricable de bras

17. Comwne-Bumber, 1935 
dvagants, Les larges méandres de III empruntent plusieurs cours dont certuns, en se reioignant, foment des Nes, telle lellipse sur laquelle sest edfiee Stasbourg. La Buche, enfm, longe le bas de la terasse de Schitugheim et se jette dans lml en trois endroits diferents au moins : a la Wontugne Verte, pres des ponts Coments et au nord de la ville. Quant aux inondations, aucune information nexiste a ce momentla pour lepoque romane; par contre, leur frequence et leurs mefaits ont be largement colpones par les chroniques medievales et modemes ${ }^{10}$.

Le questionnement sur le site de Stabbourg a, depuis lors, té négligé, la demiere carte geologique, en 1984, marquan meme une cetaine regression. le centre ville étant representé sous le terme générique "dalluyions indifferenciées ". II est vrai que la densite du bati, et lépaisseur des remblais ne favorise pas une cude du sous -sol.

Henri Vogt, en revanche, a recemment repris de fond en comble le probleme de lagencement des unites naturelles de la large region stasbourgeoise. II propose une chronologie de mise en place des formes sédimentaires et fait le point sur la hierarchisation du reseau hydrographique. Il apponte ainsi deux types de questionnements qui ont des implications directes sur les observations géoarchéologiques au centre ville.

En premer lieu, apparât lidee d'une "compétition " entre les compétences des cours d'eau baignant la cite. Le Rhin est, bien sûr, largement dominant, mais il faut aussi tenir compte de limpact de la Bruche dont le regime torrentiel est superieur à celui de 171 , en temes de dynamique fuvale. II attire surtout lattention sur le fait que la confluence de lwl await migré, a une époque tardive (antiquite?), du sud de Strashourg vers le nord. Les arguments atayant cette hypothèse sont de divers ordres, à la fois traceurs culturels (nom de Bruche attribué a l'Ill au centre de Strasbourg au Moyen Age) et obseryations de terain (dense réseau de chenaux et fossés entre III et Rhin a hauteur derstein).

En second heu, la chronologie de la mise en place des terasses alluviales thénanes constiue un domaine important qui reste a exploner, la stablisation de la basse terrasse inféreure thénane ayantété la condition sine qua non de linstallation de thomme dans la plaine ${ }^{\text {ta }}$.

18. lew toude precse rete i fare: wne lixte de ces inondations est

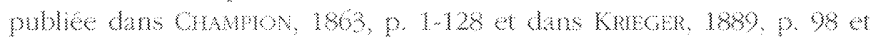
s.

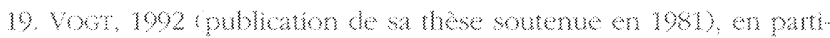

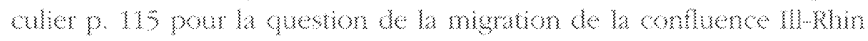

Au total, lanalyse du réseau hydrographique jusqu'a ces toutes demieres annés a éé fate selon deux orientations bien différenciees. Les premiers érudits, entre le xve et le xvmr siede, ont transposé aux origines de la ville le réseau des Cosses defensils et cours deau quils avaient encore sous les yeux ${ }^{20}$ : en forgean limage dun réseau en quelque sorte immobiliste, Is ont constitué un cadre géographique dans lequel historiens a archeologues, y compris ceux des $\mathrm{xIx}^{2}-\mathrm{Xx}$ siedes, veront natre et se developper la ville. Ainsi la premiere cate archeologique du Strasbourg antique propose par De Monlet en 1860 est-ele la copie confome du plan de sibermann pour lAntiquite' ${ }^{21}$. Les ouyrages de synthese recents sur thistoire de Strasbourg reproduisent toujours les mêmes schemas"2.

Les géologues et geographes, a partir de la hn du XIX siede, ont introduit a la fois les notions de dynamique fluviale et devolution du reseau. Cest ainsi que la plaine allwiale du Rhin est généralement représentée sous la forme dun écheveau complexe qui va progressivement se reduire à partir de lantiquite. Mais cete idee devolution reste cantonnée aux périodes les plus reculées, géologiques en loccurrence pour Schumacher, subhistoriques pour Vogt. Pour les périodes historiques, le schéma immobiliste reste la nome : si Goehner représente bien lecheveau complexe du reseau naturel du Rhin, pour les periodes historiques - y compris pour l'Antiquité - il reproduit purement et simplement le plan dEnoch Meyer. II y a donc toujours identité entre les cours deau et les fosses defensifs, ceux-ci étant une simple regularisation de ceux-1a.

Mais tout le monde saccorde finalement pour considérer le site primitif comme repulsif, avec de nombreux cours d'eau et marécages régulèrement submergé par des inondations.

Du point de vue des conditions de limplantation et du développement de la ville dans le cadre alluvial, trois questions principales ont donc été posées et qui niont pas encore reçu de réponse dénitive:

- la herarchie des cours deau principaux en particulier la chronologie et les modaltés de Vindividualisation de lill et de la Bruche aux epoques historiques:

- Le rappont entre ces cours deau et les fosses a fonction économique (tel le fossé des Tanneurs) ou défensive:

- la nature et le niveau du sol primitif d'Argentorate.

20. Ce resean es hen shr defalue des fosses du systeme hastone depogue modeme que ces crults ont soin va metre en place soit, dans le cas de Spedin, concu eux menes.

21. DE Monu, 16001861

22. Kund, 1986, p. 8; Wut et Rap, 1987, p. 29 


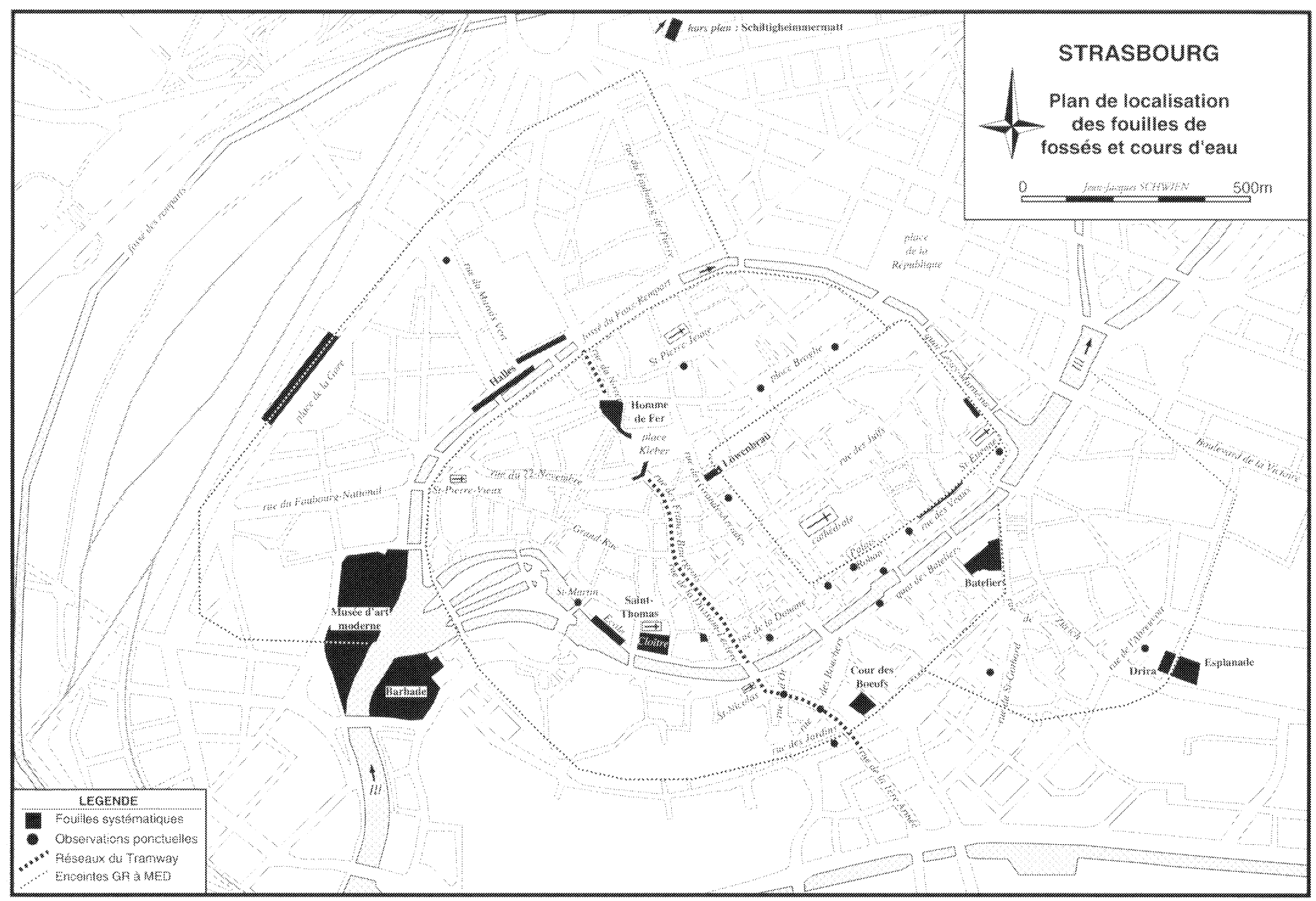

Fig. 8 plan de localisation des sites archeloginues ches dans le texte.

\section{LES ORIENTATIONS ACTUELLES}

Une nouvelle phase de cette recherche est engagée depuis le milieu des années 1980 gráce àne double evoIution Lessor de larcheologie preventive, dune part, a permis la multiplication des observations (fig. 8). Une dizaine de chantiers aux surfaces conséquentes (de 1000 a $20000 \mathrm{~m}^{2}$ ) ainsi quane demi-douzane dinterventions ponctuelles ont toutes peu ou prou mis au jour, sinon toujours des éléments du réseau hydrographique, du moins des tranches du sous-sol alluvial. Les développements récents de la sédimentologie appliquée à larcheologie ansi que de larchéométrie (datation par $\mathrm{Cl}$ a et dendrow chronologie, dautre part, ont procure les outils de mesure qui manquaient jusqualors pour apprehender les couches muettes, sans antefacts caractérisés (céramiques, monnaies, etc) : la première définit la nature des sédiments, leur mode de dépôt, leur origine géographique, la seconde date les matieres organiques (troncs. branches et autres végétaux plegés dans ces niveaux.

Sur le terain, il a fallu adapter les méthodes d'investigation a cet objet particulier. Une partie du réseau hydrom graphique, en particulier lorsqu'il êtait constitué d'aména. gements "en dur "(murs de quai), a été abordé avec les moyens d'une fouille classique (dégagement et relevé en plan). Mais lessentiel des traces dactivites alluviales etant constitué de sédiments naturels de composition quasi identique et dont linterêt premier réside dans leur succession et leur pendage (pour localiser les niveaux de berge), il a te necessaire de privilegier lanalyse stratigraphique. Centaines foulles Barbade, Bateliers, Musée dart moderne) ont ainsi componte des tanchees de plusieurs dizaines de mètres de long et quatre à cing mètres de haut pour observer les couches naturelles accessibles au-dessus de la nappe phréatique; le suivi des travaux damenagement du Tramway entre 1991 et 1993 a même 
été entèrement effectué par ce biais avec des tranchees qui, mises bout a bout, ont mesure plus dun kilometre au travers de la vielle ville. Seule la construction du parking de lHomme-de-Fer a permis de descendre largement sous le toit de la nappe phréatique (pompee en cours de chanther avec des moyens puissants), livant par paliers successifs une coupe de $10 \mathrm{~m}$ de haut. Les cudes de sol realisees par carotage en prevision dun projet de constructon de métro souterain antereur à celui du Tramway completent toutefois notre information sur les nveaux dans la nappe et ce a lechelle de la ville : la coupe (restitué) qui en résulte live un transect sud-nord de la plane allwiale entre Mkirch-Graffenstaden et Cronenbourg, soit 8 kilometres de long er $20 \mathrm{~m}$ de profondeur ${ }^{23}$.

Ces recherches recentes ont, par ailleurs, rapidenent dépassé la problematique initiale du site naturel primitif pour aborder le rapport de la ville a leau au cours de lensemble de son histore. Plutôt que dessayer de dessiner la seule toile de fond gégraphique des premiers habitants, il sest averé quil était au moins aussi important dobserver et de comprendre comment la ville avait progressivement dominé ces eaux superficielles ou souterraines pour les utiliser ou s'en défendre.

Les facettes de ces recherches sont multiples puisqueles concement autant le substat naturel et le réseau hydrographique que lhistoire de la nappe phreatique, les modes de fondation en milieu humide, les fosses déensifs, les puits et latrines. Les premières seront abordees ici de facon privilegiée. les autres étant seulement évoquées dans les perspectives densemble ${ }^{24}$.

\section{LE SUBSTRAT}

Ce substrat, a premiere vue, semble dune grande homogénéite. Sur lensemble des chantiers de foulles, en effet, les mêmes grandes séries stratigraphiques ont éte invariablement mises au jour avec de bas en haut:

- les graviers. Immergés dans la nappe phreatique, is ont été déposés au cours de lultime période froide du Quatemaire. Lessentiel est formé delements déposés par le Rhin. Dorigine jurassienne et alpine (gales granitiques

23. Ces domkes geologinues, istues des sondages des sociétes

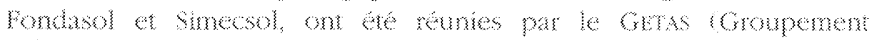

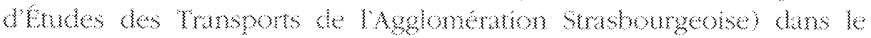

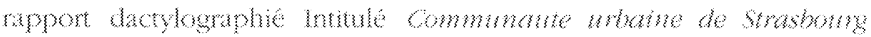

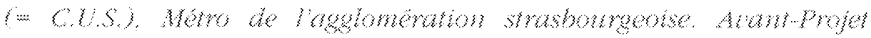

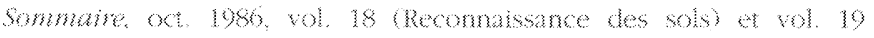
(Hydrologie). et cristallins, galets calcares, sables micaces), Is sont en généal de conleur grise. Is sont recouvers, partois entailles, en de nombreux endroits par des sediments dorigine vosgienne transpontes par la Bruche (galets granitiques et cristallins, schistes graurackeux et sables rouges). Leur mise en place temoigne decoulements torrentiels dans des conditions hydrodynamiques totalement diferentes de celles acmelles. La plupart des auteurs les attribuent sans plus de précisions au Wurm. Les graviers thenans sous Strasbourg sont ratuches au debut du Würm (128000 BP) par Henri Vogt. En effet, apres cette période, lare d'alluvionnement du Rhin se serait retrécie vers l'est. C'est au Wurm recent que les callouts de la Bruche ont en partie recouvert ces dépôts, dont la puissance atteint 100 a $150 \mathrm{~m}$ a hateur de Strasbourg avec un toit a la cote moyenne de $135-136 \mathrm{~m}$ NGF pour le centre ville:

- les alluvions fines, de 1 a $2 \mathrm{~m}$ dépaisseur cote super ficle $137-138 \mathrm{~m}$. Eles taduisent un changement radical de la dynamique fuviale, une diminution progressive de la competence des riveres. La charge solide passe du sable fin a des limons et argiles dont le depot suppose des conditions calmes a stagnantes, volre un enviromement marécageux. Une séquence sableuse marque cn fait la transition entre les dépôts graveleux et les sediments tres funs (limons et argiles). Là encore, ont été constatées deux origines principales, la Bruche avec sa dominante de sables rouges et le Rhin avec des sables jaunes et gris. Ces sables correspondent au passage progressif à des debits plus fables tout en restant des sédiments issus de courants de traction, dans le lit majeur des cours deau. Us reapparaissent ponctuellement dans les niveaux supéreurs limoneux sous forme de fines lentilles dextension varable, mais ils sont deposés dans ce cas par des cues.

Les limons et argiles forment, au-dessus de ces sables, l'essentiel du dépot sédimentaire fin. Ces allwions tres fines présentent une stratification très régulière et sowent subhorizontale. Leur mise en place est issue de processus de décantation au-dela des berges des rivieres, dans la plaine dinondation et à distance du chenal principal. L horizontalie des couches laisse supposer une amvee massive et unifome deaux boueuses après débordement, puis une stagnation pemettant le dépôt des grains trans-

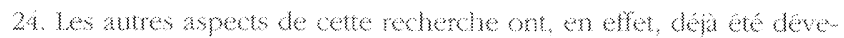

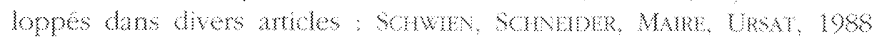

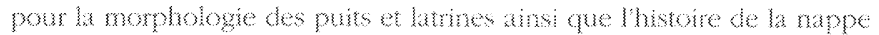

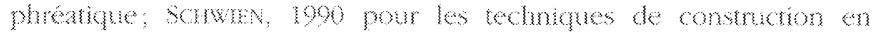

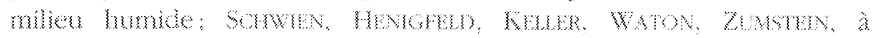

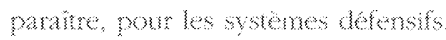


pontés par leau. Parfois ces argiles accompagnées de matiere organique colmatent des concavités dans les graviers. marquant ainsi la trace de chenaux creusés puis abandonnes par les rivieres, Leur reperage, lors des foulles, est hequent mais leur tace tout comme leur datation restent le plus souvent hypohétiques. Ces sediments fins sont globalement atribués a Holocène par les géologues, cest a dire posterieurs a la demière pérode glaciare, il y a 10000 ans.

Les limons "loessoides "dejà observes anciennement forment un cas particulier de sédiments fins. les foulles récentes confiment la présence de ces dépots dans le centre et sur la bordure nord-ovest de lellipse insulate (Homme-de-Fer, rue des Frano-Bourgeols, hótel Mercure pres de Saint-Pierre-le-Jeune). Une forte teneur en argike (plus de $40 \%$, des élements grossiers quarzeux, la présence de calcaire et de concrétions carbonatees ainsi quine colleur jaune leur confere ffectrement des caracteres proches des loess. Mais Thypothese dune plaque de loess in sim doit être définitivement exclue : leur datation (au-dessus de graviers déposés il y a quatre millenaires au plus pour lHomme-de-fer) et surtout leur nature argileuse, traduisant un mode de mise en place par décantation dans un milieu sature en eau, est incompatible avec un apport eolien quaternaire;

- les niveaux doccupation archéologiques proprement dits. Résultant des activités de construction, doccupation et de destruction et mesurant entre deux (en périphéric) et six metres (au centre) dépaisseur (cotes de la voirie actuelle $140-144 \mathrm{~m}$ ). ils forment le dernier etage de la statification ${ }^{2 \%}$.

L'homogéneité apparente du substrat cache, en fait, des questions complexes de chronologie et d'extension dans lespace des divers apponts.

\section{LA CHRONOLOGE DES DÉPÔTS}

\section{Le toit des graviers}

Les analyses absolues de troncs, branches ou végétaux piégés dans les graviers ${ }^{26}$ permettent aujourd hui de proposer des points dancrage chronologique pour la mise en place des alluvions grossieres les plus recentes.

25. Cet chument est diferent pou le hubourg antique de Koengshofen, drectement instale sur lo bes quatemane. La formation de ces loess contrarement aux sédmens qui now ocupen on par

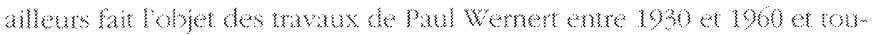

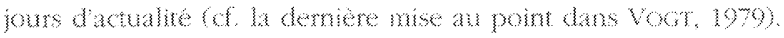

La senle sére graveleuse importante observee est localisé sur la place de Thomme-de-Fer. En plusieurs endroits et dans divers chenaux ensables, mais à des cotes altumétriques sensiblement equiralentes (132-134 $\mathrm{m}$ NGF), des bois ont été datés entre 11300 a 9400 ay. I. C. Au même endroit, le toit des graviers (et donc la base de letage des sédiments fins), a la cote $136 \mathrm{~m}$ NGF, a été daté de même entre 2500 et 2000 ar. J.C : les deux a quatre demiers mêtres du dépôt graveleux ont ainsi été apportés au cours de Holocene et non du Wüm récent, ce qui rajeunit considerablement les dates proposées jusqualors.

Les fragments de bois prelevés en plusieurs endroits sur le toit des graviers permettent, en revanche, danalyser à lechelle (dune partie de) la vile, la séquence chronologique terminale de cet etage graveleux (fg. 9). Ainsi, douest en est, a été noté un toit des graviers à $6000 \mathrm{av}$. J.C. aux Halles (rive gauche du Faux-Rempart), a 2300 av. J.C. sous la place de lHomme-de-Fer, a $400 / 200$ av, J.-C. sous la Grand-Rue (rue de la Division Leclere) et à $400 / 600$ ap. J.C. en rive droite de III (Bateliers, cour Saint-Nicolas). II apparat donc que cete chronologie est etagée douest en est, traduisant sans doute le retrait progressif des eaux tumultueuses du Rhin ef lindividualisation de ses affuents (II, Bruche).

\section{Les sediments fins}

La difference entre le toit des graviers el la base des niveaux anthropiques foumit théonquement la dure de lacumulation des sédiments, cest a dire la période dactivité des eaux de surface entre la fin du régime torrentiel du Rhin (et sans doute de la Bruche) et linstallation de thomme le terminus ante quom du depot des sediments fins est foumi par les premieres couches archéologiques (fig. 10). Pour les mêmes sites que precédemment, les lourchettes chronologiques de linstallation anthropique sont les survantes: vers $+1200 / 1300$ aux Halles, vers 15 av. J.C. 15 ap. J.-C. sous la place de WHommede-Fer, vers 90 av. J.C. 100 ap. J.C. sous la Grand-Rue, vers $700 / 900$ ap. J.C. en rive droite de III. Pour la place de WHommede-Fer, il faut preciser quin niveau doccupation sporadique, a $20 \mathrm{~cm}$ sous le toit des sédiments fins, est daté par des tessons de lage du Bronze et de la faune 27 : larrêt de la sedimentation principale s'y situe donc au debut du

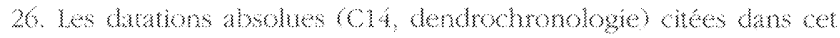
aride on dé, sauf mention explicte, realises par archeolabs.

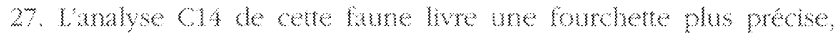
entre 1400 \& $1100 \mathrm{av}, \mathrm{JC}$. 


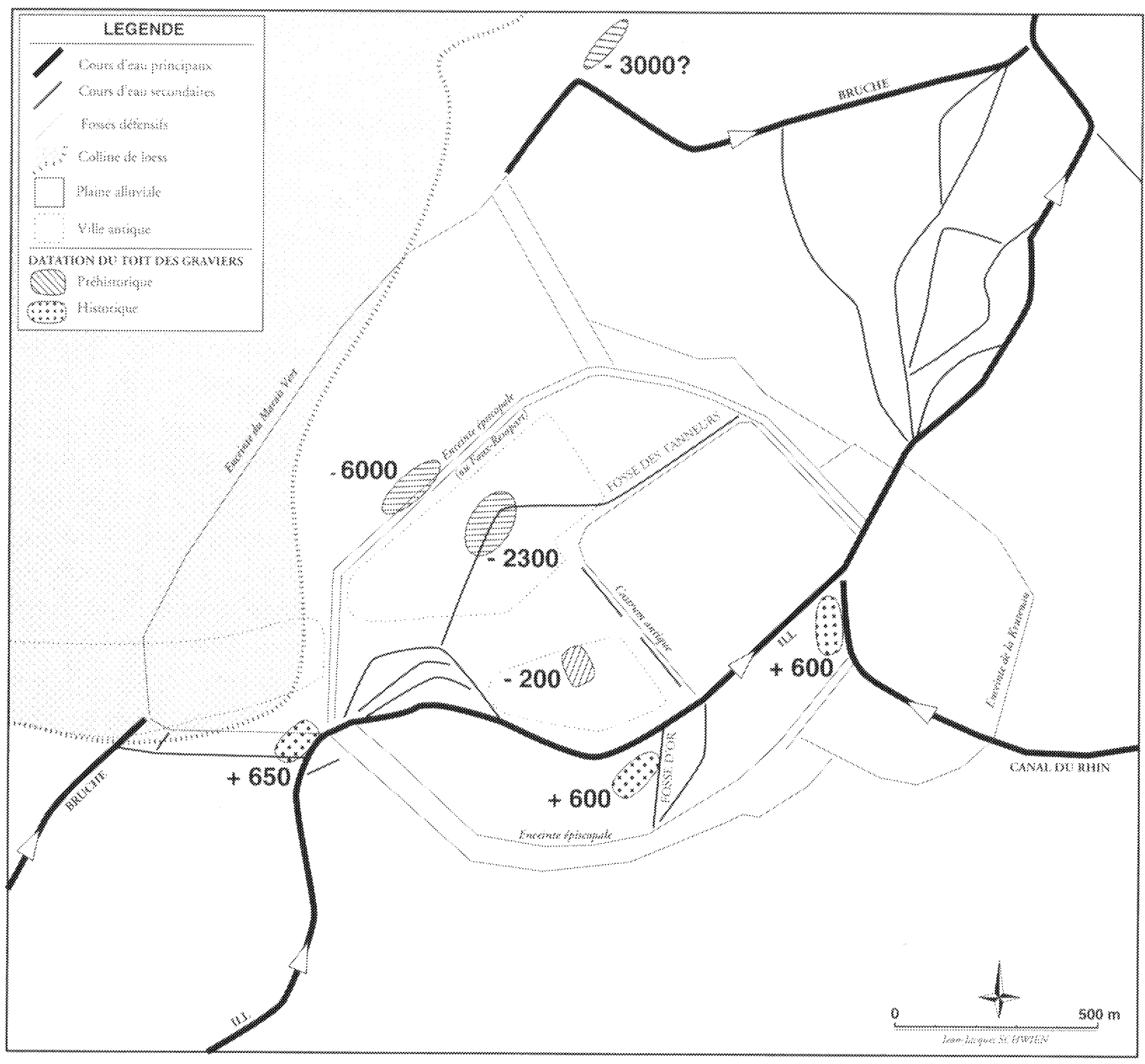

Nig. 9 La datation du toit des gravers an centre whe de Strasbourg, selon les analyses Cl4 de bois fontes. premier millenaire av, J.-C., un mince depôt venant encoresy ajouter entre cette date et le debut de lantiquite.

En rappelant que le dépót fin mesure partout entre un et deux mètres d'épaisseur, on est surpris par les différences considérbles qui ont été observées avec des durées de 7200 ans (Halles), 1000 a 2000 ans sous la place de Homme-de-Fer, 100 a 400 ans sous la GrandRue, 100 à 300 ans en rive droite de III. Letagement ouestest de la chronologie notee pour le toit des graviers est donc egalement attesté pour les sedments fins et il faut soulgner qu'll y a convergence avec lhistoire générale de la ville : lellipse insulaire a té occupee en premier parce que son sol etat forme depuis un a plusieurs siedes avant larrvee des Romans alors que lextension en rive droite de III na pu se faire ayant le haut Moyen Age en raison justement de labsence dun tel sol.
Ainsi, la place de Homme de Fer appartient à la fois au secteur ou l'on a observé des traces doccupation sporadiques de lage du Bronze et au noyau augustéen de lagglomération. Le secteur de la Grand-Rue est, lui, urbanise an to siecle ap. J.C. La rive droite de ITll, enfin, inoccupee dans lantiqute. est intégree défnitivement dans lespace ubain avec la constuction de lenceinte épiscopale vers 1200 : les foulles de ces demieres amees y ont toutefós détecté une occupation légerement antérieure, carolingienne pour la place des Bateliers, du Xl-xne siecles pour les autres sites.

Un seul cas semble aberant, celui des Halles en rive gauche du Fux-lkempart : la tourchene est la plus large. alors même que le site est le plus éloigné du Rhin. Selon son toponyme médieval, ce secteur des halles correspondait à un marais jusqua intégration dans lenceinte vers 


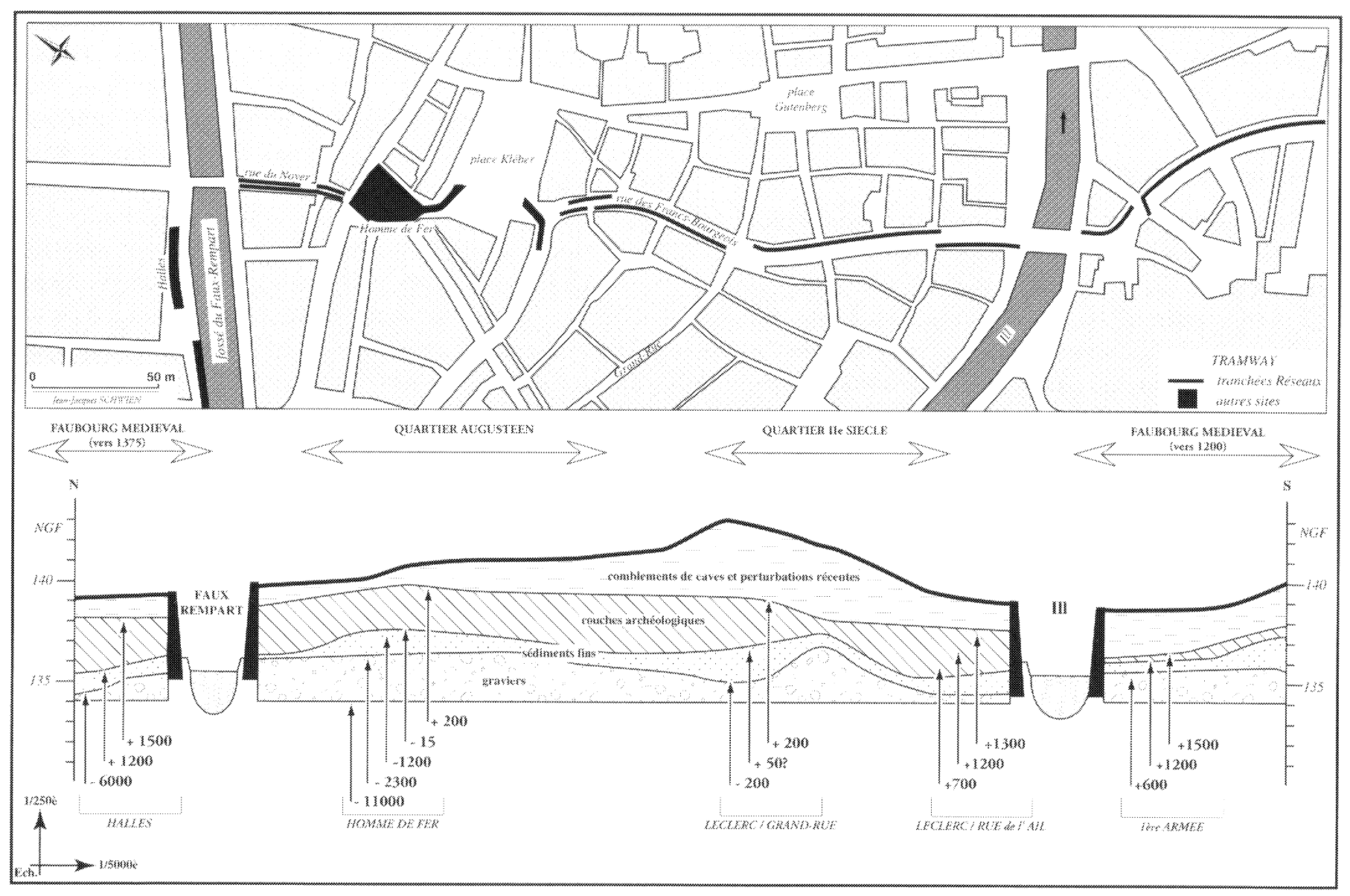

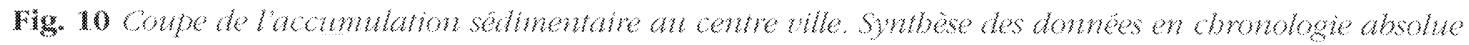
par grand ype de bepot des foniles du Thaman.

$1374^{28}$. Les foulles n'y ont pourtant pas observé une sédimentation fine diferente de celle des autres quatiers, les dépôts étant fomes de sables et limons de debordement et non dargiles de decantation. Quatre analyses de bois flotes en dvers endroits du toit des graviers ne laissent aucun doute quant a la date du sommet de cetage. II faut done poser comme hypothese de travail soit un manteau de sédiments fins déposé très tô - mais il est alors

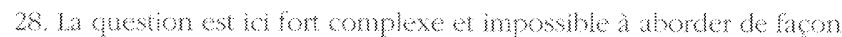

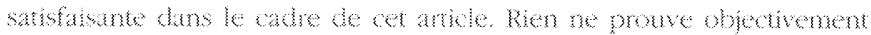

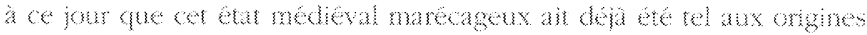

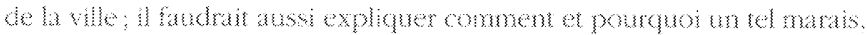
conce dest en ouest entre le coeve de lagglomeraton antigue et a

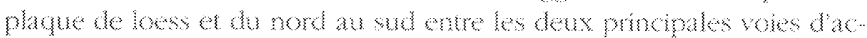

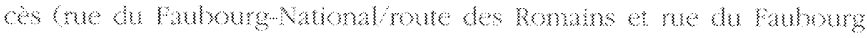

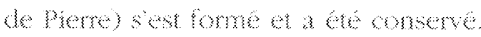

curieux que les Romains ne sy soient pas installes - soit un secteur a la dynamique complexe que seule la multiplication des observations sur tout le large quarter permetrait de comprendre. Pour cette dernere hypothese, if faudrait compter avec des remises en mowement des alluwions qui ont pu, a un ou plusieurs moments, dépla cer des sables, limons et argiles déposes par des cues anténeures, ne lassant, au bout du compte, que les dernieves traces de lactivite furatile sur tout ou parte de létage des sediments fins.

En fait, nos donnees sont trop peu nombreuses pour resoudre toutes les questions, analyser les incohérences apparentes et, imalement, proposer un schema theorique de la mise en phce du manteau de sédments fins. Cette demiere question est cepentant primordile puisque cete mise en place a bé la condition sine qua mon de la mais- 
sance et du developpement de lagglomeration : les sédiments fins forment lelement compact qui, au-dessus du toit de la nappe phréatique, lui sert de premier sol.

\section{L'extension des sèdiments}

Les deux étages dalluvions (graviers et sediments fins) sont partout présents sous la wlle les foulles de ces dernieres années ont pu apponter des précisions importantes sur lorigine geographique et lextension spatiale des alluvions superficielles (toit des graviers et sediments fins) et, par suite, defmir les lits majeurs des cours deau de Holocene (fg. 11). Les graviens thénans foment le substrat subaffeurant dans les quartiers est de la ville (Esplanade) ou ils sont drectement au contact de l'étage des sédments fins. Pour lessentel de la ville ancienne, ils sont toutefois recouverts soit par des graviers et sables vosgiens soit par des sables dlo-ménans. Ces demiers niveaux présentent des aires de répartition assez bien definies. Les sables (rouges) de la Bruche sont cantonnés en bordure ouest de la ville, le long du cours superieur de lill actuelle (de la caseme Barbade a Sant Pierrele-vieux et Saint Thomas) et sous lancien quartier du Marais Vent (actuel Centre Halles). Les sables et limons ménans, melanges a des sables vosgiens, ont éte observés ponctuellement dans le centre ville (notamment place de lHomme-de-Fer, ou ils natteignent que quelques dizaines de centimetres d'épaisseur sur les graviers: ils sont plus largement representés au sudest, en rive droite

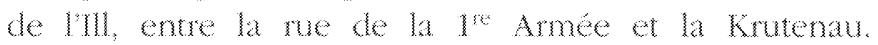
Lextension des limons fins "loessoides ", enfin, est cantonee au centre de lellipse insulaire.

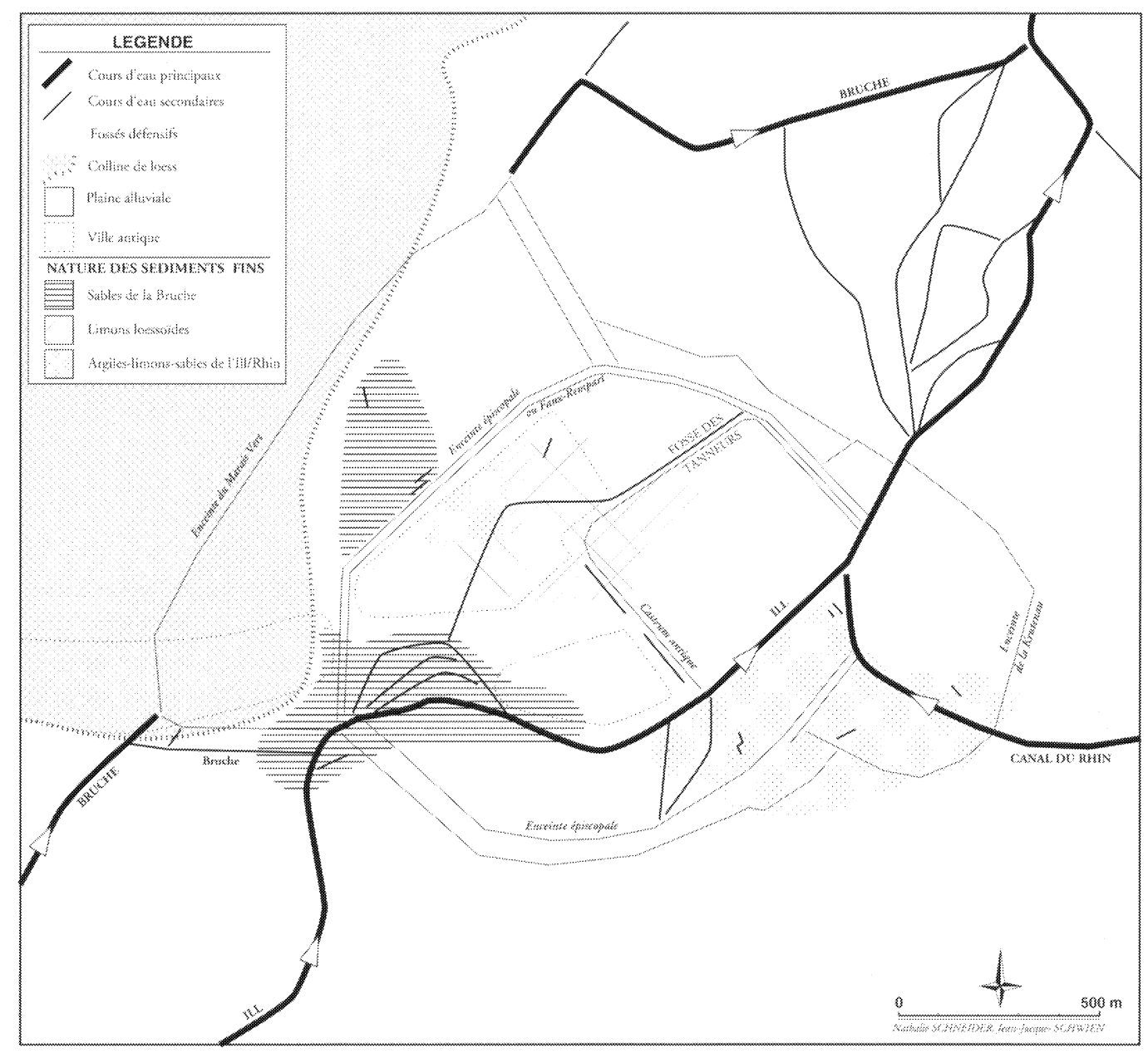

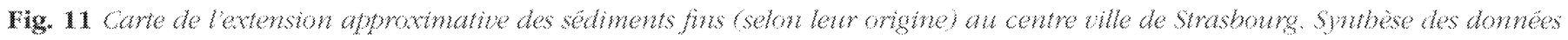
ancienues at récentes. 
Ces donnees sont bien sur incompletes et à maner aved précaution. Deux condusions peuvent toutefois en être tirees. En premier lieu, lextension assez importante des depots de la Bruche vers lest indique que ses divagations ont modelé le paysage avant que lun ny inscrive son cours: ce qui était déa supposé par les géographes, mais sans cartographie précise, est ainsi confime: du meme coup, la "confusion " entre les noms de Bruche et dul fate par les Strabourgeois peut effectivement tre attribuee à la conscience quils ont eue de la predominance de la premiere sur la seconde jusqua une periode tres recente. En second lieu, lextension des limons loessoides redonne une certaine actualité a lhypothese de Forrer qui cherchait les noyaux initiaux de la ville sur des les : lextension de ces limons correspond au caur de la ville augustéenne telle qu'il a pu etre récemment définie ${ }^{2 \%}$, Ceci voudrat dire que ces limons loessoides foment la partie la plus ancienne de létage de sédiments fins, etage indispensable pour une installation durable dans la plaine alluvale

\section{LE RÉSLAU HYDROGRAPHIQUE}

Le hasard des foulles a pemis dobserver un troncon au moins des cours deau principaux (sauf le Rhin et la Bruche) et dune partie des rivieres et ruisseaux secon. daires qui ont sillonné la ville et ses abords immédiats.

\section{Le Rhin}

Nous ne l'exoquerons que pour mémoire, en l'absence de donnés recentes.

Il est dair que des l'Antiquité, il a joué un rôle fondamental en tant que frontiere, voie de communication et divinite. La présence meme du camp legionnaire etait directement liee au limes ménan avant la conquete des Champs Décumates en 70 ap. J. C., puis à nouveau après leur perte vers 260 . Son role commercial est atteste par la présence de moellons en basalte dans les fondations du premier camp legionnaire, sans doute transportés depuis les carrèes du Kaiserstuh près de Vieux-Brisach, mais aussi par la découverte dun bateau échoué au ure siècle, avec sa cargaison dune trentaine de meules, a la confuence actuclle de ITI a la Wantzenau ${ }^{30}$. Quant a sa place dans le panthéon, elle est evoquée sur une stele du ur siede, découverte dans le comblement dun puits au

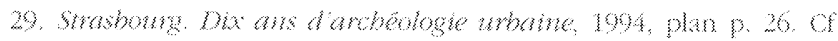
aussid ing. 16.

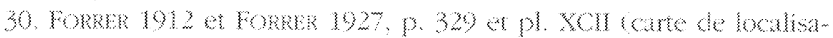
ton desin des restges du bakau). centre ville, dédiee "Au Père Rhin (par) Oppius Severus, légat diuguste :3t.

Malgré les assurances de plusieurs auteurs sur lexisten. ce dun pont pour las uns, dun gué pour les autres, le mode de passage du Rhin lumeme reste foncierement inconnu. La seule certitude est lexistence dun axe important, wne borne milliaire decouvente en rive droite commémorant la création dune route joignant Argentorate a la Rhetie en 74 ap. J, . C.

Ce n'est quau cours du Moyen Agge que nos informatons se précisent. Aux xn'-xme siedes, il etait franchissable par bac en trois points au moins; un premier pont en bois n'est construit qu'en 1388, entrainant labandon des anciens passages; il est déplace vers le nord en 1566 apres une importante inondation: au moins à partir de ce moment ha, il mesure environ 1,1 kilometres et se compose de troncons reliant trois des aux deux rives principales. La construction de la citadelle er du fort de Kehl au Xutr siecle ont entraine quelques modifications, mais ce n'est quavec la régularisation de lensemble du cours au XIX siecle que sera élife un pont en dur.

A ce jour, le cours du Rhin lui même n'a pas fait lobjet de recherches archéologiques, si ce ne sont quelques observations de Charles Gochner au moment du creusement du port vers 1930, soit sur les fondations (non datées) dun pont en bois de $100 \mathrm{~m} \times 10 \mathrm{~m}$ sur lun de ses bras ainsi que sur celles dune premiere redoute an xyme siecle ${ }^{32}$.

\section{La Bruche}

Comme le Rhin, ce cours deau na pas fait lobjet dinvestigations recentes. Son histoire et son statut sont complexes. II importe de distinguer son cours en amont et celui en aval de la ville.

\section{En amont}

Son tracé "originel "est difficile a appréhender, la basse vallee ayant été réaménagée par le canal de la Bruche pour l'approvisionnement en pierres de taille du chantier de construction de la citadelle en 1681-1683. A partir de ce moment-la au moins, le cours d'eau comporte trois élé. ments principaux, la Bruche elle-même, le canal et un lacis de bras d'eau dénomme Mablbach Canal du mou lin). Cest ce demier lacis de bras d'eau qui nous interes se au premier chef pour appréhender la situation primiti-

3). HATR 1970.

32. GOMHNR 1934 
ve. Les foulles du début du siede a la Montagne Verte lui conferent tout dabord une importance ancienne quil na plus aujouthui. $R$. Forrer $y$ a brevement signale la decouverte dun bateau ${ }^{33}$. Mais cest P. Amiet qui y a découvert, en 19381939, des aménagements porwaires consequents du ne secle ap. I.C. soit un dense resen de pilotis fomant des quais on des darses, deux radeax en bois et un stock de marchandises pondéreuses (pierres de taille en gres avec trous de louves, piecs de bois dun échafaudage, ${ }^{34}$. Il a de méme relevé le dispositif complet dun pont en bois long de $20 \mathrm{~m}$ et large de $3 \mathrm{~m}$ en aval de ce port; Il lattrbue au Moyen Age en ratson de la présence de pieux munis de sabots en fer. Par alleurs, le Whblbach porte le nom de Bruche sur le plan dEnoch Meyer en 1617 er se jette dans le fosse défensif ouest de la ville a la Ponte Blanche; ce même nom est donné à un autre bras deau (a fonction de canal de decharge?) qui sen détache avant la jonction avec le fossé défensf pour se jeter directement dans IWI pres du barage Vauban.

\section{En aval}

Le cours d'eau qui se détache du fosse défensif ouest ât hauteur de la Porte de Pierre ponte lui aussi le nom de Bruche jusqua sa confuence avec laar sur le plan dEnoch Meyer de 1617. Selon les fouilles de C. Goehner et P. Amiet à la Scbiligbeimermall en 1934-1935, son existence est attestee des la préhistoire. Celles-ci ont mis au jour a la fois un cours deau (avec une berge), des couches de tourbe ainsi quine ocupation anthropique continue entre le Nélithque final et le Hallstan, les vestiges principaux étant des planchers en rondins de lâge du Bronze ${ }^{35}$. Ce site est important, malgré d'importants problemes dinterpretation, le cours deau par exemple étant impossible a cartographer avec les données publiees: c'est le seul amenagenent décloppé pour cette période reconmu à theure actuelle dans la plaine alluviale a hateur de Strasbourg et il passe parfois pour un lieu dorigine possible de lagglomération.

Au total, si lon additione lensemble de ces informa tions - port antique, pont de $20 \mathrm{~m}$ de long, nom de Bruche attrbué au cours deau a lentree et a la sortie du Cossé defensif, bras deau préhistonque - on peut poser comme hypothese de travall lexistence, sinon du cours principal, du moins dun bras important longeant initialement le pied des collines de loess dans la parte nord de

33. wowne 1027, p.539, nowe 2

34. Amb $19 \%$

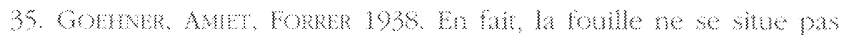

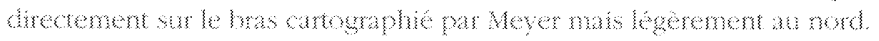

la valke alluviale: les aménagements anthropiques, au plus tard avec la construction du systeme defensif ouest de la ville, ont déplacé le cours primcipal pour créer ou stabiliser une confuence avec lWll au sud de la vallee allu. viale; le creusement du canal de la Bruche vers 1680 a finalement lossibe les anciens chenaux de la patie nord de la vallée.

\section{L.'III}

Ce cours deau principal de la ville. figuré selon un etat immuable des cartes anciennes aux representations les plus récentes, a cependant une histore complexe a la mesure de son importance dans le reseau. Un chenal pré historque (mais il sagit peut-ête dun bras du hhin a té localisé ente reglise Saint-Thomas et le pont du Cobeau : les sondages carottés prealables à un premier projet de métro y ont mis en evidence une couche de tourbe (non dateo), large de $200 \mathrm{~m}$ et epaisse de $3 \mathrm{~m}$, a $20 \mathrm{~m}$ sous le cours actuel de lull (cote $119 \mathrm{~m}$ NGP) $1 \mathrm{e}$ suivi des Réseaux du tramway a aussi revele une importante levée graveleuse, de lordre de $2 \mathrm{~m}$ (cote supérieure $137 \mathrm{~m}$ NGF, dans la rue de la Division Lederc, à hauteur de hae des Seruriers, soit a $200 \mathrm{~m}$ du quai actuel; cette levee peut asoir delimite un lit majeur de 1211 peu de temps avant la conquete.

Mais cest pour les periodes historiques, en particulier Mntiquté et le haut Moyen Age. quion dispose du plus whe ensemble dinfomations (fig. 12) Des observa tions deja anciennes de R. Forrer pour lÉcole SamThomas et la rue des Veaux ansi que de Jean Jacques Hatt pour les rues de lail et de la Douane avatent delimité, à partir daménagements de piquets el de dépotoirs de berge, la rive gauche soit du cours principal soit dun bras de lin a lintérieur des teres actuelles.

Les foulles récentes apportent sur ce point des précisions capitales. A Saint-Thomas, la berge en tere des $1^{\text {th }}$ If siecles ap. I.-C. (datation C14), a pres de $40 \mathrm{~m}$ du quat actuel, a de consolide avec un alignement de poteaux en chêne de 18 \ $20 \mathrm{~cm}$ de diametre pour un espacement de 0,90 a $1 \mathrm{~m}$. Une nouvelle rangee de poteaux en chêne, a $3,60 \mathrm{~m}$ de la premiere, lui succede apidement Au cours du me siecle (datation par la cermique), un bâtiment en dur est construit a cet emplacement ce qui implique un nouveau déplacement de la berge. Les vestiges de lepoque merouingienne sont difncles a interpreter. La

36. Le catalogue datule de ces obsermions archeologiques est

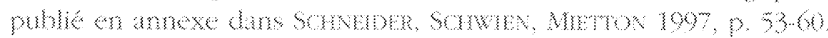



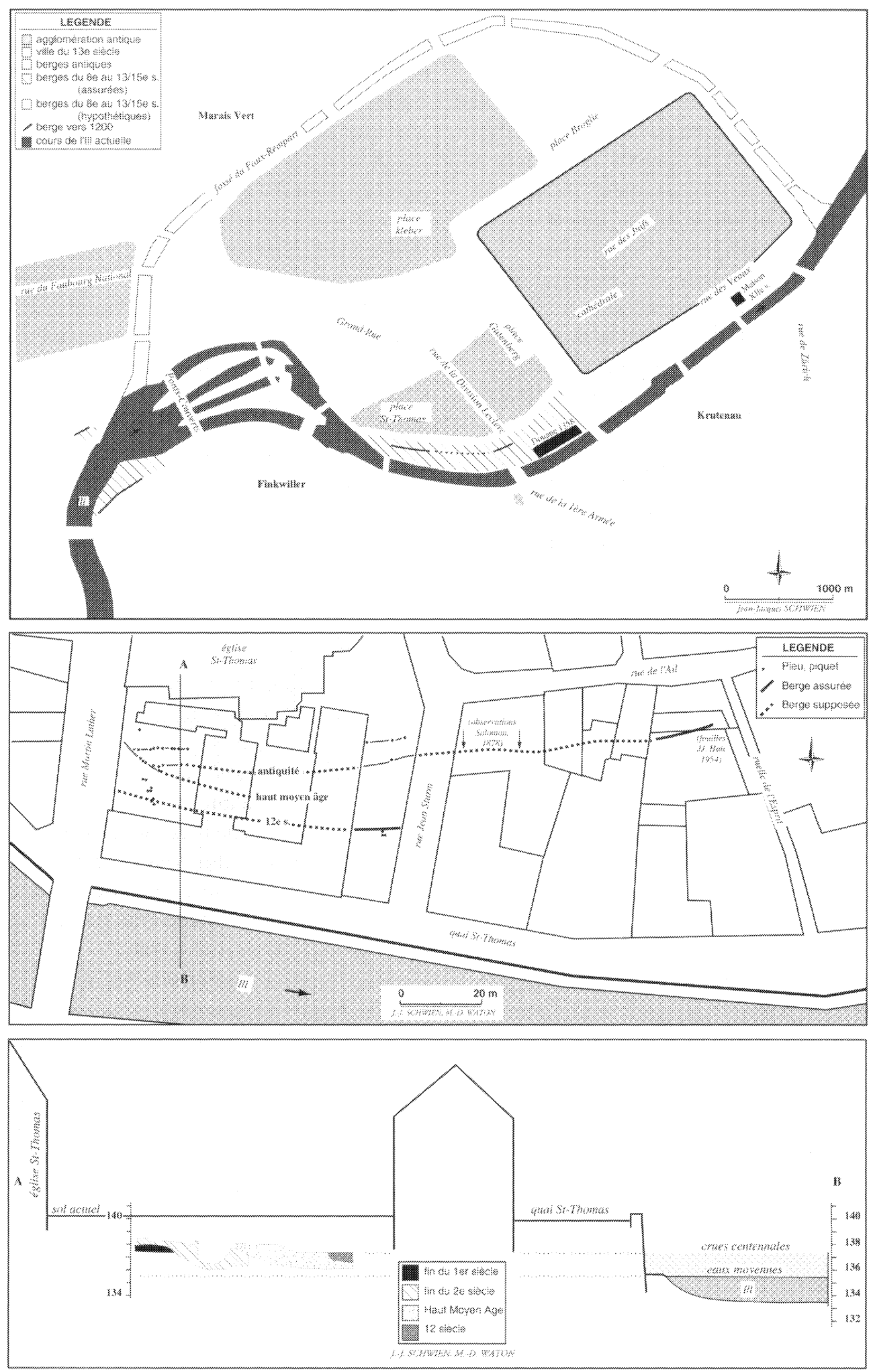

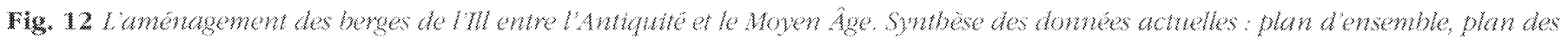
foulles du secteur de Samt-Thomas, coupe schematique des foulles de Saint Thomas (cf. Strabourg. Dix ans darehéologie urbaine, 1094, 949 
berge carolingienne, en revanche, est à nouveau mieux assuree formant un lgger arc de cercle, ses niveaux organiques de la base (racines at pieux d'aulnes) a $35-40 \mathrm{~m}$ du quai actuel ont éé datés de 775/1020 par C14. Au xure siecle, enfin, cette berge arec un ponton date par dendrochronologie de 1120-1127, a encore dé déplacé dune dizane de mètres; ce déplacement se poursut dalleurs au siede suivant mais la berge ellememe est des lors hors site.

La rue de la Division Ledere (site des Réseaux) a live des donnees chronologiques convergentes : dans lAntiquite, la berge (sans pieux) est située a $90 \mathrm{~m}$ du quai actuel; consolidée avee des piquets, elle n'est plus quà $65 \mathrm{~m}$ a lepoque carolingenne et a $45 \mathrm{~m}$ vers $1000-1250$. ces déplacements qui se soldent (volontairement ou non) par une extension de lespace urbanise, se sont faits de même par des remblaiements successifs où dominent les teres noires organiques, altemant partois avec des couches de dépotoir plus riches en mobilier archéologique.

Dans les deux cas, cependant, la foulle n'a pu determiner sil sagissait de la rive principale ou de la berge dun bras lateral : a Saint Thomas, cest à cause de la limite même du site et, pour la rue de la Division Lederc, à cause des caves profondes et des perturbations sous la vole du quai que manquent les donnees sur un espace dune trentaine de metres entre los fouilles et la berge actuelle. Ces précisions auraient été les bienvenues pour résoudre lune des énigmes du cours de l'ill à savoir la présence de ces bras près des Ponts Couverts a moins de $300 \mathrm{~m}$ en amont de Saint Thomas et dont on ne sait sils sont artifciels (soit des canaux pour alimenter les moulins) ou naturels. Dans ce dernier cas, cela pourrait you loir dire que les chenaux en aval des Ponts Couverts ont ete comblés sauf un, celui qui est encore sous nos yeux.

Pour la rive droite au centre ville, aucune donné n'est disponible si ce nest par defaut : la presence dune occupation antique à lemplacement de leglise Saint-Nicolas permet de supposer qua cet endroit, la berge contempotaine se situait non loin de lactuelle.

Sur les confins de la ville, enfru, en amont des Ponts Couverts (stes de Barbade et du Musee d'Art modeme), l'll a été sommairement aménagé avee des pieux et des piquets au xe siecle : elle mesurait alors pres de $180 \mathrm{~m}$ de large ${ }^{37}$.

37. Pour phs de precison, vor w notice consace a lemee de lw

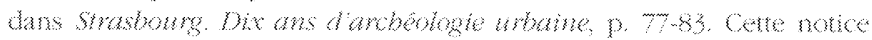

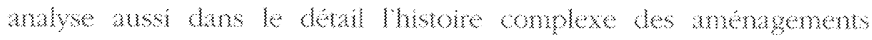
defensils entre le Xm et le xym
Aundel de lan mil labsence dinfomations archeolom giques oblige a fare appel aux sources historiques. Nos sources sont dailleurs tardves, le depoullement des archives medievales restant cncore à fare dans le cadre de cette problematique. II semble toutefois que, pendant longtemps. on se soit contente des ces berges en tere parfois mantenues par des piquets en bois a en juger dapres les dessins de Wenzel Hollar ou de J.J. Arhard au xwr siecle (quais de la pete france et des pecheurs, soit a lentre et sortie de la ville) ${ }^{38}$. Une piere commenomm la constuction du quai des Batelicrs entre 1412 et 1423 constue a theure actuele notre plus ancien témoignage dun quai maconné mais il hut antendre les dessins de Holar et Amardt pour être enterement assure de la canalisation du cours de III au centre de lagglomeration (quais Saint-Nicolas et Samt-Thomas). Presque tous les quais actuels, enfin, ont cé construtts ou reconstruits au xxe siede pour accompagner les modifations en profondeur de la navigation ${ }^{3}$.

Au total et indépendamment de la question dun chenal unique ou de bras multiples, it apparat que lhistore de III entre lAntiqute et nos jours est dabord celle dun rérecissement progressif de son lit qui passe de 100

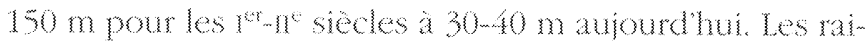
sons et les modalités de ce rétrécissement restent encore largement à définir. Tout comme reste à déteminer la fin de cette evolution : selon lemplacement dun certain nombre de bâtiments bien datés en bordure du cours deau, telle la Douane du milieu du xwe siede, la stabilisation definitive des berges pour le centre ville devait se situer entre le xm siecle (domnées de foulles) et la fin du Moyen Age. Ce retrecissement, par alleurs, conceme principalement la rive gauche; mises bout a bout, les donnees archéologiques anciennes et recentes, entre léglise Sant-Thomas et le fosse est du camp legionnaire donnent l'mage dune berge plus rectligne que celle du large meandre quion lui connat actuellement; il semble de ce fait que limportance des remblatements a cte plus importante au centre du troncon observé (nue de la Division Ledero) quaux extrémites. La morphologie des quais, enfm, n'est connue que dans ses trè grandes phases: de Mntiquité a la fin du Moyen Âge domine la berge en tere et en bois, les quais maconnés en continu n'étant assurés qu'à partir du $\mathrm{XIX}^{\circ}$ siecle.

38. Pour honographe tant de lll que des auve cous dean voir Fomsu, Kux, homkn, Rume, 1904.

39. I nexicte pas a theure aruele dewhe reatan os amenage

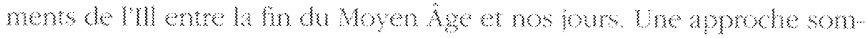
mare est propose dans 50 mwnen. 1990. 


\section{Le fossê du Faux-Rempart}

Lorigine naturelle de ce bras de l'II na jamais pose réllement probleme aux chercheurs. II est vrai quil sert de limite a une partie de la ville antique front nord du camp legionmaire et bordure ouest des quartiers civils de la plaine alluviale; de mème, pour les deux fossés du systeme defensif du xur siede, larges de $25 \mathrm{~m}$ et $14 \mathrm{~m}$, il peut sembler logigue davoir utilise un chenal preexistant: enfin, il retrouve tout "naturellement " sa vocation premiere lors de la transformation en canal de navigation vers 1830 au moment ou etait projetee la céation dun port a lemplacement actuel du secteur des Halles ${ }^{40}$.

Indépendamment même de linterpretation par Von Apell de la chronique de Koenigshoven qui stipule le creusement du fossé ${ }^{4}$, la question dine origine artifielle prend cependant un sens si on la replace dans un plus large contexte. Tout d'abord, dapres les observations archéologiques, le front nord du camp legionnaire disposait dun fossé distinct de lacuel Faux-Remparti2 : on peut en dédure soit un systeme complexe de fossés soit linexistence du Faux-Rempant Par alleurs, le troncon jumeau du systeme defensif du xms siecle en rive droite de 171 disposat, avec les modifications de la fin du Moyen Age, du même double mur avec double fossé 43 si daventure, la ville ayait projeté la création de son nouveau port dans les quartiers de la Krutenau ou du Tinkwiller, il $y$ a fort a parier que la transformation des fossés aurait pris le même visage que celui du fauxRempart. Contrairement aux cours deau (II, Buche. Rheingiessen..), enfin, ces fossés niont pas de toponyme en propre: sur les plans du XY" au mileu du Xwr" siecle. ils ne sont pas dénommés; Sibermann en 1775 parle de "innere "et "aussere Zollgraben " alors que Hemann en 1817 les connatt sous la denomination de "Burggraben ", des noms dérives de portes situées sur le fosse ${ }^{44}$; larchitecte Blondel, en 1765 , les appelle "fosse interieur large

40. If manque malkevreusement une ewde de fond pour ce tosse.

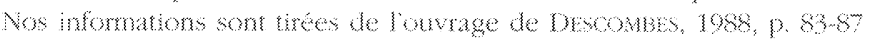
ansi gue des arches munipaks, en particuler les proces yebaux du consel municipal ente 1830 et 1833 . Cest dankurs dans les sénces du

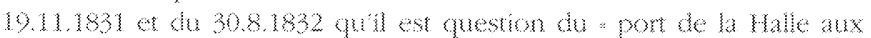
bles " he projet de pont est aussi evoque dans kutw, 1986, p. 63.

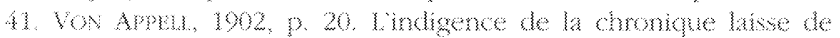
wute hon ha quetion onverte, ferme de "crewement powant ves

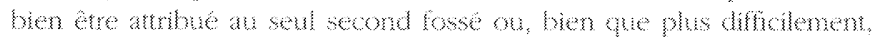
a la reguariotom dun cours preexistunt.

42. Wh, 1969, fouldes E. Kem an qui Lezay-Mamesia.

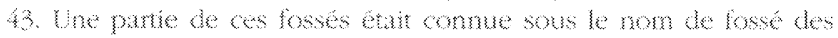

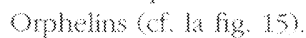

et fossé extericur ćtroit "; la premiere mention du FauxRempart est celle du plan de larchitecte Villot en $1821^{\text {s5 }}$

Les recentes foulles du Tramway nont pas permis de resoudre definitiement cette question des origines (fig. 13). En rive droite (site des Reseaux), le fosse mediéval était délimite par un mur dencente en briques. Des tranchees perpendiculaires ont mis au jour un dépôt de gravier argileux sur une vingtaine de metres derriere lenceinte a une cote inhabituelle (sommet a $137 \mathrm{~m} \mathrm{NGF}$ : on ne sait si ce dépot, ni franchement naturel ni franchement anthropique, a un rapport avec lenceinte (base dun rempart ou avec le creusement du Cossé. Nulle part, cependant in foulle na révele de traces de cours deau ancien dans les terrains naturels superficiels.

En rive gauche, un chenal daté de 8000 av. J.-C. a eté observe dans les graviers naturels (sous le toit actuel de la nappe) a $30 \mathrm{~m}$ environ du quai (site des Halles) L'ensemble des couches tant naturelles quarchéologiques relevees demiere ce même quai accusent un pendage géneral vers lintérieur des teres comme si ce chenal avait continué à fonctionner jusquaux périodes historiques ${ }^{60}$ La reconnaissance des sols effectuee dans le cadre du prom jet du métro souterrain/Val a aussi mis en valeur un important chenal marque dans les graviers sous le quartier ouest (jusquà la gare) a $10-15 \mathrm{~m}$ de profondeur environ.

Signalons enfin que des recherches subaquatiques ${ }^{48}$ menees sur le cours d'eau actuel ont confrmé la destruction totale des vestiges archeologiques - et en partie sans doute naturels - par les tranux de dragage du $x x^{\circ}$ siecle

Lensemble des infomations recueilies est, au total difficle dinterpretation. II semblerait qu'un on des cours deau aient plutot sillonne le secteur a louest du fossé du Faux-Rempart et que celui-ci ait eté creusé, partiellement au moins. Le noud du probleme, en fait, se situe sans doute légerement en amont des sites ctudies, là où le fossé se detache de lil. Cette defluence est, en effet, localisee au point de passage de laxe majeur antique qui, via la Grand-Rue et la rue du Fabourg National menait du

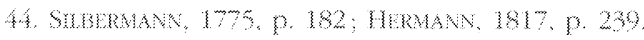

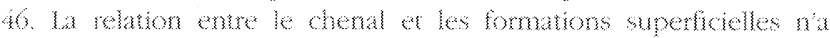

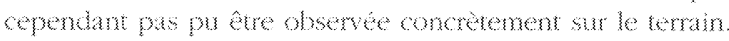

47. Momes refences que note 23

4\%. Ces recherches on be werues pur la semon dide au

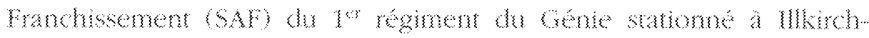

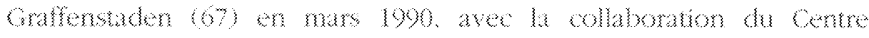

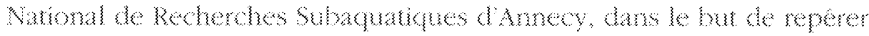

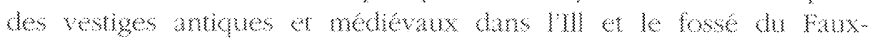

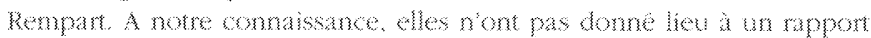

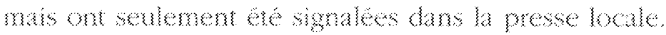



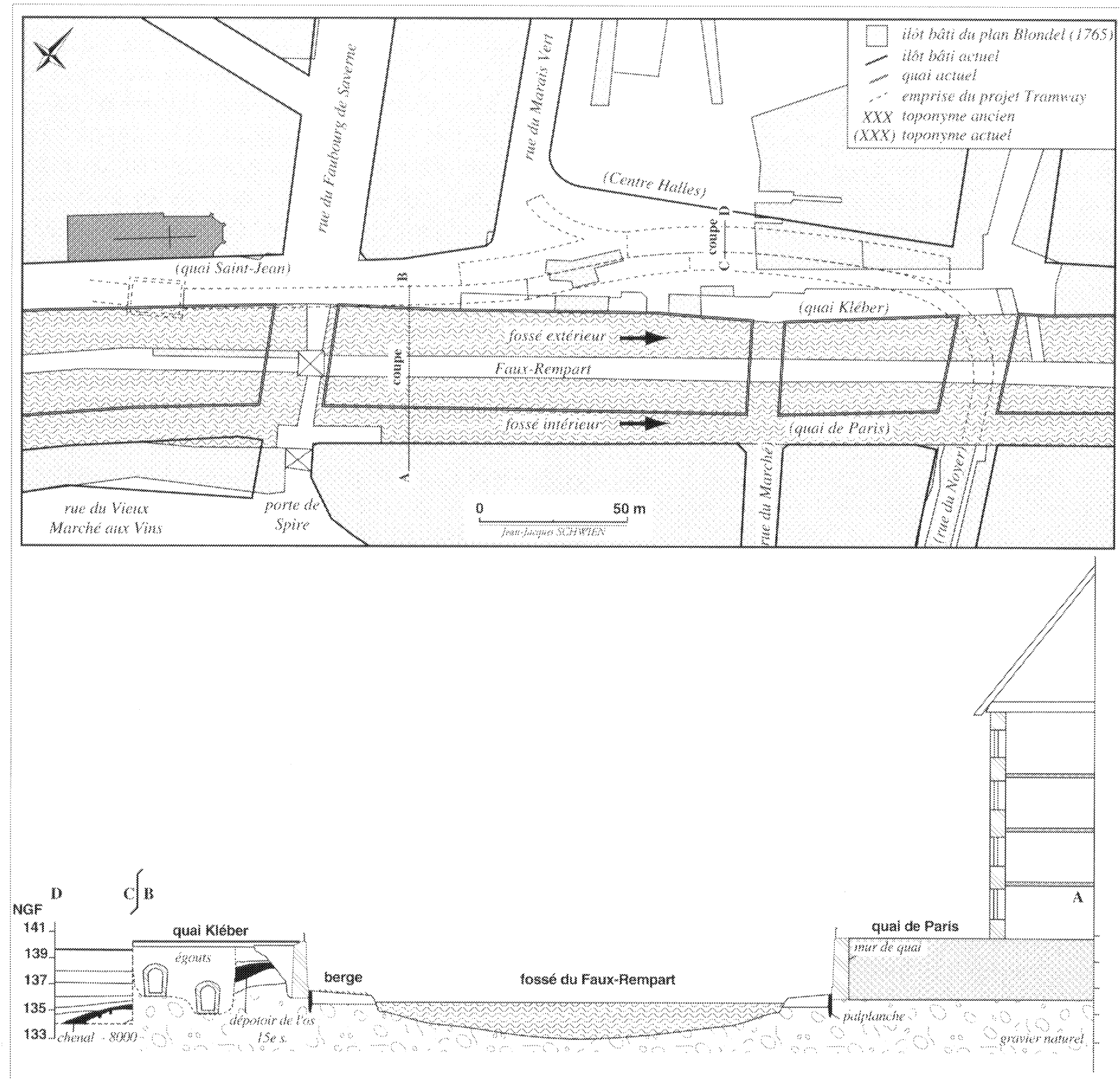

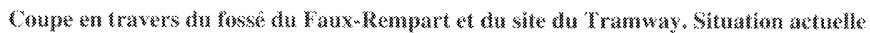

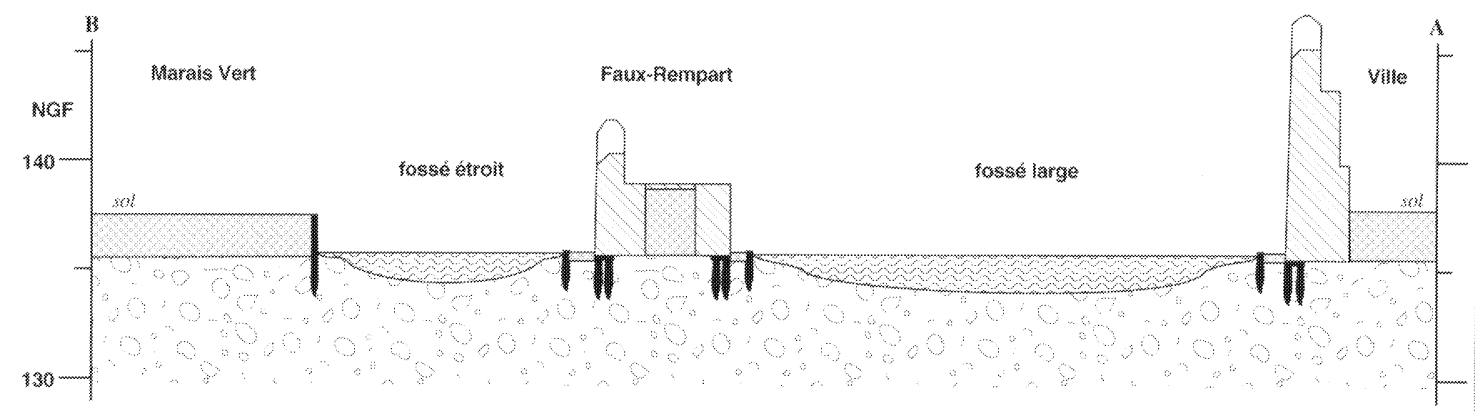

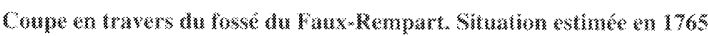

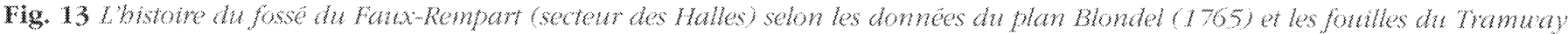
(jhan de symbere et coupes. 
camp legionaire au fabourg de Koengshoffen : si le Faux-Rempart a existé des lAntiquite, in n'y a que la quon pourait en trower des vestiges indubitables. If faudrait aussi y vérfer si la topographie des terains sous ces deux rues - pami les plus a cleves " de Stasbourg (42$143 \mathrm{~m}$ XGF pemetait naturellement le passge dun cours deau entre lextemite de la plaque de loess et la plaine aluviale ou si les fossés defensifs médievaux on entalle une kevee alluviale.

\section{Le fossê des Tanneurs}

Son histoire est au moins aussi complexe cet aussi peu éudiee) que celle du lossé du raux-Rempant. (n premier troncon a pu servir de fossé au camp legionnaire puisquil longe son front ouest (sous lactuelle place Broglie). Mais les fouilles, là encore, ont déterminé un systeme de fossés defensifs spécifques: comme, d'après le plan Blondel en 1765, le lossé des Tanneurs coulait à $33 \mathrm{~m}$ devant la courtine antique, il sagissait au mieux d'un fossé tres avance. Un second trongon, entre les places Broglie et de Homme de fer a pu appartenir au systeme defensif dit du haut Moyen Age: citee par les chroniqueurs du Xve siecle et aumdela, cete enceinte n'a pas encore été confrmé et localisée par les foulles la question reste done ouverte. Le demier troncon, entre linl quartier de la Petite Fance) et la place de Homme de Fer, passe parfois, mats sans véritable argumentaire, pour une premiere étape du Cosse défensif du haut Moyen Age

Sa premiere mention dans les textes est indirecte puisquil sagit du pont de la Haute-Montee place de THomme-de-Fer) en 1257; le fossé lui-même etant cté en 1310 (Rimsütergaben), on est des lors assure de son existence mais pas vértablement de sa fonction ni de son track. Une partie seulement, le cours supéreur dans le quartier justement appele des tanneurs, doit almenter les moulins a tan et les fosses à tannage; pour le reste, cest à dire lessentiel du fossé, aucune active précise nest connue: on ne sait même pas exactement sil ćtat navigable. Le tracé, quant à lui nest dome que par les premers plans de la ville de la fon du xye et du debut du XvI sicele: serpentant depuis les bras de III a la petite France jusquau fosse du Faux-Rempan au nord de la place Broglie, il dive lellipse insulaire en deux parties

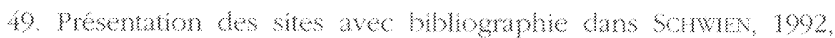

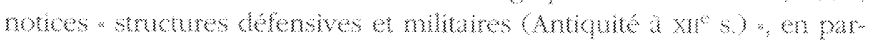
viculer $p .5$ amm que la notice du fose des Tanneve p. 106.

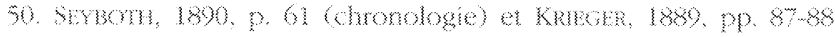
(notice generule)

51. Wher, 1929,92, , mote
}

inégales; selon le plan Blondel en 1765, it mesurat entre 8 et $10 \mathrm{~m}$ de large. Il est comble, pour des questions dhygiene, entre $1836-1840$ pour le troncon Grand-Rue/place Broglie ef apres 1870 pour le reste ${ }^{30}$.

II sagit au total dun lossé ou cours deau dont histoire et la fonction restent énigmatiques, la fome particulère de son tacé attendant encore une explication satisfaisante. Il cet clair, toutefois, quil ocupe une place particulère dans le reseau hydrographique : un visiteur venitien le compare au Grand Canal en $1518^{5}$; cest aussi le seul cours deau à disposer de facon systématique de ponts voutés en pierres des le Moyen Age ${ }^{5}$. Mais on ne sait si cente importance est fortute, du fait quil sagit de lun des derniers témoins a partir de lépoque moderne et hors les lossés defensifs du dense réseau hydrographique primiti progressivement comblé, ou si elle a été réclle dans ce reseau.

Les foulles de la place de lHomme de Fer ${ }^{5}$ ont apporte quelques réponses a nos questions : leur caractère limite - par rapport à la longueur totale du fossé de pres dun klomètre - ne permet cependant pas den tirer des conclusions génerales. Le troncon etudié (fig. 14) a incontestablement une origine naturelle : une série de chenaux ensables a té relevee dans les nveaux de graviers naturels, sous le niveau habivel de la nappe phreatique; trois dentre eux. larges de 15 a $20 \mathrm{~m}$, situes aux cotes 132 134 m NGF et datés par C14 entre 11300 et 9400 av. J.C., constituent les lointains ancetres du fosse des Tanneurs; leurs axes n'ont pas pu être reconnus. Un quatrieme chenal, au nveau du toit des graviers à la cote $136 \mathrm{~m}$, semble, lui, sinscrite dans laxe du fossé des Tanneurs, sa we droite ayant dé observée legerement derrière le quai maconne mediéval et son fond vaseux sous le quai nive gauche: la largeur totale n'est pas connue mais doit avoisiner les $20 \mathrm{~m}$; les brindiles recuellies dans la vase le datent entre 2450 et 2040 av. I.-C. Ce demier chenal correspond aussi à larrêt de lalluvionnement graveleux et a la base de létage de sédiments fins; cette seconde phase d'aluwonnement setend sur environ un millenaire, le toit des terains naturels fons a la cote 137,50 recelant quelques tessons et des ossements animaux dates par C14 de $1450 / 1110$ av. I, C.

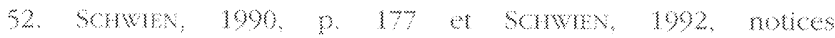
"Frndimesments ", en particulier p. 108 a 125.

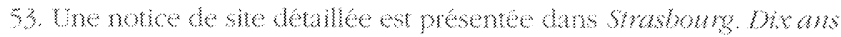

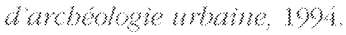

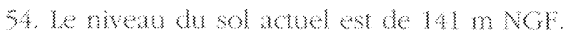




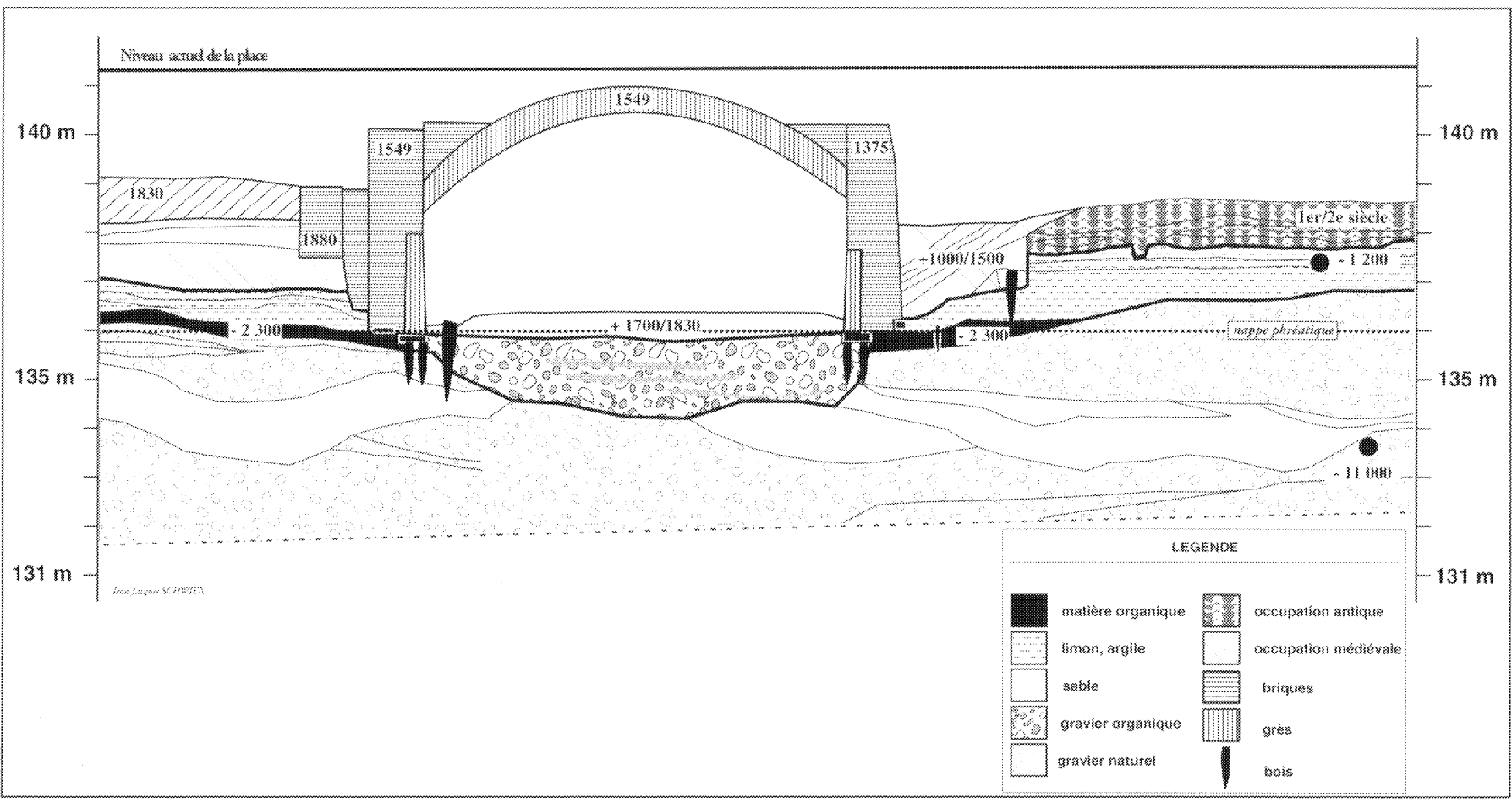

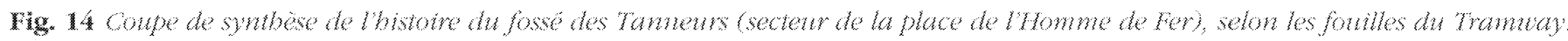

L'époque romaine, pourtant bien marquée sur le site. n'a pas laissê de traces d'aménagement du fossé. Il faut attendre le milieu du Moyen Âge pour voir débuter la canalisation du cours deau: des piquets en bois a la base de la berge en terre en pente douce (rive droite, sous le quai maçonné ultérieur), permettent sans aucun doute d'en freiner les divagations; l'un d'eux a eté daté par C14 entre 900 et $1160^{55}$; a partir de ce moment-là en tout cas, cette berge est stabilisee et sert de depotoir pour les résidus de foyer, destruction de poeles et autres objets de la vie quotidienne; selon les traces de deux poteaux en bois a mi-pente, est aussi edifé un pont en bois.

Ce premier aménagement cede la place quelques siècles plus tard à des quais maconnés, stabilisant mais rétrecissant aussi définitivement le cours d'eau. Ces quais sont construits de la même manière que les enceintes de la ville mediévale avec un mur en briques, un parement extérieur à la base en dalles de grès, le tout étant fondé sur un systeme de planches et pieux à fleur de nappe

55. Lx re gawhe, perwber par des hatmens depoue modeme nemit pas conerevere. phréatique. $45 \mathrm{~m}$ de long pour chaque rive, soit $90 \mathrm{~m}$ de murs, ont ete releves: le chenal mesurait alors $8 \mathrm{~m}$ de large, les murs étant conservés sur $4,50 \mathrm{~m}$ de haut environ, cest à dire quasiment jusquau sol actuel; leau dont la profondeur ne devait pas excéder 1 a $1,50 \mathrm{~m}$ (selon la hauteur du parement en grès) coulait a $3 \mathrm{~m}$ environ sous le niveau de circulation contemporain. Les analyses dendrochronologiques de 64 pieux et 5 planches ont revélé plusieurs phases de construction. Deux planches de fon dation en réemploi sur des pieux plus récents, datees respectivement de 1233 et 1244 , signalent sans doute un premier quai. Mais cest entre le XIVe et le XY siecle que sont construits les murs at le pont du Hibou voute en briques degages par la fouille. Quatre atapes ont, en fait, tê observees: 1375 et 1477 pour la rive droite (culee du pont puis mur), 1486-1547 et 1548-1549 pour la rive gauche (mur puis culée) : une risberme (file de pieux) destinée à proteger la base du quai des affoullements par leau est construte pour la rive gauche entre 1632 et 1675. Lensemble, comble au xix" siecle, est "remplacé "par un collecteur d'assainissement voûté en briques en usage jusqua nos jours. 
Les deux principales surprises sont venues de la mauvalse qualte des maconneries et de la proprete du lossé luimême. En elet, une parie des pieres en gres etait deltée, descellee ou remplacé par des briques; la culee de 1375 ctait aussi fendue de haut en bas dans laxe du mur en raison sans doute de léboulement et de la reconstruction du pont (en 1549). Cette mavaise qualite semble a metre au compte de labsence dentretien à partir de la fin du xwe siecle par alleurs, le lond du fosse etalt consttué de gravier sableux organique mais naturel sans cete vase ou ces déritus qui, selon les assertions des historens, auratent dus le caractériser. A lexeption de quelques couches peu epaisses des xwr-xum" siedes, lessentiel des sédiments du fosse - briques, tuiles, mor. ther, sable, gravier, céramiques... - correspondat au comblement de 1830.

Au tow a été observe une activé hydrographique importante des le debut de lHolocene; le chenal sindivi dualise sur son tace definitif a lage du Bronze (entre 2000 et 1000 av. J.C. ) : ll est ensute canalise au cours du Moyen Âge ayant d'être comblé au xIX" siecle Par rappont a la tadition historique, plusieurs corrections ou présions sont donc appontees: il ny a pas de traces dune fortifcation du haut Moyen Age: le lossé prexiste aux mentions de son creusement au xme siede; par contre, ha canalisation en dur remonte effectivement à cette période, accordant un certain crédit aux chroniqueurs; le caractere insalubre du cours - a lepoque moderne - ne peut provenir que de levacuation des luides mais pas de son utilisation en tant que dépotoir à eaux stagnantes.

\section{Le Rheingessen ou canal du Rhin}

Ce cours deau de pres de 3 kilometres de long reliat le Rhin et lil dans laquelle il se jetait pres de leglise Saint Gullaume. Bien quil ait une importance particuliere pour les Strasbourgeois a cause dun fameux episode de batehers Zürichois qui lont emprumé en 1576 pour honorer un pari, sa place réelle dans le réseau hydrographique, en particulier son role en tant que canal de jonction permettant des lAntiquté aux bateaux thenans de venir acoster au port de l'm, est tres mal connue. Situe, par ailleurs, dans un secteur fortement bouleversé a partir du xye siecle par les extensions successives du systeme defensif urbain, son origine (naturelle ou anthropique) ainsi que son tracé primitif ne se lassent guere appréhender par la documentation histonque à notre disposition: son trace même, en tavers de la plaine alluviale et non dans laxe de la pente, plade a prior pour un aménagement artificl du meme type que le Rebergergraben.
Cite une premère fois en 1296, il amait poné deux noms successifs, celui de Johamisgresen (fosse ldu cou vent de Saint-Jan-aux-ondes entre lo xur et le xho siede, puis celui de Rbeingiesen (canal du Rhin) a partir de la construction de la citadelle ${ }^{56}$. Trois troncons differents peuvent etre distingués pour la période antérieure a la ciadelle.

Le premier correspond aux demiers $250 \mathrm{~m}$ avant la comfuence. Selon les foulles de la place des Bateliers, il est améragé dés lépoque carolingienne au moyen de piquets en bois; translomé en fossé defensif vers 1200 , il mesurat alors $20 \mathrm{~m}$ de large environ et recuellait les eaux du fosse des Orphelins.

Le second troncon est celui qui coule au travers de la Krutenau et, de ce fait, a éte integre dans lespace fortifé avec lenceinte des amées 1404 1441. Le point le plus delicat tait le passage de lenceinte elle-méme; on sait seulement qu'un pont couvert y existait avant 1531, date à laquelle il a été reconstruit: un dessin du $x y^{e}$ siecle le représente de linterieur avec un barage en bois ot une galerie couverte, une herse coulissante ménageant un passage aux bateaux 5 .

Le demier troncon est celui entre la ville et le Rhin. Son thacé a eté modifí lors de la construction de la citadelle.

Son histoire est mieux connue a partir du xwo $\mathrm{s}^{5 \%}$, Parmi les modifcations impontantes, if faut signaler la construction des deux ecluses teminales en $1733-36$ pour facilter la navigation et retenir les grandes crues. Au xx siecle, il est suntout utilise pour les trains de bois lottés, en particulier pour tout lo bois de chauflage venant de la rive drote du Rhin ${ }^{50}$; avec la mise en place dun réseau de canaux hors les murs, il perd ensuite sa raison dêtre: comblé en 1872 (pour la parte dans laggloméra tion, il est remplacé par un collecteur deaux usees principal sous les actuelles rues de Zürich et du Marechal Juin.

\section{Les antres cours d'eau}

\section{Les fossés dor et des Boucbers}

Nous les traterons en même temps, Thistoriographie et les recherches archéologiques les ayant toujours observe de concert. Ces deux cours deau sont issus du Kalmasser

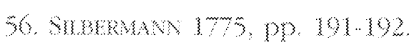

57. Arohves muncipales de strabourg, m

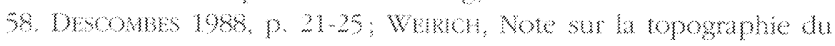

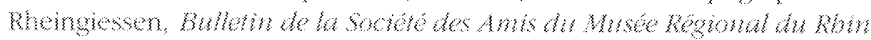
et de la Navigabion, 1993, p. 35-42.

59. MEMAN $1817, p, 246$ 
ou Rhin Tortu; is fomatent dabord un chenal unque avant de se subdwiser a hanteur de la porte de lHopital pour enfin confuer avee III sur racuel quat samtNicolas. Ces fosses on eté comblés progressivement a patir de la construction de lenceinte en rive droite de llll au xur siccle le fosse dor ou coldgiessen est cite une premiere fois en 1163; en 1326 et 1410 , les archives signam lent lexistence dun petit pont (Pfafenlapplickelin im Giesen. le nom du cours deau est sans aucun doute lie au charriage de pépites dor en provenance du Rhin : en 1849, en tout cas, lors du curage du cours de lni a lemplacement de lancienne confuence avec le fosse dor, la machine a remonte plusieurs morceaux de quarz avec des pépites d'or. Le fosse des Bouchers, quant à lui, a ponté plusieus noms (Smiedegiessen, Metzgengiessen, Vhegiesen) est cité a partir de 1291; sa dénomination est lice au marché aux bestiaux ${ }^{6}$.

Lhistoire at le trace de ces fossés sont en fait très mal conmus: ils ont éé combles avant les premeres repré sentations graphiques de la ville, ce qui met serieusement en doute toutes les representations des historiens; comme ils ont tete remplaces en ville par des rues portant le même nom, la période de ce comblement ne se laisse pas facilement cemer. Leur histoire pose une question interessante pour lurbanisation de la rive droite de $1 \mathrm{~m}$ : anterieurs a la construction de lenceinte vers 1200 , ils sont conservés pour des raisons sans doute importantes puisque leur passage fragilsait la ligne défensive; is pouratent avoir été combles pour, en partie du moins, bliminer ce handicap.

Les foulles ont localisé et grossierement date les deux fossés des le debut de ce siecle. Charles Gohner en releve le tacé approximatif a loccasion des travaux de la Grande Percee, vers 1930. II n'en donne malheureusement pas de description détallee mais presente un plan et des coupes: le fosse dor mesurat environ $20 \mathrm{~m}$ de large; il etait delmité par endroits par des pieux verticux ou enfonces de facon oblique: quelques uns taient aussi situes dans le cours deau; dautres servatent de fondation à des maisons. Dapres le rare mobiler recuelli (tessons de sigllee et scramasaxe, il a au moins fonctionné de l'Antiquté au haut Moyen Âge. Le fossé des Bouchers, par contre, tant dapres sa documentation que dans ses commentaires, ne se laisse guère cemer!

Les recentes foulles du Tramway nont pas definivement résolu les questions en suspens (emprise des fosses,

60. Semm 1888, p. 7275

6) GOWNak $1938,161.162$. periodes damenagement of de comblement, une bonne partie des structures etant pertubees par danciennes caves profondes et des resenux. Le transect du fossé dor na pas pu etre rellement observe mais la datation C14 d'un piquet preleve dans le lit du cours deau donne wne fourchette de 1020-1255; dapres le (rare) mobilier céramique, il aurait éte comble au xive siecle Par contre, deux petits affuents complementaires en rive gauche, larges de 5 a $6 \mathrm{~m}$ chacun, ont ete reconnus, le comblement du premier est daté par ses végétaux entre 895 et 1160; pour le second, lanalyse dendrochronologique des pieux de fondation dun gand bâtiment qui s'installe après son abandon donne une date ante quem de 1190. Quant au fosse des Bouchers, il a encore dé plus difncle de le reconnâtre en stucture: un preu en chêne préevé dans le cours deau a ćé date par C14 de 1225-1395; le mobiler du comblement situe son abandon entre 1500 et 1550 .

\section{Le Rbin Tortu}

Ce nusseau se detache du Rhin pres du village de Plobsheim, à une quinzaine de kilometres du centre ville, et se jette dans 171 au lieu-dit la Montagne Vete: il forme le principal cours d'eau entre 111 et Rhin au sud de la ville et coulant quasi parallelement par rapport à eux; il alim mente aussi tous les autres petits fosses ou ruisseaux qui parcourent cette partie de la plaine allwviale, à un moment ou a un autre (Ziegehaser, Riebergergraben, fosse dor

Son histoire est très mal connue. Mais, par chance, grâce aux foulles realisees par Goehner a la Meinau vers 1912-1913, on sait quil remonte au moins à l'Antiquité. Lors de Velargissement de la route de Colmar, il a, en ffet, relevé un cours deau large de 20 m avec une eparse couche dargile gris-noir au fond; des pieux a pointe tres acérée sans sabot en fer. longs de $1.50 \mathrm{~m}$, correspondent au pont de la voie menant de Strasbourg a Bale: Vattribution a l'Antiquité est lié à la présence de mobilier spécifque dans la vase et a la difference morphologique des pieux avec ceux du Moyen Âge; il semble avoir eté comm ble au $\mathrm{XY}$ sede dapres un cruchon, un couteau et divers tessons, le cours deau sest sans dout déplace au cours du Moyen Age : un nouvel amenagement de $13 \mathrm{~m}$ de large, $200 \mathrm{~m}$ plus an nord, a en effet été reconnu au cours dune seconde campagne de foulles; le pont exat construt avec des pieux a sabots en fer marques aux armes de la ville de Strasbourg; il nest dono pas date precisément más est indiscutablement postérieur a lantiquité dapres les données histonques, ce passage a été fortife par la constuction dune tour de guet en 1392 commandant le principal acces sud de la ville, doublee 
dun péage. Ce passage, ainst gue Iensemble du Rhin Tond dancurs - bien que tanshomes - ont subsiste tus qua nos jous

\section{Des fosses et comps denu hoommus, decomverts par les foulles}

A cote de ces elements foulles qui on pu etre rataches au resea hydroghaphque généal grâce au contexte (donnes historiques et reseau actue), un cetain nombre damenagenents mpossiblos a replacer dans un contexte precis ont encore ete decoments. Il est mpotant de sou. ligner qu'll sagit, quast dans tous les cas, de cous deau ou Cosses mineurs correspondant en quelque sorte a un resean interstide, completant celu des rvieres et canaux principaux.

Lessentel dente eux est sive en hive drote de lll, dans le large quarter de la Krutenau. Lun on laute pourait correspondre a des cours dean cites par les textes mais non localisés, le Scbonmemanmesghessn en 1276 . le Segegiessen en 1349, le Markesgiesen en 1391. le Segenublegraben en 1438 . Nous presenterons les decouvertes du sud vers le nord.

- Le Cossé de la Cour des Boubs. Ce perit chenal de 5 a $6 \mathrm{~m}$ de large etait amenage avec des picux entrelacs de fascines servan a la stabilsation des berges. De nom breux restes organiques ont ée découvers an fond du chenal : is sont sans doute dates du xu' siecle Au debut du xue siecle, il est réménage avec un qua fome de poutres equaries le comblement de cetre seconde phase est scelle par une couche de roscaux daté par C14 de 1035 m 1260 . II semblerait que lactuele rulle des Bowus ait repris lemprise de ce fosse 6 .

- Le Cosse de la rue du Sant-Gothard. Non loin de la. lors de la constuction dun immeuble, a ete relevé un autre aménagement mais dans des conditons plus del cates. Un alignement de piquets sur $10 \mathrm{~m}$ environ, obser vé au neau de la nappe phrétique, marquait vrasemblablemen une berge aménaze. Ces piquets, de $120 \mathrm{~m}$ de long pour $10 \mathrm{~cm}$ de damere chient espaces de 0,80 a $1,20 \mathrm{~m}$ enwion. Leur axe, avec une orentation SW-NE, ctait approximatyenent parallele a la me les omplins (etau fosse dor?), correspondant an cours deau cou

62. Gomane $19 \%$

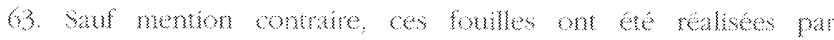
N. Schneider of I. I. Schulen

64. Somm 1889, p. 107

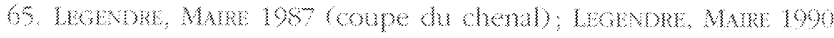

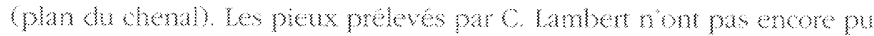

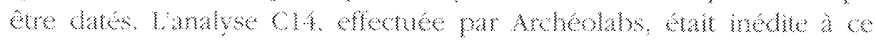

lane en becton de IMl. Lun des piquets a dé date par 0.4 be 104012806

- Les chenar de la place des batelers. Ces Konles-

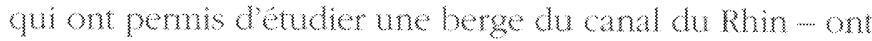
auss lve phsieurs autes chenax, dont deux seulement ont pu ctre dates plus precisement. Le premier, mesuman $5 \mathrm{~m}$ de large environ, fait caracterise par une legene depression dans le gravier $(50 \mathrm{~cm}$ ) il a ete comble en deux ctapes, dabord par du sable gns et du limon brun Conce sans doute nawrels puis, apres mise en place de piquets de berge, par de largle tres organique. Observe sur $10 \mathrm{~m}$ de longueur, Il bat axe SENW. Trois elements en ont cte dates, un premer piquet de 780 1150, un atre de 1030 1260, le comblement vegetal, enfn, de 1030 1265. Le second chenal a ete plus difficie a reperer pare que ses berges nétant pas res fanches: en fome de cuvetre de $4 \mathrm{~m}$ le large, inorimée dans la sére sélimen. tare fre langement audessus des gravers, il a éte dabon comble par du lmon sableux gris pus de largile gris bleu. Dapres le moblier archeologique, ce comble ment se sime au xum xur siecle.

- Le chenal de la rue de Dorewroir. Le suivi des ter rassements lors du creusement dune cave en 1991 (10, rue de labrewoir) a revele un chenal de 6 a 7 m de large incisant le gravier haturel sur 40 ch environ. Il a be com blé par du sable gris tres organique en deux phases, mar quant un resserement du lit avec un chenal teminal de $3 \mathrm{~m}$. L'axe semble etre $S W \sim \mathrm{NE}$ et poumat conespondre à un bras roine m petr afluent du canal du Rhin. Aucun element de datation na été observe.

- Le chenal de la rue du Marais Vent. Un aure chenal. non date, est stue en rve gauche du fossé du FauxRempar, sur le chantier de construction de l'Avancee en $1991.35-40$, ne du Marais Vert). Ce chenal de $425 \mathrm{~m}$ de large, caracterise par une incision nete dans les gravers rouges fins tres sableux, a dabond dé comble par du sable grosster rose plus ou moins organque, epais de $40 \mathrm{~cm}$ (chenal acti) puis comate par du hon grossier bun tres organique, sur $30 \mathrm{~cm}$ depasseur. Son axe est probablement $5 \mathrm{~W}-\mathrm{NE}$ (a $45^{\circ}$ par rappont ax rues du Marais Ven et du Faubourg de Sayeme). Un prélevement de brindlles fotres lans le graver du substat a ete rea

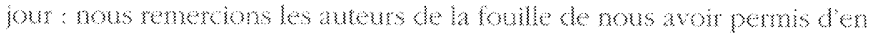

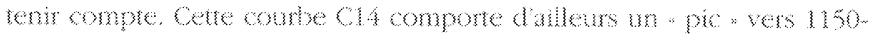

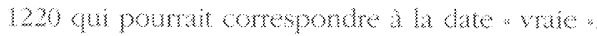

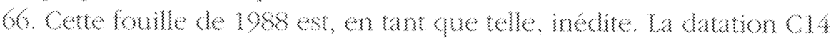

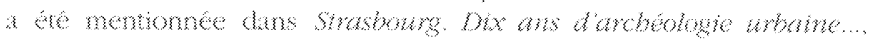
199,, 20 
lise, mais if ny avait pas assez de matiere pour une analyse 014 .

\section{Les fossês dêtrensîts}

De même que pour le reseau hydrographique, un troncon au moins des dwerses phases d'aménagement détensils a ete observe. I en ressont deux enseignements principaux. En premier lieu, les principes defensifs antiques of médevaux sont radiclement diferents. Le castrum légionnaire est construit en pieres (basalte, calcaire et gres); ses fondations, parfois assises sur le graver naturel, sont généralement situees $1 \mathrm{~m}$ au-dessus de $\mathrm{h}$ nappe phreatique; leur base est constituée dun herissonnage de pierres posées de chant. Ses losses, sépares du mur par un tere-plein, sont aménages avec un profil en $Y$ sans revetement; a une epoque tardive (bas Empire et/ou haut Moyen Âge, ces fossés comportent des parois droites revêtues de planches. $\mathrm{A}$ c jour, rien n'indique que ces fossés aient été en eau tant que lenceinte a conservé sa vocation defensive; selon certaines sources ecrites, le fossé ouest (sous les vocables de lossé des Talleurs et Umergraben) semble toutefois avoir servi degout pendant une partie du Moyen Âge. Enfin, il n'est pas clairement ctabli quil y ait eu un fossé defensif sur le front de III. Le systeme defensif médieval et moderne, entre 1200 (date de la première enceinte en dur) et 1680 (au moment de la conquete francaise), est lui concu sur dautres bases. Le mur est en briques, revêtu de dalles en gres a la base du parement externe; fonde sur des pieux, sa premiere assise est systématiquement située à fleur de nappe phreatique. Le fossé a fond plat est délimité par ce mur (sans présence de terreplein) et par une contrescarpe (revêtue de facon systematique au moins à partir de lépoque modeme). A plusieurs reprises ont eté observes des bâtardeaux formés de pieux et de planches protêgeant la base du mur d'escarpe des affoullements par leau, Les données des textes et des foulles convergent pour definir une hateur deau maximale de 1 a $1,50 \mathrm{~m}$; afn de reduire les mélaits de leau sur les maconneries, les ingenicurs militaires semblent toutefois s'être efforces de limiter leur présence permanente au moyen de barrages el de vannes, en particulier a partir du xur siede.

En second lieu, la momphologie du systeme défensif médieval/moderne (tout au moins en partie fondation) est identique en tous points a celle des quais de cours d'eau en dur". Cette identite est tellement forte quine partie du réseau est mixte (fossés défensifs/cours deau).

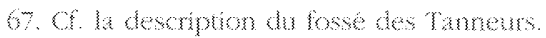

Ce tour thorizon des observatons ardéologiques fates ces demères années, complétes par des données plus anciennes, debouche sur plusieurs condusions importantes. Lorigine des fosses et cours deau, wout dabord, apparât contrastéc. II se confme que IVI. la Bruche, le fossé des Tanneurs et probablement le canal du Rhin preexistent a lagglomention. De fontes pré somptions, en revanche, pesent en faveur du caractere artifiel du fosse du Faux-Rempart. A lexception dun court troncon pour le canal du Rhin, rien ne vient etayer pour le moment lidée d'un systeme de fossés détensifs calqués systematiquement sur le réseau hydrographique naturel.

II se confime aussi - a en juger par le nombe de découvertes -... que ce réseau naturel a ete dense : sa res. titution complète apparait cependant comme hors de notre portée puisque les vestiges, étant domé la nature même des foulles urbaines, ne sont jamais que des minuscules troncons dont les "raccords "Confluences, défluences) nous échappent.

Un troisieme enseignement est plus inattendu : I semblerait que la ville antique n'ait aménagé que la rive gauche de IIII qui la bordait directement. Cest seulement a partir du haut Moyen Age quest apparemment engage un processus (en deux ctapes) de matrise du reseau hydrographique (6g. 15): les cours deau importants et les petits bras d'eau sont stabilises dans un premier temps au moyen de piquets en bois; ceux qui n'ont pas disparu par comblement ou envasement sont canalisés ultericure. ment, entre le xure et le XIXe siecle, avec des quais macon. nes.

En demier lieu, la ville médievale a invente (ou adapté) un outil qui lui servait a la fois pour ses besons defensifs et la canalisation du réseau hydrographique. Alors que les legionnares se sont installes a cheval sur les collines de loess et dans la plaine alluviale mais sans la structurer en profondeur. les hommes de l'evêque, patriciens et bourgeois ont conquis la plaine alluviale en canalisant et reduisant le réseau hydrographique au moyen de plusieurs outils dont le plus impontant et le plus efficace a éte lescarpe mur de quai. Ceci toutefois nest pas contradictoire avec Vidée dune non-adequation systematique entre reseau hydrogaphique naturel a losses defensifs : tout semble indiquer pour le moment que la canalisation en dur des cours deau naturels (III, fossé des Tanneurs) soit largement postérieure au developpement des systemes defensifs: en dautres temes, ce serait le principe defensif qui aurait ete applique au réseau hydrographque et non linverse. 


\section{LE SEUL DHABTABIUTÉ}

Le substat naturel, du fait de la presence de la nappe phréatique, et le reseau hydrographique se conjuguent pour faire du site de Strasbourg un milieu sature en eau. Au terme de cette analyse qui a aborde les deux aspects separement, il importe de considerer les conditions theo riques minimales pour la nassance et le developpenen de lagglomeration: il sagit en somme de calculer à partir de quel seul ou cote altumétrique thomme a pu sinstaller a labri des crues tant de la nappe que des eaux de surface.

te nizean du premier sol ta topographie de la ville actuelle naccuse qu'un très léger relief avec des cotes situees entre 139 et $144 \mathrm{~m}$ NGF. Dans le detail, on note cependant une sorte de proeminence ou arête (142$144 \mathrm{~m}$ qui, de la Grand-Rue a la rue des Juifs, epouse le tracé de lill, le niveau du sol formant une légere pente. vers les cours deau (cote des quals a $140 \mathrm{~m}$ ) : elle prolonge de fait la terasse de loess qui vient mourir, touburs a la cote $144 \mathrm{~m}$, a lextremite de la rue du Faubourg National. Cetre arete correspond grosso modo à laxe de developpement du Strasbourg antique entre Koenigshoffen et le front nord du castrum; clle restera le cour de la ville médiévale.

Une cartographie sommaire des informations issues des foulles réalises depuis la fin du siecle demier suggere une topographic du site primitif très éloignée de ce relief actuel (hg. 16. Lanalyse a été fate en extrapolant la cote altimetrique de la base des couches archélogiques de 90 sites environ pour lesquels les donnees dordre stratigaphique sont precises: elles appartiennent en majorté au castrum et a la vile civile gallo romane. Seuls les sols dhabitat ont éte retenus: les informations relatives aux structures en creux (fossés, fosses, puits mais aussi tombes en sont exclues lorsque le niveau dongine du

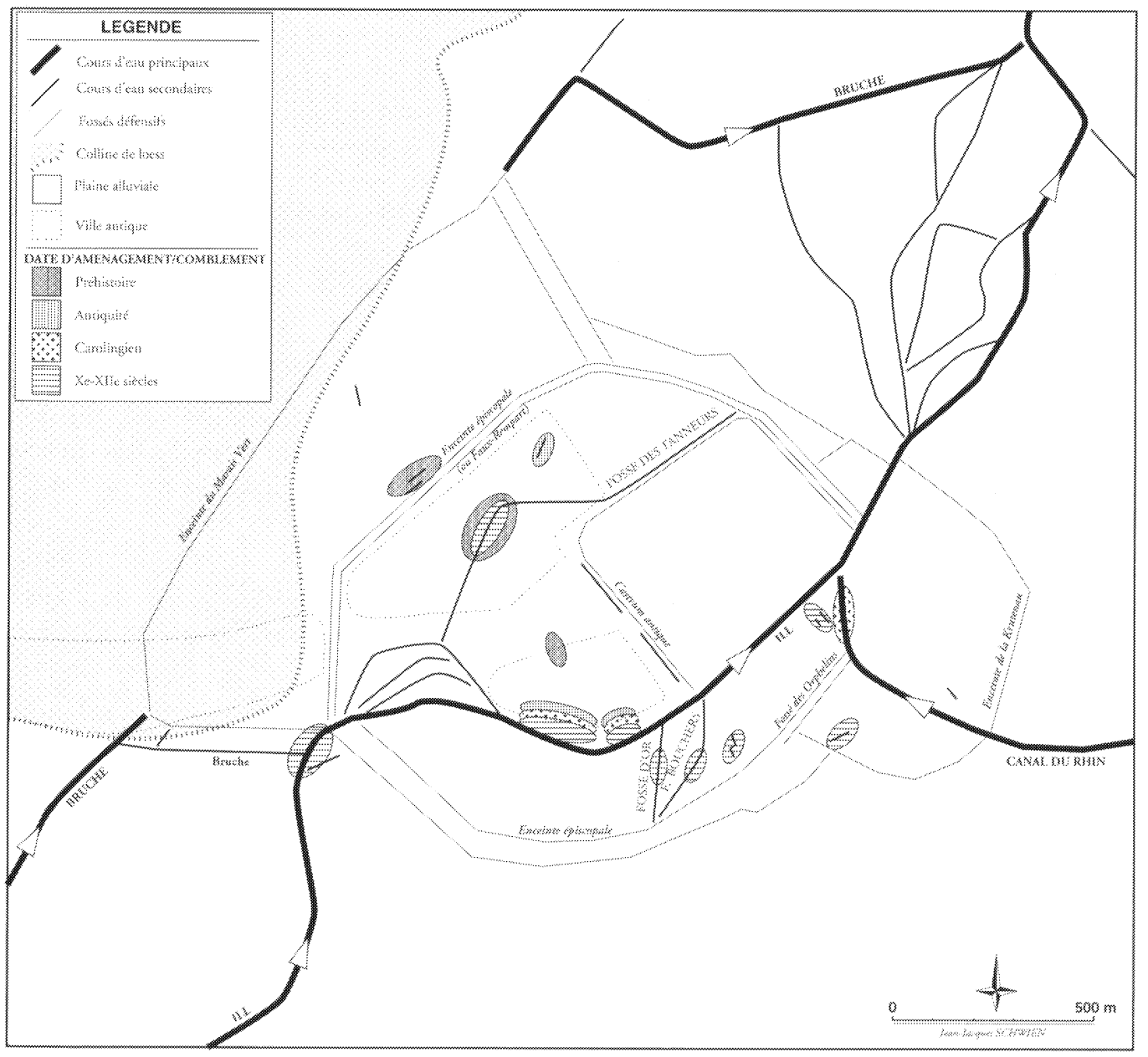

Fig. 15 la chronologie des aménagements etou com. bements des cours deam an centre whe de Stabbourg, selon les domees de foulles recentes. 

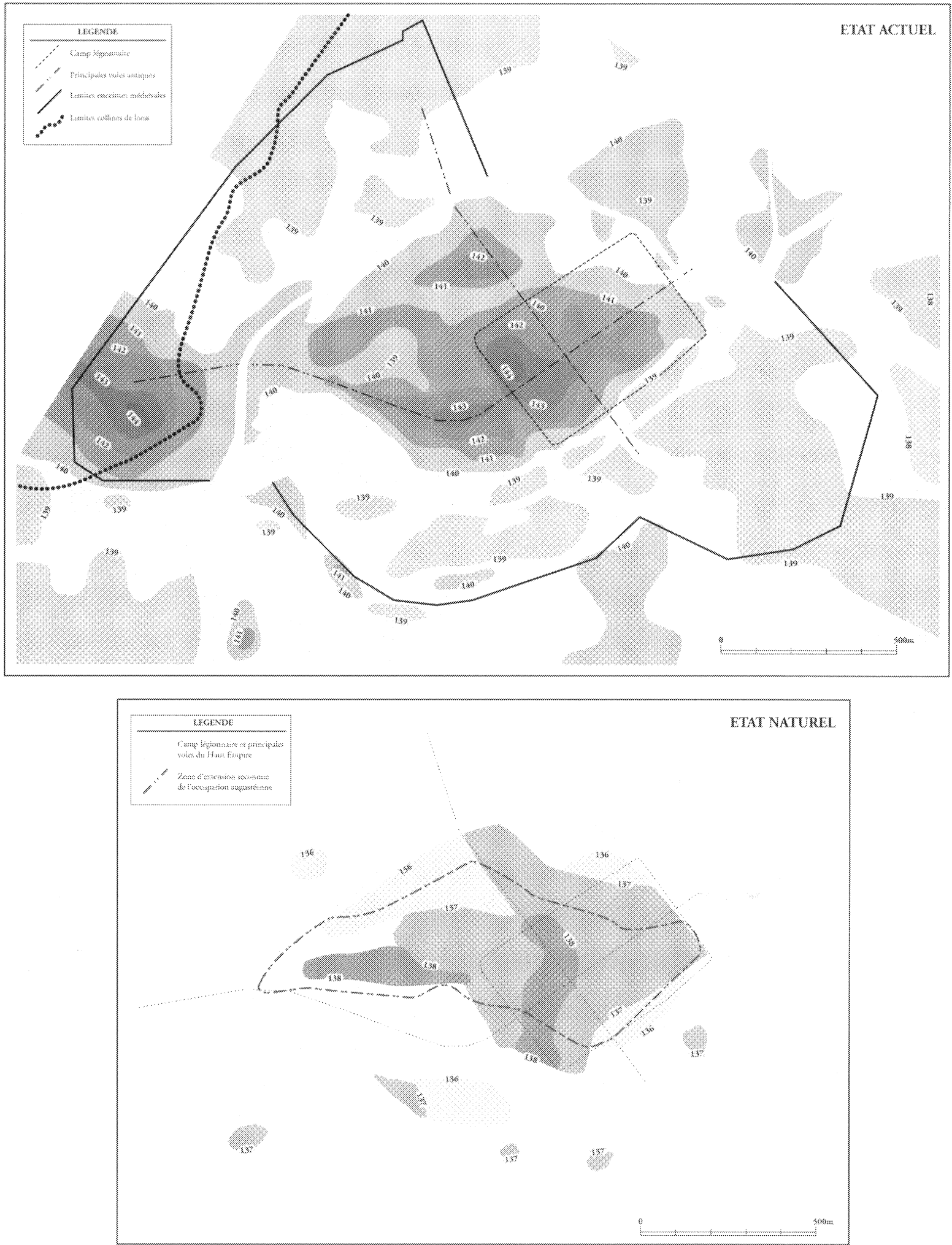

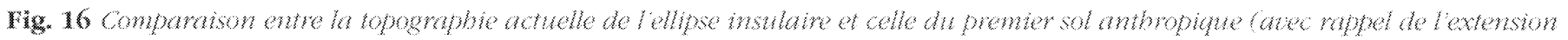

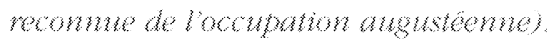


creusement est ixconnu. On observe pour lellipse insulaire une plateforme a ve altude de $137-138 \mathrm{~m}$ sans vertable procminence mas avec des franges (vers mil et le Faux-Rempart legerement plus basses, de lordre de $136 \mathrm{~m}$. Cette situation correspond pour lessentid a celle des debuts de lépoque romaine Couches augusternes et tiberiennes) : mais les sites extéreurs lellipse insulat re et amenagés au Moyen Age seulement foumissent des altitudes "primitives "similaires, vers $137 \mathrm{~m}$ NGF. On peut donc retenir la cote $137138 \mathrm{~m}$ comme sewl dhabitabite pour le centre ville de Strasbourg tan a lepoque galloromaine que mediévale.

\section{LES NIVEAUX D'RAU}

Nos seuls elements de reference, a theure actuelle, sont ITll et le Faux-Rempart. La hauteur deau est de $2,50 \mathrm{~m}$ au milieu du lit avec un niveau de surface moven situe à $137,50 \mathrm{~m}$ en amont du barrage Vauban et de $135,50 \mathrm{~m}$ en aval des ecluses de la petite Prance. On calcule gêneralement une elevation de $2 \mathrm{~m}$ de ce plan deau pour les crues centemales (soit respectivement $139,50 \mathrm{~m}$ et $137,50 \mathrm{~m}$ : ces chiffes sont a la fois des projections mathematiques et des mesures reelles des grandes inondations de 1778 et $1882^{\text {to }}$. Extrapoler ces mesures sans discemement aux origines de la ville, avant la canalisation progressive des cours deau e la suppression d'un certain nombre dentre eux, est delicat dautant plus que les zones d'epandage en amont ont pu naturellement ecrêter les crues.

Letude du toir de la nappe phréatique peut, en revanche, apponter ces mesures qui nous manquent. En effet, le mécanisme des échanges napperivière est aujourdhui assez bien connu pour quon puisse établir une correlation entre le toit de la nappe et le plan des

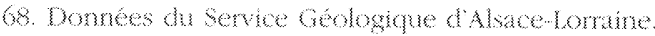
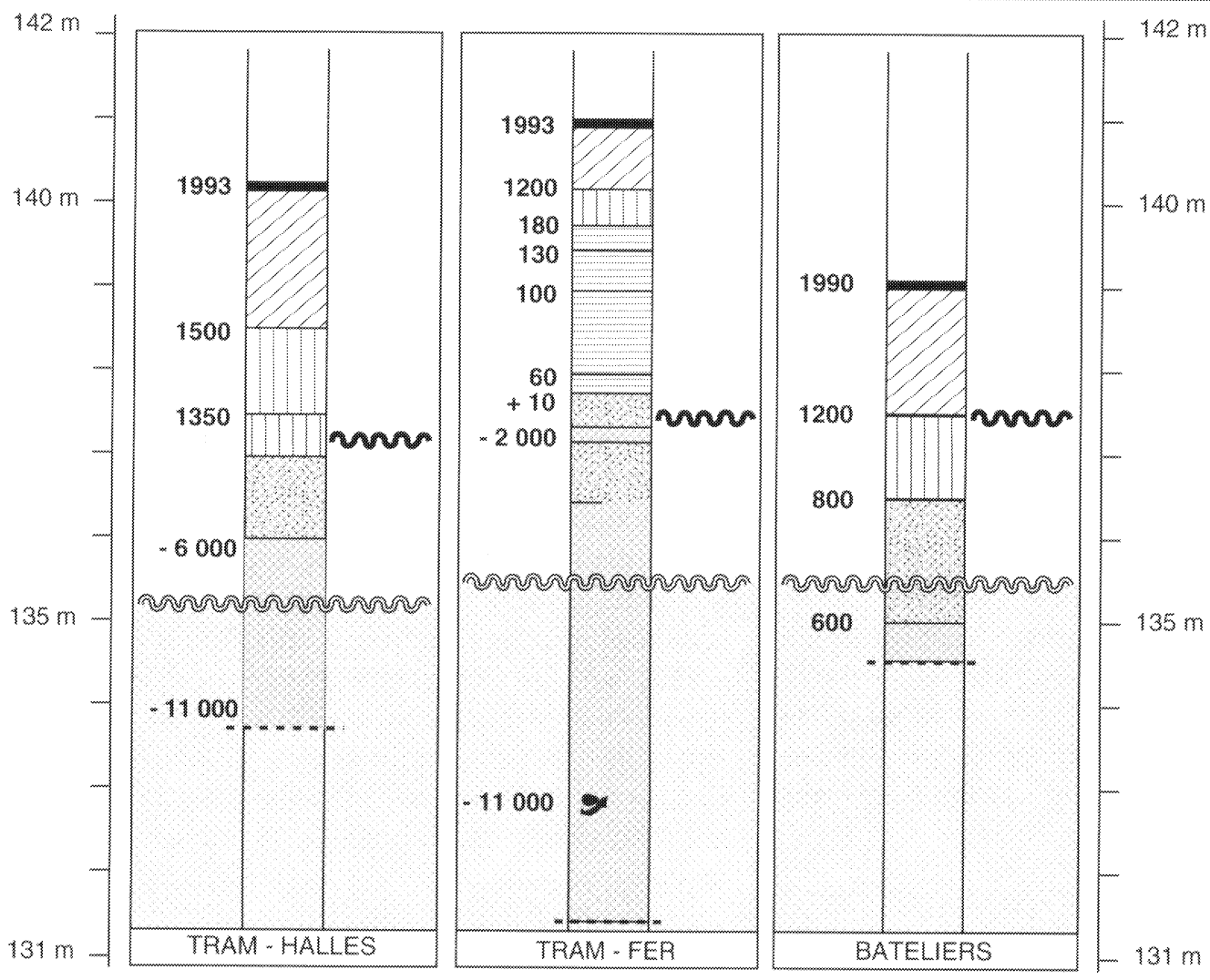

\begin{tabular}{|c|c|}
\hline & LEGENDE \\
\hline \multicolumn{2}{|c|}{ Stratigraplite } \\
\hline & Ryomper moderne \\
\hline & Mazyen Age \\
\hline & 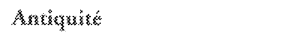 \\
\hline & Brotoklukscoire \\
\hline & 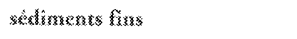 \\
\hline & gravier \\
\hline Nas & ge pluxéctuzque \\
\hline & 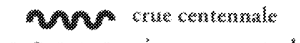 \\
\hline ns & WUYNYS mis. moyen actuel \\
\hline
\end{tabular}

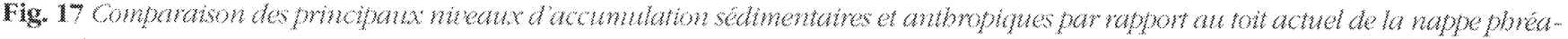

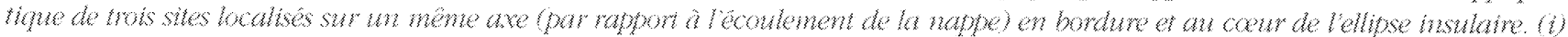


cours d'eau: le premier se sime en général legerement en dessous du second $(0,50 \mathrm{~m}$ a proximite de IIII a Strasbourg) et suit ses huctuations (crues, etiages) avec un delai de quelques jours au plus. En confrontant les informations relatives aux puits gallomomains et médiévaux avec les donnees actuelles, on est arive a la conclusion dune stabilte globale du toit de la nappe pendant les deux demiers millenares, On peut ansi proposer un plan deau naturel moyen, correspondant tant au toit de la nappe quau réseau de surface, de $136 \mathrm{~m}$ a $135 \mathrm{~m}$ entre le sud et le nord de la vieille ville. Même en prenant la valeur actuelle des crues centennales (plus $2 \mathrm{~m}$ ), le seuil dhabitabilite reconnu se stue a leur niveau voire au-dessus, sans digues ou remblaicments.

Au total, si les premiers habiants - les legionnaires pour lellipse insulate et les bourgeois pour les faubourgs - ont pu sinstaller dans la plaine alluviale, cest grâce au manteau de sédiments fins qui les metait a labri des crues phréatiques et hydrographiques habituelles (fig. 17). Ces citadins ont certes subi lune ou lautre inondation plus importante: si les traces pour lantiquite restent a confimer, les chroniques mediévales tout comme les documents du xix" siècle disent assez quelles ont été une realite. Mais pour ce qu'on en sait ces épisodes nont jamais été que localisés sans menacer lexistence de la cite : a mellkure preuve en est linstallation des premiers sols a mème le toit des couches naturelles, sans apports de remblas destines a clever ces niveaux dhabitat audessus des crues ${ }^{7 !}$.

\section{CONCLUSION}

Aux trois principales questions qui ont animé la recherche ces demieres années, les reponses sont tres inegales En premier lieu, nous sommes tres loin de pouvoir toumir limage dun reseau hydrographique onginel. Sil se confirme que la Bruche avec ses dépots de sable rouge a longtemps constitue le cours deau principal concurrencé par le whin pour la rive droite de lactuelle III, il reste impossible de préciser si cest avant ou apres la creation de lagglomération quelle est supplantée par III. Quant au reseau secondare, les quelques vestiges

69. Scrwme, 1988

70. Les actures whanes par le jea des consmutions et destrutons on cenes about a w exhassement global avan un efet dastamiss. ment Wais lintenton premere ne residat sus coute pas a pusque ha

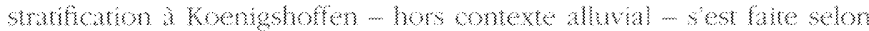

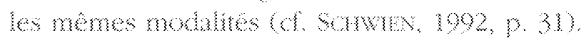

observes ca ta ne pewent être replaces dans un contexte densemble a lexception des cours deau qui, tels le Rheingiessen ou le fossé des Tanneurs, ont perduré fusqu’à des périodes récentes. De fait, il est difficle de conserver lambition do restiver par le menu ce réseau initial puisque, dans des conditions naturelles, le lit des cours dean est dune instabilte extreme et que larchéologie urbane naborde que détroites fenêtres sur le soussol au regard de la superficie concence. II semble plus important de considerer en quoi et comment la naissance et le developpement de l'agglomeration ont contraint $c$ réseau à se stabiliser. La part de la ville antique se réduit pour le moment a laménagement de la seule rive gauche de ImI alors que se profle a partir du hau Moyen Age une volonte de dominer les dragations dun reseau qui semble rester dense. Les petits cours deau disparaissent de ce fait avant 1500 (par envasement "naturel "ou comblement, les plus importants etant canalises à partir du xw sicde au plus tard. La regularisation du Rhin ponctuellement engagée au xy" siecle avec la construction de la citadelle (et du fort de kehl en rive droite) prefgure dune certaine maniere les travax à léchelle du cours tout entier réalisés un siede demi plus tard.

En second lieu, si les fossés a fonction économique de la fin du Moyen Âge (Rbeingiesen, fossé des Tanneurs) ont incontestablement des antécédents naturels, il est moins certain que les fossés defensifs médiévaux corres.pondent à un reseau originel fossilisé. Les kilometres de Cossés amenagés pour le systeme bastionné du Xyre siede, citadelle y comprise (avec des moyens guere differents de ceux des Romains ou des bourgeois mediévaux), sont en tout cas artficiels puisque le plan du reseau hydrogaphque dEnoch Meyer en 1617 ne les signale pas : ils pemettent de mesurer la capacite des citadins a faconner une topographie selon leurs besoins.

La nature et le niveau du sol primitif, en dernier lieu, commencent à se dessiner de facon globale au moins puisqu'il apparât que les premiers habitats ont ete construits sans amenagements spécifques sur des terrains argilo-imoneux situés legerement au-dessus des crues habiuelles voire centennales. Ce qui a surtout été mis en valeur ces demieres annés cest la chronologie de ces formations alluxiales superficleles puisque, si certanes sont largement anterisures a la venue des premiers hommes, dautres en bordure de l'agglomeration ne se constituent qu'au haut Moyen Âge.

Longtemps donc, les Strasbourgeois ont vecu dans un milieu saturé en ean : il reste a se demander pourquoi. II est generalement admis que cette situation a ete delibérement recherchee tant pour les facilites en matiere de 
defense, do commerce d, au mons pour le Moyen Age, de production (moulins). Les Coulles de ces derienes annes ne contredsent pas ce sehema. Maheureusement. les recherches archeologhues ne peuvent guere sonder les intertions des hommes dont des suvent les taces: mises bou a bout, cellesm revelent touto is une oppow siton forte dans 1 gestion du wiliew alluval pusque la vile romane, a cheyal sur la terasse de loess et la plaw ve cole hace a une agglomeraton medievale entere ment inscrite dans ctre mene plane avec une expansion vers le Rhin a lepoque modeme.

Ces questons sur le ste de strasbong dowem auss etre roplaces ans a perspective plus large du mapon de la vile et de la rièe. Les histonens ont monte depus

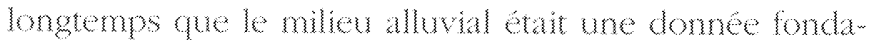
mentale de thistoire urbane. Wa these dAndre Gulleme sur le rapon a lean des cites du bassin parsien resume bien les problematques de ce point de vue : lle met lac cent sur deux pénodes principales, wne phase de cois sance ubaine aux xu-xure siecken hason avec la domnaton du mileu allural (navgation et soure denenge pour lanisanat puis une phase do stabite voire parois de régression du Xw au xvm siecle caracterisee par une atrophe des cours deau, la muliplicaton des amenagements barrages pour les moulins, quais et enceintes pour les camaux et fosses) provoquan la baisse des débis et une augnentation de la polution.

Lessor recent de ce qu'll est convenu dappeler la geom archeologie appore les comees de terain qui manqualent pour à la his replacer ces questions dans la longue duree et en observer les efets concrets. En Fance, les ravaux de Bravar, Brochier, Campy ou leveau ont, a divers tres, donné une impulsion nouvele a letude des fommations geologiques superficles et place larcheolow gie au premer rang des sources dinfomaton sur la pélogenese. Meme si ces marux pontent avant tout sur les questions de methodologie, quils concenent trop peu de sites urbans et encone noins les periodes historiques recentes, il est dores et dêa acouis que toute approche serieuse de Whistome des viles passe desommis oblgatoirement par whe collaboration avec les goographes. Cest

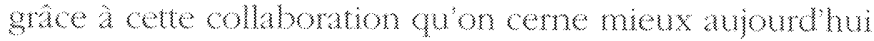
les dapes de lamenagement de la presquhle de Lyon a la conluence du Rhone de la saone" oún sait que Constance a grignote aux xw"xw siecles une bande de 150 m de large environ sur les rives du hac que les viles de Bristol (OB) et Bergen (Noryege) ont gagne respecti vement $60 \mathrm{~m}$ et $100 / 50 \mathrm{~m}$ sur leurs cours deau?

Beaucoup de viles disposent mainenant de telles don nés sur la micromistoire le leur environnement geogra phique mas ces infomations restent souvent inedites (pour les grandes foulles preventives recentes), epar pllees dans un grand nombre de revues parfois confi dentielles et sumout deconnertes des fonds documenvives archeologiques et historiques) anciens. Lexemple de stasbourg montre tout linteret quil y a a disposer du catalogue des somres de lhistoine topographique le plus complet possible de sonte a pouvoir integrer les découvertes apparemment les plus anodines dans une rélexion d'onsemble. Ce qui etait rai de laxheologie urbane "anthropique "lest encore plus pour l'eude de l'enyi ronnement naturel puisque ces recherches gé-archéolo giques wbanes n'en sont qua leurs balbutements: les méhodes éant desomais acquises, tout ou presque reste a faire du point de vue de la defnition des problematques. Nous souhaitons que les quelques nelexions prom poses conthbuent a leur energence.

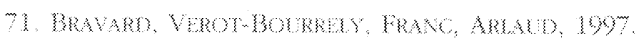

72. Omun 1992

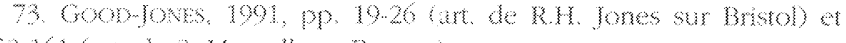
150.16) Can des. Myrwll sur Bergen. 


\section{BIBLIOGRAPHIE}

\section{REFERENCES GENERALES}

Brrome I, W

1995. "Facteurs anthophues et manels de leyolution des paysages romans at protomedevaux du hassin valumais " Downe, p. 79 114.

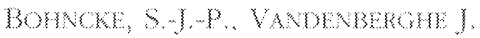
1991, "Palcohydrological developmen in the southern Netherands during the hat 15000 years ", dans smakx 1 . Grwory K.... Thornes I, B. (ed), Tempenate palobyarology Chichester: Jonnwey \& Sons, p. 253-281.

BONNET C. W al.

1989, "Les premers ports de Geneve"

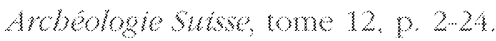

BRAVRO J.P., VEROTBOURREY A. SALVDOR P. . G.

1992. "Le climat dapres les infomations Coumes par les enregivements sedi. mentaires luviatles etudies sur des sites ancheologiques ", Les Nomelys de larchelogie tome $50, \mathrm{p}, 7413$.

BRAVBRD J.P.

1993, "Oynamique Murale, structure hydro geomorphologique des hydrosys temes ", dans Anoros C., PETS G.-E. (dir), Hyarosytemes Muvand; Pans. Masson, p. $61-103$.

BRAYARO I.P., PRESTREY M. (dir)

1997. Dynambare da paysage. Entrotions de geoarbbologie. Actes de la table ronde de Lyon 1995, Lyon, Documents dArcheologie en Rhóne Alpes (DARA), $n^{\circ} 15,28 \mathrm{mp}$,

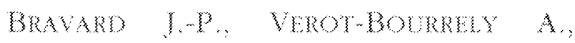
Frane O., Akune C.

1997. "Paleodynamque du she Muril de Lyon depus le Tardighoire" dans Documents dincbeologie en kbone. Alosen n 15, D. 177-201.

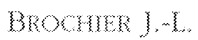

1991, "Enviromement culture: etat de la question dans le sudas de la France et principes deude antour du chasseen dans hayeme ralle du Rhone " Actes du colloque de Nemours.

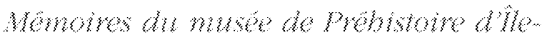
demonoe, p. 315325

Brown A. C C

1995. "Holocone chand and hoodphin change : a Uk perspective " dans Gronen A. prems $\mathrm{G}$ (ed), changing wer bannes oncheser, Joh Whey a Sons, p. 3 . 6 .

CAMPY M., MACBNE J.J.

1989, Goologie des fommations smerf. cielles : goodmamiane, facies, utimat ton, Pars, Masson, 443 .

CHOUYUer $G$

1993, Howne dinn paysage de bouge gan. lowe a mos jous -... Emm Bowrogne ot Franche Comé $\mathrm{Ed}$. Erance, Pans, $119 \mathrm{p}$.

DE IYARRA R,

1993. Hommes of Hounes en Gaule romal ne, Ed. Erance, Paris, $240 \mathrm{p}$.

Goom $\mathrm{G},-\mathrm{L}$, Jones R.-H, (dir)

1991. Waterront arboology. Procedings of the thind intenational confernce on wateyrom arwabolowy held at Brinol 23-26 Soptember 1988, Council for British Archaeology, Londres, 200 p.

GUWWRME $\mathrm{A}$.

1983. Les Tomps ae lean. La we lean des technigues (nord de la France, fin it ... dem $x x^{*}$ siecte), Champ vallon, coll. Mileux, Seyssel.

LEEAY P.

1997. "Societes historiques ef mileux humides. Un modele systemique des donnees applicables aux maras continentaux de cuvete ", dams Namme Sciences Soctete, vol, 5, no 2, p. 5-18.

MAON M

1995, bue Howlo du climat Des dentems manmoutbs au siecle ale lawowoble. Ed. Ermae, pars $176 \mathrm{p}$.

OExt:

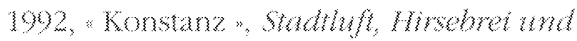
Betemonch. Die sadi un 300 , cala- logue de lexpositon de 2 urich, 26 jum.. 3) ocobre 1992, Zunch Stutuan, D. 53m 67.

\section{RÉFÉRENCES LOCALES}

AMrer?

1952. "Un port de riviere romain sur la Bruche a la Montagne Verte ". Cabiers Asachens dint of distome, p. 8998 .

AN. 12

1988, AN-12, Anx orighes de strasbours. calabogne de hexposimon du muser bis rorigue de strasbours. Stasbours.

APELI. Y V

1902, Geschiche Aer Befestignng wh Strasburs i. E. Vom Whederabou der Shat nach de? Volkenanderms bis zam Jabre 3681, Smasbourg.

CWMMYON M.

1858-1864. Les hondations en France doputs le th siecle jusqua nos jours. paris, Dunod, $6 \mathrm{kol}$.

DE MONET

1860m1861, " Notice sur lenceinte dingenoratum restuce dapres les bulles excotes en 1859 et 1860 dans lancien couvent de samthrenne " Bullotin de la societe pour la consentation des Monuments Horongues dAlsace, ome WV, p. 29-37.

Descomese $\mathrm{R}$

1988. Canaux et batellente on Ahace. Histohe of anecdotes, strasbourg, le Verger.

DUBOIS $G_{0}$ GOETSC:

1946, we lmon jame loessoide du centre de la ville de Strabourg:, Bublesin de la Sociele Geologinue de trance. wone 16 , 1. 171.173

Fomsse G, KUWN J.P, WUDMAN J.M.

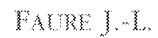

1984. Strabloums. Ponorama monnmental et architecumal des ongines a 1914 , Strasbourg. 
Fonken $\mathrm{R}$

1912, "En versunkerer spatanker

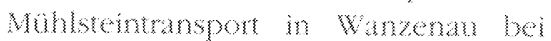
Strassumg ", Anzeiger for Whaswische

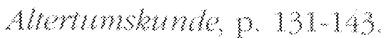

Fonker R.

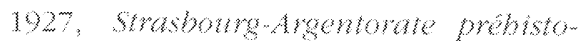
wine, gabowoman et merounglen. srasbours.

Gomuner $C$

191\%. "Romsche und mivelateriche Uebergange Wber den Kummen Rhein

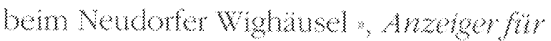

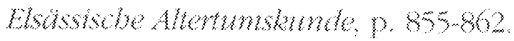

GOMNER $\mathrm{C}$.

1934. "Mitelaterliche Brickenteste bem Bruckhot " Cabiers Alowens dithwo ef diarchologie p. 88.90

GOWHer $\mathrm{C}$.

1934, "Bau der Zolschanze am Kleinen

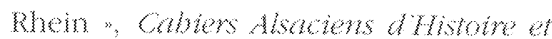
dinbologie, p. $188-192$.

Gompler $\mathrm{C}$

1938. "Rombche Klentunde und mero wingischer Langsax aus dem Strassburger Goldgiessen ", Cabiess Alsaciens distome of dArcheobole. tome VIr, p. 161-162.

Gommer C., P. AMme P., R. Forker R. 1938, " Les palantes prehismones in adeaux fotants et fres de la Schitheheimmemat pres de Strabbourg " Cablers Alwatens

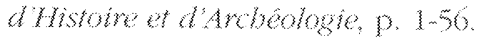

GOHNER C., Brumor: L.

1935. Geschiche der ränmbichen enwicking der suds smascums. Strabbourg.

MATIS

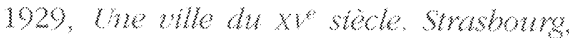
Strasbourg.

HAT I...

1069. "Decowertes a observatons now velles sur les encemes de strasbung " Cables Abacions barboologie, danet dHstolne, come $13, \mathrm{p}, 7398$

HxT? ].W.

1970, "Decouvertes ancheologiques a Strashourg, ne du purs " Cabiers

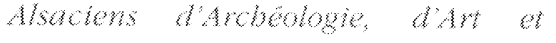
diskohe, p.91-100.

HERMANY I.M.

1817. Nohice bisorianes, shatwhines of bit.

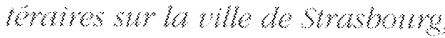

KWw, I.

1986. Shasbowrs: arbitecture ot whonis we hes onghes a 1870 , smashours.

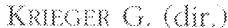

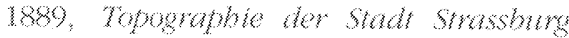
nach anzlich-bygienschen Gotobtspunkan bearbitet, strabourg.

MEGWDRE ].M., MADEE ].

1987, "Strasbours, les homles du quatien mediéal de la con des Boens "

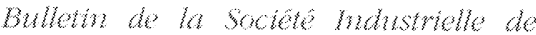
Mnkonse, p. 83m86.

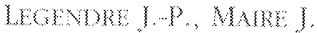

1900, "Un exemple d'evolution de la tame urbine : le sire de la cour des bouns a Strasbourg ", Whe an Moyen Age, p. 51.55 .

WWT (S., RAY I. (dir)

1980-1982, Histome de Srasboum des on gines a nos jom Strabourg, 4 vol.

MVET G., Raps W. (dir)

1987, Hiwhire de Shabourg, Toulouse, Prival.

SADLAU A. SCMEMDER $H$, STECRNER $H$, 1989, Dhe lange Bribls. 600 Jabne Wege zum Nachbam, Kehl am Rhen, 1989,

ScसmIT $C$

1888. Smassminger Gassen und Howsemamen in Witelater, 2 ed. Strabourg

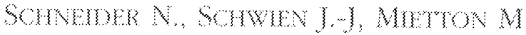
1997. "Le resean hydrogmphique de Swabourg Des cartes ancimnes aux recentes donnees de terain " Flukes. riveres of camala dans Thurope occi.. denhle es mádiane, Actes du cologue de Smabourg rumis par RACWE P. CNDP/CRDP de Loraine, p. $11-83$.

Sommen J.J. Sornownr N., MAKE I. URSAT

1088, "De sources en nappe. Une histore des eawx soutcrines de Strabourg " Saison ditsace, wome 101, p. 21-33.

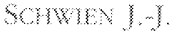

1992, "Srrashourg; ché lacustre" Introducton aux fondations sur pienx bu

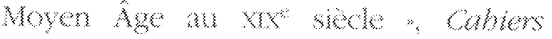
Alscions darcheobgis diat of d'Wwohe, 1980, whe Xxxm, p. 165-188.

Sowwex,$\ldots$

1992. Shabonms. Dowmont denuhaton

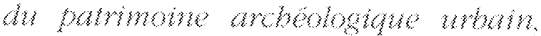
Minstere de la Culure/Cente Natoma dArchologie Unbane.

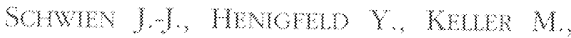
Waron M,D. Zumsm

A partire, "Motome et archébogie des enceintes de Strasboum "dans $12 \%$ Congre National des Sociubs Sammes Nice 1996, Gnenties unbaines.

SEmotri $\mathrm{A}$.

1890, Das alte Strassburg wom Xly jabmunder bis zum labre 3870 . Geschichtiche Topogwobie nach den trownden und den Cononiken, 1800

SWBRRMAN I,

1775, bocaluescbicble der stadt Srasumis, stasbourg.

Straboums. Dix ans darcheologie mbane, 1994. catalogue de lexpowinon presente a Strasbourg du 15 octobre 1994 an 29 invier 1995, Editons les Musees de ha vile de Strashourg.

Wwre an Moven Age. Thente ans darcho. logie medbrale en Alace.

1990, catalogue de lexpostion presentee a stasbourg du 17 mat au 30 septenbre 1900, Edibons Les Musces de la Vlle de Strasbourg.

Vorth. (dir.)

197\%, "Goomomphologie et préhiotoire dans la region da Strabourg " Rechenbes geo. graphigues a smabourg. tome 7.

Vog: 1

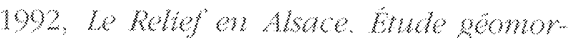
bbologinge du robord sud occhental du fose nebran, strasbourg, oberin.

Werver $A$.

1993, "Note sur la hopgraphe du

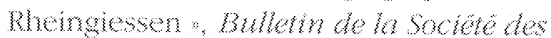
Amls du Mure Reglonal du thin et de la Nargation, p. $35 \mathrm{~m} 2$. 
